\title{
1. - \\ Long-Term Industrial Energy Forecasting (LIEF) Model (18-Sector Version)
}

by M.H. Ross, ${ }^{\star}$ P. Thimmapuram, R.E. Fisher, and W. Maciorowski

Policy and Economic Analysis Group,

Environmental Assessment and Information Sciences Division,

Argonne National Laboratory, 9700 South Cass Avenue, Argonne, Illinois 60439

May 1993

Work partially sponsored by United States Department of Energy,

Office of Domestic and International Energy Policy,

Office of Environmental Analysis

"Ross is affiliated with the Department of Physics, University of Michigan, Ann Arbor. 


\section{CONTENTS}

ACKNOWLEDGMENTS $\ldots \ldots \ldots \ldots \ldots \ldots \ldots \ldots \ldots \ldots \ldots \ldots \ldots \ldots \ldots$ viii

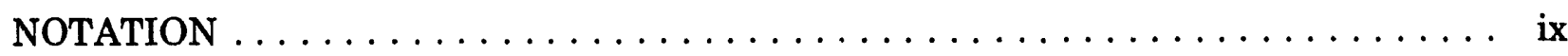

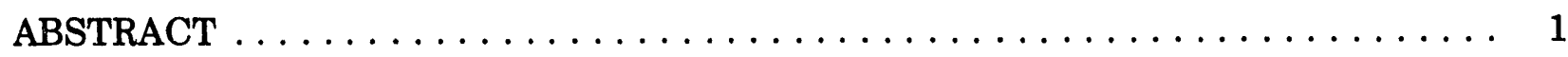

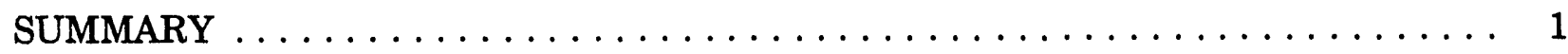

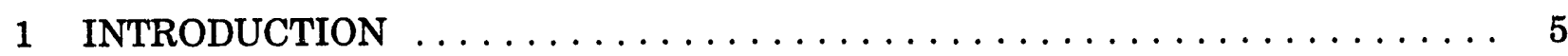

2 STRUCTURE OF THE MODEL AND DSM REPRESENTATION $\ldots \ldots \ldots \ldots .6$

2.1 Energy Demand Forecasting with LIEF $\ldots \ldots \ldots \ldots \ldots \ldots \ldots \ldots \ldots$

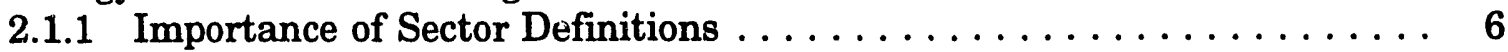

2.1.2 Real Energy Intensity Forecasting Approach $\ldots \ldots \ldots \ldots \ldots \ldots 10$

2.1 .3 Policy Analysis with LIEF $\ldots \ldots \ldots \ldots \ldots \ldots \ldots \ldots \ldots \ldots \ldots$

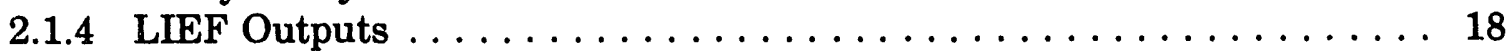

2.2 The Demand-Side Management Representation . . . . . . . . . . . . . 19

3 HISTORICAL PATTERNS OF ELECTRICITY AND FÓSSIL FUEL USE $\ldots \ldots \ldots 21$

3.1 General Characteristics . . . . . . . . . . . . . . . . . 21

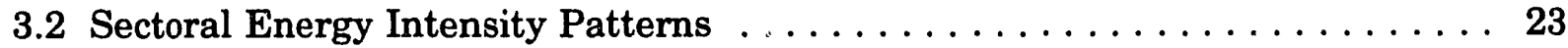

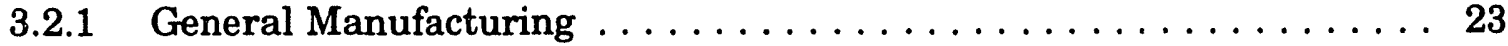

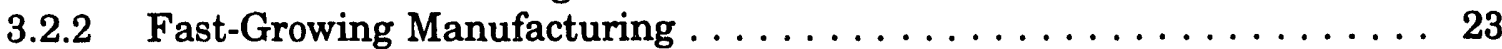

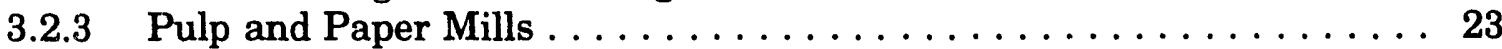

3.2.4 Industrial Inorganic Chemicals $\ldots \ldots \ldots \ldots \ldots \ldots \ldots \ldots \ldots 25$

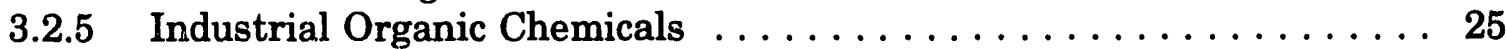

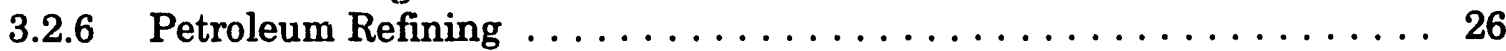

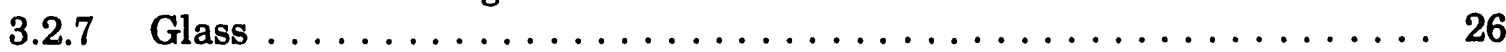

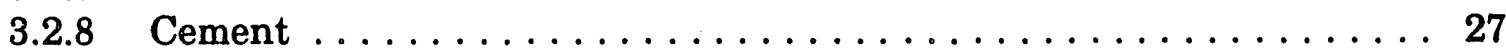

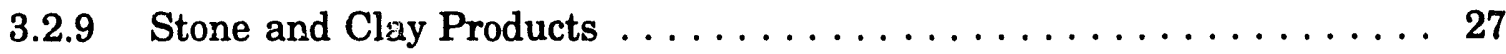

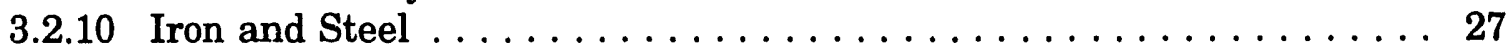

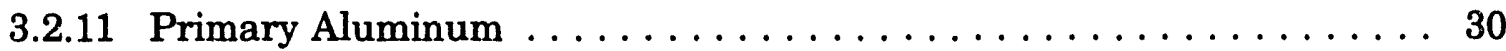

3.2 .12 Nonferrous Metals $\ldots \ldots \ldots \ldots \ldots \ldots \ldots \ldots \ldots \ldots \ldots \ldots \ldots$

3.3 Sectoral Energy Prices $\ldots \ldots \ldots \ldots \ldots \ldots \ldots \ldots \ldots \ldots \ldots \ldots \ldots \ldots \ldots \ldots$

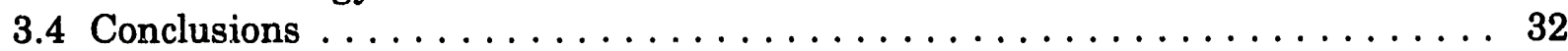

4 HISTORICAL PARAMETERS: CONSERVATION SUPPLY CURVES AND PENETRATION RATES $\ldots \ldots \ldots \ldots \ldots \ldots \ldots \ldots \ldots \ldots \ldots \ldots . \ldots \ldots$

4.1 General Comments . . . . . . . . . . . . . . . . . . . 34

4.2 The Conservation Supply Curve - General Properties ............. 34

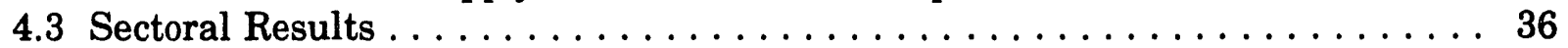

4.3.1 Sector 1: General Manufacturing ................ 36

4.3.2 Sector 2: Fast-Growing Manufacturing $\ldots \ldots \ldots \ldots \ldots \ldots \ldots$

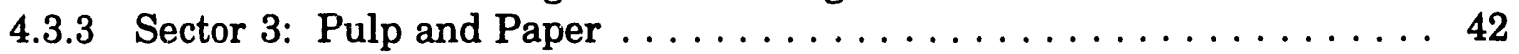




\section{CONTENTS (Cont.)}

4.3.4 Sector 6: Petroleum Refining . . . . . . . . . . . . . . . . . . 42

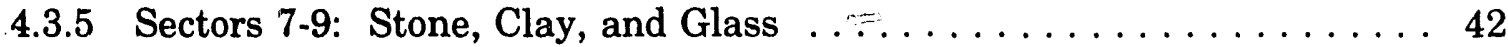

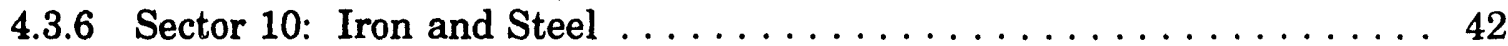

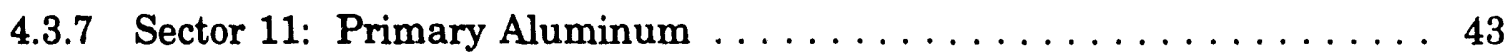

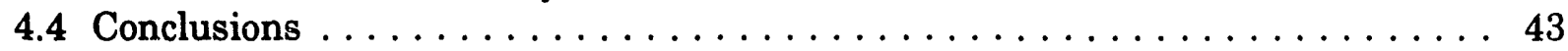

5 SIMULATION RESULTS - EXERCISING THE MODEL . . . . . . . . . . . . . 46

5.1 Base-Case Scenario . . . . . . . . . . . . . . . . . . . 46

5.2 Demand-Side Management Scenario $\ldots \ldots \ldots \ldots \ldots \ldots \ldots \ldots$

6 ISSUES IN INDUSTRIAL MODELING WITH LIEF $\ldots \ldots \ldots \ldots \ldots$

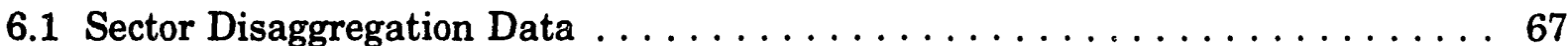

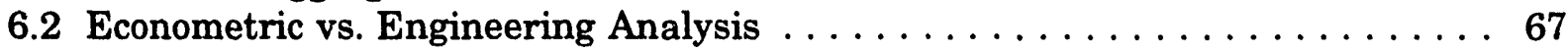

6.2 .1 Categories of Technical Change $\ldots \ldots \ldots \ldots \ldots \ldots \ldots \ldots \ldots \ldots$

6.2 .2 Econometric vs. Engineering Relationships $\ldots \ldots \ldots \ldots \ldots \ldots$

6.2 .3 Vintage of Production Facilities $\ldots \ldots \ldots \ldots \ldots \ldots \ldots \ldots \ldots \ldots$

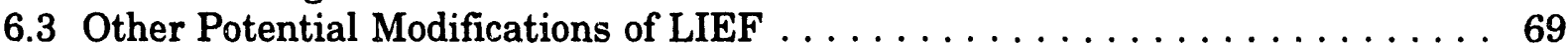

6.3.1 Expanding the Detail Represented . . . . . . . . . . . . . 69

6.3 .2 Modifying Relationships in LIEF $\ldots \ldots \ldots \ldots \ldots \ldots \ldots \ldots \ldots \ldots$

6.3.3 Modeling Technologies Explicitly $\ldots \ldots \ldots \ldots \ldots \ldots \ldots \ldots$

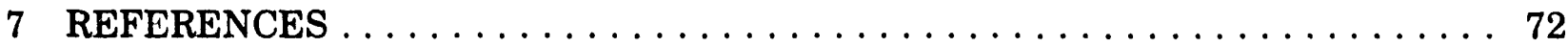

APPENDIX A: $\quad$ LIEF User's Manual $\ldots \ldots \ldots \ldots \ldots \ldots \ldots \ldots \ldots$

APPENDIX B: $\quad$ Model Documentation $\ldots \ldots \ldots \ldots \ldots \ldots$

\section{EXHIBIT}

2.1 Example of Marginal Capital Costs of Conservation Projects

\section{TABLES}

S.1 Summary of Base-Case and DSM Electricity Forecasts $\ldots \ldots \ldots \ldots \ldots$

2.1 LIEF 18 -Sector Model for U.S. Industry $\ldots \ldots \ldots \ldots \ldots \ldots$

2.2 Overview of LIEF Model Equations $\ldots \ldots \ldots \ldots \ldots \ldots \ldots$

2.3 Policy Handles in LIEF $\ldots \ldots \ldots \ldots \ldots \ldots \ldots \ldots \ldots \ldots$

$4.1 \quad$ Data Series Analyzed $\ldots \ldots \ldots \ldots \ldots \ldots \ldots \ldots \ldots \ldots$ 


\section{TABLES (Cont.)}

4.2 Parameters from Historical Analysis $\ldots \ldots \ldots \ldots \ldots \ldots \ldots \ldots \ldots$

4.3 Penetration Rates used in Historical Forecasts . . . . . . . . . . . . . . . 40

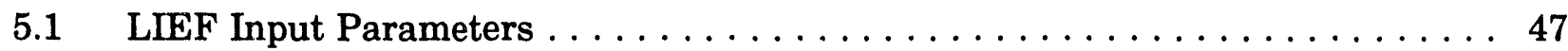

$5.2 \quad$ Base-Case Forecasts for Electricity Demand $\ldots \ldots \ldots \ldots \ldots \ldots \ldots \ldots$

5.3 Summary Results of Total Industrial Electricity Demand for Base Case . . . . . 56

5.4 Divisia Decomposition of Electricity for Base Case $\ldots \ldots \ldots \ldots \ldots \ldots$

$5.5 \quad$ DSM-Case Forecast for Electricity Demand $\ldots \ldots \ldots \ldots \ldots \ldots \ldots \ldots$

5.6 Summary Results of Total Industrial Electricity Demand for DSM Case . . . . . 65

5.7 Divisia Decomposition of Electricity for DSM Case $\ldots \ldots \ldots \ldots \ldots$

B.1 Grouping of Manufacturing and Nonmanufacturing Sectors in the 18 -Sector LIEF Model $\ldots \ldots \ldots \ldots \ldots \ldots \ldots \ldots \ldots \ldots$

\section{FIGURES}

2.1 Dynamic Structure of the LIEF Model $\ldots \ldots \ldots \ldots \ldots \ldots \ldots \ldots \ldots \ldots$

2.2 Conservation Supply Curve - Engineering Perspective $\ldots \ldots \ldots \ldots \ldots \ldots 12$

2.3 Conservation Supply Curve - Economic Perspective $\ldots \ldots \ldots \ldots \ldots \ldots$

2.4 Dependence of Conservation Supply Curve on Capital Recovery Factor . . . . . . 16

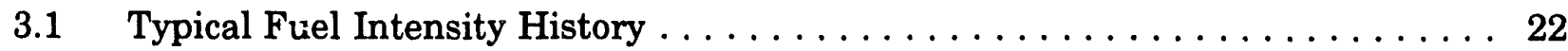

3.2 Typical Electricity Intensity History $\ldots \ldots \ldots \ldots \ldots \ldots \ldots \ldots \ldots \ldots$

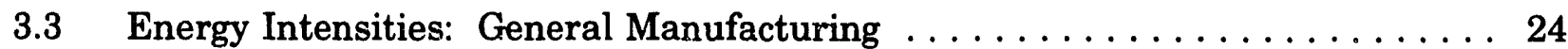

3.4 Energy Intensities: Fast-Growing Manufacturing $\ldots \ldots \ldots \ldots \ldots \ldots \ldots 24$

3.5 Energy Intensities: Pulp and Paper Mills $\ldots \ldots \ldots \ldots \ldots \ldots \ldots \ldots \ldots$

3.6 Energy Intensities: Petroleum Refining $\ldots \ldots \ldots \ldots \ldots \ldots \ldots \ldots \ldots$

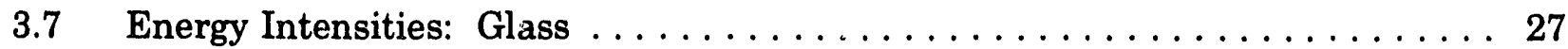

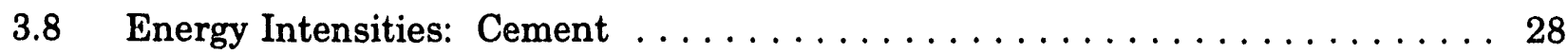




\section{FIGURES (Cont.)}

3.9 Comparison of BLS and SCB for Cement, Sector $8 \ldots \ldots \ldots \ldots \ldots \ldots$

3.10 Energy Intensities: Stone and Clay Products $\ldots \ldots \ldots \ldots \ldots \ldots \ldots$

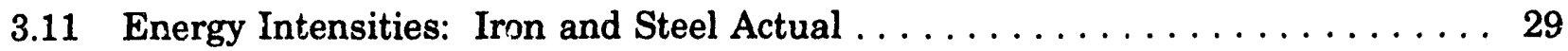

3.12 Energy Intensities: Iron and Steel Hypothetical $\ldots \ldots \ldots \ldots \ldots \ldots$

3.13 Comparison of Electricity Intensities in the Primary Aluminum Industry as Found in Two Data Sets $\ldots \ldots \ldots \ldots \ldots \ldots \ldots \ldots \ldots$

3.14 Energy Intensities: Primary Aluminum $\ldots \ldots \ldots \ldots \ldots \ldots \ldots \ldots \ldots$

3.15 Prices of Fossil Fuel and Electricity: Cement Example . . . . . . . . . . . 33

4.1 Conservation Supply Curves in LIEF $\ldots \ldots \ldots \ldots \ldots \ldots \ldots \ldots \ldots \ldots$

4.2 Historical Forecast of Electricity Intensity, General Manufacturing,

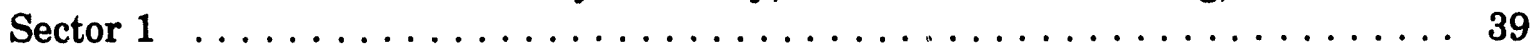

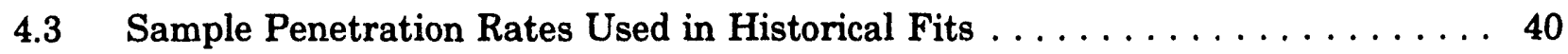

4.4 Relationship of F'enetration Rates on Fossil Fuel Prices:

General Manufacturing Example $\ldots \ldots \ldots \ldots \ldots \ldots \ldots \ldots \ldots \ldots \ldots$

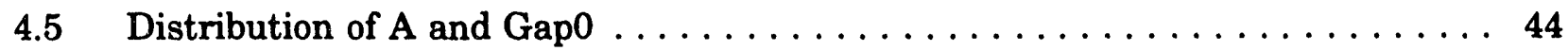

5.1 Comparison of Base-Case and DSM-Case Electricity $\ldots \ldots \ldots \ldots \ldots \ldots$

5.2 Comparison of Base-Case and DSM-Case Electricity Intensities $\ldots \ldots \ldots \ldots 57$

A.1 Opening Screen of LIEF $\ldots \ldots \ldots \ldots \ldots \ldots \ldots \ldots \ldots \ldots \ldots \ldots$

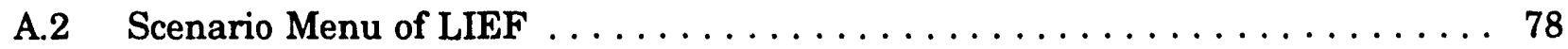

A.3 Economy Menu of LIEF $\ldots \ldots \ldots \ldots \ldots \ldots \ldots \ldots \ldots \ldots \ldots \ldots$

A.4 Economy Display Screen of LIEF $\ldots \ldots \ldots \ldots \ldots \ldots \ldots \ldots \ldots \ldots$

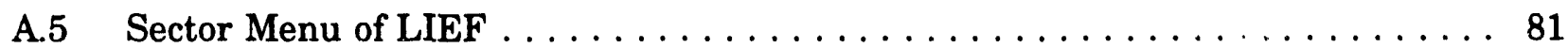

A.6 Sector Menu Display Option of LIEF $\ldots \ldots \ldots \ldots \ldots \ldots \ldots \ldots \ldots \ldots \ldots$

A.7 Results Menu of LIEF $\ldots \ldots \ldots \ldots \ldots \ldots \ldots \ldots \ldots \ldots \ldots \ldots \ldots$

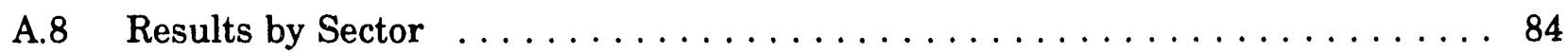




\section{FIGURES (Cont.)}

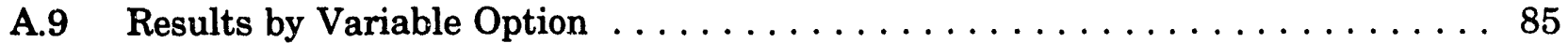

A.10 Results by Summary Option $\ldots \ldots \ldots \ldots \ldots \ldots$ 


\section{ACKNOWLEDGMENTS}

This documentation of the Long-term Industrial Energy Forecasting (LIEF) model is intended to support Argonne National Laboratory (ANL) Task No.9.5 for the U.S. Department of Energy (DOE), Office of Environmental Analysis (OEA). Ted Williams is the Director of OEA, William Breed is the DOE Project Officer, and Donald Hanson is the Project Manager at ANL. The LIEF model is being used in Task 9.5 to represent the electricity savings potential of demand-side management in the industrial sector.

The authors would like to thank Donald Hanson, Gale Boyd, and John Molburg of ANL and Roland Hwang of Lawrence Berkeley Laboratory for their comments. 


\section{NOTATION}

The following is a list of acronyms and abbreviations used in this document.

$\begin{array}{ll}\text { ANL } & \text { Argonne National Laboratory } \\ \text { ASM } & \text { Annual Survey of Manufactures } \\ \text { BBS } & \text { bulletin board } \\ \text { BLS } & \text { Bureau of Labor Statistics } \\ \text { BPDB } & \text { Basic Petroleum Data Book } \\ \text { CCE } & \text { cost of conserved energy } \\ \text { CRF } & \text { capital recovery factor } \\ \text { CSC } & \text { conservation supply curve } \\ \text { DSM } & \text { demand-side management } \\ \text { GFP } & \text { gross farm product } \\ \text { GNP } & \text { gross national product } \\ \text { LBL } & \text { Lawrence Berkeley Laboratory } \\ \text { LIEF } & \text { Long-term Industrial Energy Forecasting } \\ \text { MECS } & \text { Manufacturing Energy Consumption Survey } \\ \text { NEA } & \text { National Energy Accounts } \\ \text { NES } & \text { National Energy Strategy } \\ \text { PC } & \text { personal computer } \\ \text { PURPA } & \text { Public Utility Regulatory Policy Act } \\ \text { RAM } & \text { random access memory } \\ \text { SCB } & \text { Survey of Current Business } \\ \text { SEDS } & \text { State Energy Data System } \\ \text { SGUE } & \text { self-generated and used electricity } \\ \text { SIC } & \text { standard industrial classification }\end{array}$




\title{
LONG-TERM INDUSTRIAL ENERGY FORECASTING (LIEF) MODEL (18-SECTOR VERSION)
}

by

M.H. Ross, P. Thimmapuram, R.E. Fisher, and W. Maciorowski

\begin{abstract}
The new 18-sector Long-term Industrial Energy Forecasting (LIEF) model is designed for convenient study of future industrial energy consumption, taking into account the composition of production, energy prices, and certain kinds of policy initiatives. Electricity and aggregate fossil fuels are modeled. Changes in energy intensity in each sector are driven by autonomous technological improvement (price-independent trend), the opportunity for energy-price-sensitive improvements, energy price expectations, and investment behavior. Although this decision-making framework involves more variables than the simplest econometric models, it enables direct comparison of an econometric approach with conservation supply curves from detailed engineering analysis. It also permits explicit consideration of a variety of policy approaches other than price manipulation. The model is tested in terms of historical data for nine manufacturing sectors, and parameters are determined for forecasting purposes. Relatively uniform and satisfactory parameters are obtained from this analysis. In this report, LIEF is also applied to create base-case and demand-side management scenarios to briefly illustrate modeling procedures and outputs.
\end{abstract}

\section{SUMMARY}

The new 18-sector Long-term Industrial Energy Forecasting (LIEF) model is designed for convenient study of future industrial energy consumption, taking into account the composition of production, energy prices, and certain kinds of policy initiatives. Electricity and aggregate fossil fuels are modeled. Changes in energy intensity in each sector are driven by autonomous technological improvement (price-independent trend), the opportunity for energy-price-sensitive improvements, energy price expectations, and investment behavior (i.e., the rapidity and extent to which industries respond to cost-saving opportunities). The role of creating new production capacity versus that of retrofitting existing capacity is not, however, explicitly modeled.

For each sector and both energy forms, there are three parameters describing the technological opportunity for improved energy intensity. One parameter is associated with 
the autonomous trend. The other two parameters correspond, essentially, to the slope and intercept of a conservation supply curve (CSC), which indicates the dependence of the energy savings opportunity on price. (In addition, there is an industrywide fuel-electricity substitution parameter.) The parameters offer a nonequilibrium description; at any time there is a gap between the cost-effective and actual energy intensities. Additional parameters describe the penetration rate, or the net movement of an industry toward its cost-justified intensity based on industry's implicit capital recovery factor. Although this decision-making framework involves more variables than the simplest econometric models, it enables direct comparison of an econometric approach with conservation supply curves from detailed engineering analysis. It also permits explicit consideration of a variety of policy approaches other than price manipulation.

The model is tested in terms of historical data for nine manufacturing sectors. The best-fit parameters conform to an expected pattern: the CSC parameters, in effect the ownprice elasticities, show a roughly monotonic dependence on sectoral energy intensity. The potential for (relative) intensity reduction is limited for the highly intensive industries, such as fuel use in cement and electricity use in aluminum, while the potential for reduction (even at existing prices) is large for the less intensive sectors. There is, however, substantial uncertainty in parameter values because only one combination of each pair is accurately identified by the statistical analysis. The autonomous trends are, on the other hand, accurately identified. They mostly increase for electricity and slowly decline for fuel. Although the autonomous trends are statistically well defined, they are largely determined by the period from the late 1950s to the early 1970s. When the 1991 Manufacturing Energy Consumption Survey and related data are available, up-to-date parameters will be determined.

The relatively uniform and satisfactory parameters obtained from historical analysis suggest that the number of independent parameters in the model could be reduced with suitable assumptions about their interconnections. Such assumptions would probably enable all remaining parameters to be accurately specified by a statistical analysis. (This program has not been carried out to date.)

LIEF has previously been used, in its four-sector form, to simulate ambitious carbon tax and demand-side management (DSM) policies. In this report, base-case and DSM scenarios are created to briefly illustrate modeling procedures and outputs. In addition to energy and intensity forecasts, the model provides a Divisia analysis of the roles of aggregate production, composition of production, and "real" energy intensity in each energy forecast. Electricity consumption forecasts and Divisia analyses are summarized in Table S.1. For example, the bottom row of Table S.1 indicates that, with the hypothesized DSM program in 2030, the energy-weighted average of sectoral electricity intensities is reduced by $1-(0.95 / 1.28)$, or $26 \%$. The model also provides an estimate of capital investment in energyefficiency projects. 
TABLE S.1 Summary of Base-Case and DSM Electricity Forecasts

\begin{tabular}{|c|c|c|c|c|c|}
\hline \multirow[b]{2}{*}{ Parameter } & \multirow{2}{*}{$\begin{array}{c}1990 \\
\text { Base }\end{array}$} & \multicolumn{2}{|c|}{2010} & \multicolumn{2}{|c|}{2030} \\
\hline & & Base & DSM & Base & $\mathrm{DSM}$ \\
\hline Total electricity ${ }^{\mathbf{a}}$ & 3.32 & 4.88 & 3.83 & 6.12 & 4.24 \\
\hline Purchased electricity ${ }^{a}$ & 2.97 & 4.36 & 3.39 & 5.49 & 3.91 \\
\hline \multicolumn{6}{|l|}{ Indices } \\
\hline Total electricity & 1.0 & 1.47 & 1.15 & 1.84 & 1.33 \\
\hline Production & 1.0 & 1.40 & 1.40 & 1.83 & 1.83 \\
\hline Sectoral shift & 1.0 & 0.88 & 0.88 & 0.78 & 0.76 \\
\hline Real intensity & 1.0 & 1.18 & 0.93 & 1.28 & 0.95 \\
\hline
\end{tabular}

a National consumption by industry in $10^{15} \mathrm{Btu}(3,412 \mathrm{Btu} / \mathrm{kWh})$. Total electricity includes self-generated electricity used on-site.

The creator of an industrial-energy forecasting model is faced on several fronts by questions of whether one's model should incorporate particular details and how fully any detailed descriptions should be supported by data. The model maker is tempted to add excessive detail. Ideally, a model should include detailed specifications only when they are critical to a forecast, and only when they can be supported by realistic information. In the context of the future development of LIEF, this question is briefly addressed in several areas, including (1) sectoral disaggregation, (2) the dependence of decision making on the general category of technology, (3) the choice between engineering and econometric relationships, (4) the vintage of production facilities, and (5) regional disaggregation and provision of environmental coefficients. 


\section{INTRODUCTION}

This report describes a new version of the Long-term Industrial Energy Forecasting (ILIEF) model. The previous version of the LIEF model analyzed manufacturing in terms of four sectors (Ross and Hwang 1992). The present version analyzes all of industry in terms of 18 sectors. A number of other modeling improvements to the 18-sector LIEF model are described in this report.

The new 18-sector LIEF model is designed for convenient study of future industrial energy consumption, taking into account the composition of production, energy prices, and certain kinds of policy initiatives. Electricity and aggregate fossil fuels are modeled. Changes in energy iniersity in each sector are driven by autonomous technological imnrovement (price-independent trend), the opportunity for energy-price-sensitive inprovements, energy price expectations, and investment behavior (i.e., the rapidity and extent to which industries respond to cost-saving opportunities).

In addition to describing the mathematical form of the model and discussing how to use it, the principal purpose of this report is to present and analyze historical data for the 18-sector decomposition. Features of the historical electricity and fossil-fuel intensity patterns, which are important for modeling, and the relatively successful fits to historical data in the modeling framework ("historical forecasts") are reviewed.

The way LIEF forecasts energy use and the rationales for the particular structure of the analysis are presented in Section 2. The representation of policies in the model, especially demand-side management, is also briefly discussed. Historical information (19581985) about energy-intensity trends in the manufacturing sectors, as well as data problems, are briefly reviewed in Section 3. Historical forecasts made with LIEF for these sectors, which provide information about some forecast parameters in the model, are described in Section 4. Input data for the 1990 base year, along with representative forecast parameters, are presented in Section 5, where two scenarios (base-case and demand-side management [DSM]) are generated and briefly discussed. Issues that need to be considered by users of the present model and considerations for further improvements in the model are discussed in Section 6. A user's manual and detailed documentation are found in Appendixes A and B. 


\section{STRUCTURE OF THE MODEL AND DSM REPRESENTATION*}

\subsection{ENERGY DEMAND FORECASTING WITH LIEF}

A new implementation of LIEF in $\mathrm{C}++$ has been made for this analysis. The model encompasses all of industry in 18 sectors (Table 2.1). LIEF continues to be restricted to two energy forms: electricity and the Btu aggregate of fossil fuels. The detailed documentation is presented in Appendix $B$.

Aggregate energy demand in the manufacturing sector ultimately depends upon three factors (Marlay 1984, 1987; Faruqui 1987; Boyd et al. 1987; Doblin 1988; Howarth 1991):

1. Aggregate production,

2. Product mix, and

3. Process energy intensity.

The modeling approach of LIEF is hybrid: intermediate between top-down econometric modeling and bottom-up technology models. Exogenous forecasts of individual subsector growth rates and energy prices are combined with endogenous forecasts of real energy intensity trends to yield forecasts of overall energy demand. For manufacturing subsector $i$, energy form $j$, and year $t$, energy intensity is:

$$
E I_{i j}(t)=\frac{E_{i j}(t)}{Q_{i}(t)},
$$

where $Q_{i}(t)$ is a measure of the annual production in subsector $i$, and $E_{i j}(t)$ is the annual energy consumption of energy form $j$. For the historical estimation of parameters, the primary sources of data are, for $Q_{i}(t)$, the real gross output from the Bureau of Labor Statistics (BLS) (BLS 1989) and, for $E_{i j}(t)$, the National Energy Accounts (NEA 1988). Figure 2.1 shows the dynamic structure of LIEF, and Table 2.2 shows the key equations.

\subsubsection{Importance of Sector Definitions}

Declining output share of the basic materials industries has characterized product mix in recent decades. These industries are primary metals; chemicals; petroleum refining; stone, clay, and glass; and pulp and paper. The tonnage of basic materials produced (and consumed) is growing more slowly than manufacturing as a whole. These industries are

* Adapted from Ross and Hwang (1992). 


\section{TABLE 2.1 LEF 18-Sector Model for U.S. Industry ${ }^{a}$}

Low-Material-Intensive Manufacturing (Sectors 1 and 2)

Sector 1: General mature manufacturing

Sector 2: Fast-growing manufacturing

Energy-Intensive Manufacturing Process Sectors (Sectors 3-12)

Sector 3: Pulp and paper mills

Sector 4: Industrial inorganic chemicals

Sector 5: Industrial organic chemicals

Sector 6: Petroleum refining

Sector 7: Glass and glass products

Sector 8: Cement

Sector 9: Stone and clay products

Sector 10: Iron and steel

Sector 11: Primary aluminum

Sector 12: Nonferrous metals (excluding primary aluminum)

Nonmanufacturing Industries (Sectors 13-16)

Sector 13: Agriculture

Sector 14: Mining (excluding oil and gas)

Sector 15: Oil and gas extraction

Sector 16: Construction

Other Manufacturing Energy Use (Sectors 17 and 18)

Sector 17: Feedstocks

Sector 18: Uranium enrichment

a The standard industrial classification (SIC) correspondences are shown in Appendix B, Table B.1. This list of 18 industrial sectors is intended to be complete and mutually exclusive. 


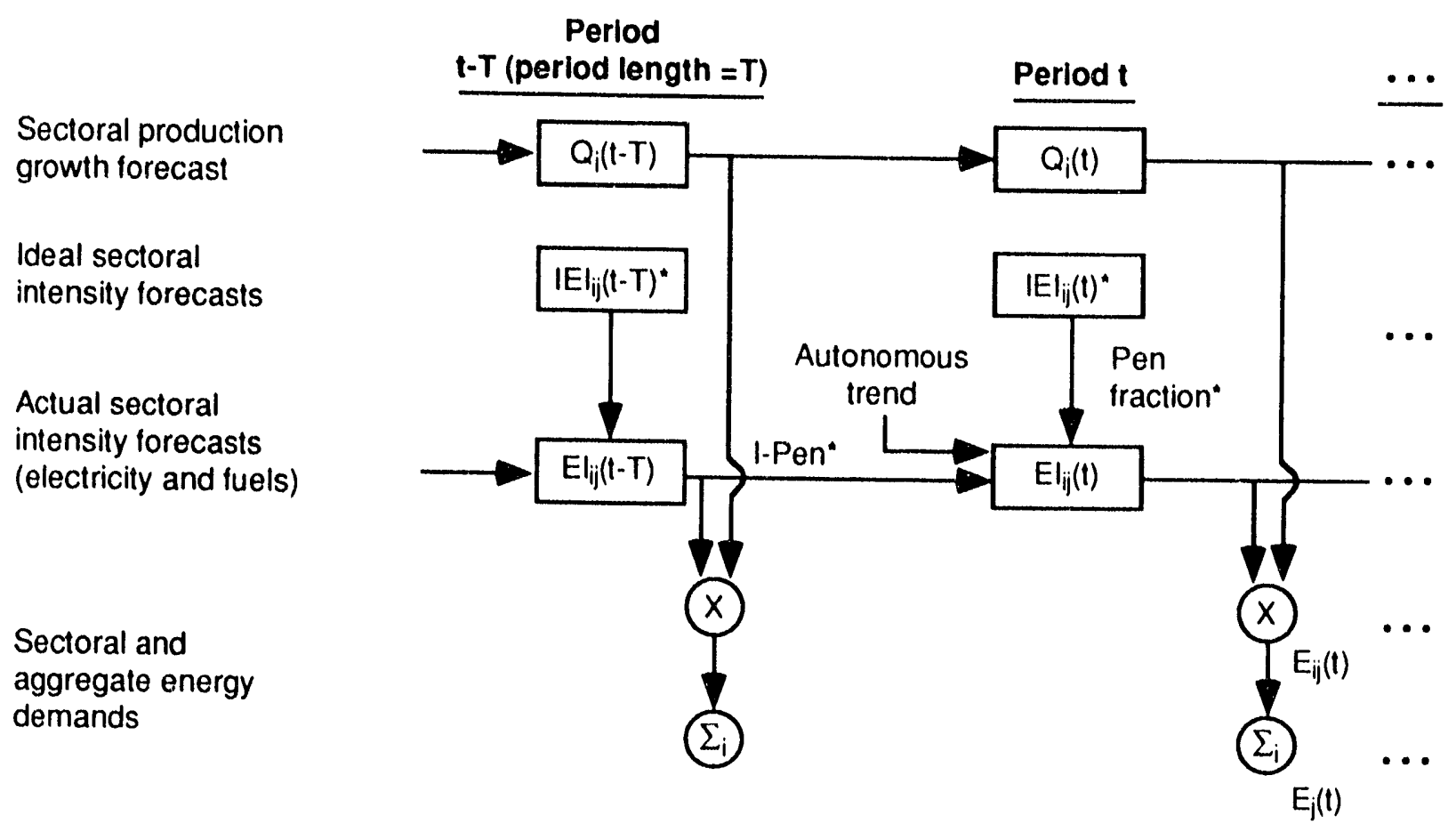

- Ideal energy intensities depend on prices and the capital recovery factor (CRF). Actual energy intensities are described by a partial adjustment process with the ideal intensity technologies penetrating at a specified traction, pen(t), each period. Energy intensities are scaled by an autonomous time trend.

FIGURE 2.1 Dynamic Structure of the LIEF Model (simplified)

roughly 10 times as energy intensive as the remainder of manufacturing. Sectoral shift away from the basic-materials industries has been of comparable importance to real efficiency improvements in explaining the historical decline in total energy intensity.

There are several explanations for the declining role of basic materials (Huntington and Myers 1987; Kahane and Squitieri 1987):

1. Increased energy prices,

2. Cyclical effects,

3. International competition, and

4. Reduced material intensity for more basic reasons.

In the fourth explanation, as the gross national product (GNP) rises in advanced industrial economies, basic materials become relatively less important (Williams et al. 1987). 
TABLE 2.2 Overview of LIEF Model Equations (simplified) ${ }^{a}$

Total Industrial Electricity or Fuel Demand

$$
E_{j}(t)=\sum_{i} E I_{i j}(t) Q_{i}(t)
$$

where: $\quad i=$ manufacturing sector,

$j=$ energy type (only two types are incorporated in the present version: fossil fuel and electricity),

$E_{j}(t)=$ total demand for energy type $j$,

$\mathrm{EI}_{\mathrm{ij}}(\mathrm{t})=$ energy intensity of sector $\mathrm{i}$ for energy type $\mathrm{j}$, and

$Q_{i}(t)=$ production in sector $i$.

Electricity and Fuel Intensities by Sector

$$
E I_{i j}(t)=(1-P e n) E I_{i j}(t-T) \exp \left(-B_{i j}(t) T\right)+P \operatorname{PenIEI} I_{i j}(t)
$$

where: $\quad$ Pen $=$ penetration rate for period $\mathrm{T}$ of cost-effective, energy-pricesensitive conservation;

$\mathrm{IEI}_{\mathrm{ij}}=$ ideal energy intensity from conservation supply curve for sector $i$ and energy type $j$;

$\mathrm{B}_{\mathrm{ij}}(\mathrm{t})=$ declining autonomous trend rate; and

$\mathrm{T}=$ length of one period for which forecasts are made.

Smoothed Conservation Supply Curve or Ideal Energy Intensity

$$
\operatorname{IEI}_{i j}(t)=\operatorname{IEI}_{i j}\left(t_{o}\right)\left[\frac{E P_{i j}(t) / C R F(t-T)}{P_{i j}\left(t_{0}\right) / C R F\left(t_{o}\right)}\right]^{-A_{i j}} \exp \left(-\Sigma B_{i j}\left(t^{\prime}\right) T\right)
$$

where:

$$
\begin{aligned}
A_{i j} & =\text { CSC price elasticity, } \\
C R F & =\text { capital recovery factor, } \\
B_{i j}(t) & =\text { autonomous trend, } \\
\operatorname{EP}_{\mathrm{ij}}(t) & =\text { expected price of energy type j relevant to conservation at time } t, \\
& \text { and } \\
P_{i j}\left(t_{0}\right) & =\text { price of energy type } j \text { in base year } t_{0} .
\end{aligned}
$$

a Neglecting price-induced fuel-electricity substitution and recycling.

This dematerialization (Herman et al. 1989) is associated with saturation of heavy products (high weight/dollar value), innovative products characterized by low weight/dollar value, competition among materials, and technological advances that reduce the use of material in standard applications.

Long-term energy demand will be profoundly impacted by which theory characterizes the future. If cyclical effects and international competition are dominant, then the shift away from energy-intensive industries could be transitory. On the other hand, if high-technology products with relatively low materials content continue to dominate industrial growth, then energy demand in the long term will be dampened. 
The impact of sectoral shifts and changing process energy intensities can only be adequately characterized if careful attention is paid to sectoral disaggregation. The choice of disaggregation can be more important to a forecast than the description of efficiency improvement. We find that disaggregation into two-digit Standard Industrial Classifications (SICs) is not satisfactory for long-term forecasting, neither for energy-intensive industries nor for energy-nonintensive industries.

The problem is not that there are too few two-digit sectors, but that they are poorly aggregated for energy analysis. Some energy-intensive two-digit industries, especially chemicals and allied products (SIC 28), contain a heterogeneous mix of highly energyintensive and energy-nonintensive sectors with quite different growth rates. Also, some energy-nonintensive two-digit sectors, such as nonelectrical machinery (SIC 35), contain a heterogeneous nix of very fast-growing sectors along with slow-growing sectors of low, but greater, energy intensity. According to some forecasts, electricity consumption in lightindustry sectors, such as SIC 35, could become huge (EIA 1990, Figure 4-12; Boyd et al. 1991). Disaggregation suggests that this is unrealistic (Ross and Fisher 1991). Therefore, for long-term forecasts, it is as important to disaggregate the fast-growing sectors as it is the basic materials sectors.

The new version of LIEF organizes industry into 18 sectors, as shown in Table 2.1. These sectors include separate mature and fast-growing low-intensity manufacturing sectors, 10 energy-intensive manufacturing process sectors, 4 nonmanufacturing sectors, a feedstock sector, and a uranium enrichment sector.

\subsubsection{Real Energy Intensity Forecasting Approach}

The fuel intensities of various manufacturing processes fell an average of about $1.2 \%$ per year before the early 1970s and fell even more quickly afterwards (Ross 1991). Before the 1970 s, electricity intensities increased by about $1.8 \%$ per year in most industries at the two-digit SIC level; after 1973, these intensities decreased (Kahane and Squitieri 1987). These trends can be explained by two main developments:

1. Steady evolution of fundamental process efficiency, and

2. Steps taken by manufacturing to reduce energy consumption in response to the 1973 and 1979 energy price shocks (conservation and "housekeeping" measures).

Fundamental Process Efficiency. Substantial evidence suggests that general progress in production technology tends to reduce all factor inputs, including energy, although there is a tendency for new applications of electricity. This "neutrality" of productivity improvement based on fundamental process change has been discussed (Solow 1957; Berg 1978). 
Conservation and Housekeeping Measures. Conservation refers here to investments for which an important rationale is energy cost reduction. Housekeeping measures are operational changes in response to energy prices. Starting about 1973, industry made major additional efforts of both kinds (Steinmeyer 1990).

Investment projects differ widely in the importance of energy prices in the entire identification and decision-making process leading to project implementation. As a convenient approximation to this distribution of projects, we put each project into either one of two categories: projects where energy price is a primary consideration and projects where it is a minor consideration. Observation of actual project selection procedures and their dependence on project size and project category (i.e., strategic, mandatory, and discretionary) suggests that this approximation may be satisfactory, although many of the most desirable small projects have multiple benefits, including energy cost reduction (Ross 1986). Even with the latter type of project, in many vases the energy benefits are calculated, while important cobenefits are hard to estimate credibly. The role played by these cobenefits may be to raise the priority given to the project while not affecting the economic analysis as such.

Electrification, primarily new applications of electricity, refers here to projects motivated by process and product improvement rather than by energy costs. For example, empirical evidence suggests that the price of electricity did not affect the adoption of electricarc furnaces (Karlson 1990). This conclusion appears to be even stronger for examples in less energy-intensive sectors (Kahane and Squitieri 1987).

Unlike electrification, fuel substitution refers here to cases where energy prices are a prime consideration in the choice between electricity and fuel. Examples of such cases include motors versus fuel-driven prime movers and high-temperature electric versus fuel furnaces, where the production process is essentially the same.

This analysis does not consider switching among fossil fuels. Such fuel switching is not as important as one might think, since natural gas already dominates fossil fuel consumption for heat and power in almost all manufacturing sectors. Petroleum products are used in sectors where they are critical to the process, such as in feedstocks, at sites unconnected to gas lines, and in cases where they are by-products. Much coal use is process related, as in iron and steel production.

Energy intensity forecasting in LIEF rests on the hierarchy of industrial decision making, as discussed above:

1. The choice of fundamental production processes, which is autonomous in the sense that it is not sensitive to energy prices; and

2. The choice of energy-related technologies, including some process changes, which is sensitive to energy prices.

For long-term forecasts, it is assumed that operational decisions, as separate from process choices, are not important. 
LIEF characterizes energy-price-independent decisions on process technology as a simple time trend in energy intensity (Table 2.2). The autonomous trend parameters, $B_{i j}$, dictate the annual rates at which electricity and fossil fuel intensities change, and the parameter, BPR, is the time it takes for the trend to go to zero - very roughly 100 years.

For the choice of energy-related technology, the conservation supply curve (CSC) is adopted as the basic analytical tool. The CSCs can be derived from engineering-economic descriptions of conservation opportunities. This engineering perspective is shown in Figure 2.2. The CSC specifies the energy conservation potential as a function of marginal capital cost, analogous to an energy supply curve. The y-axis is the marginal capital cost of a project, as illustrated in Exhibit 1. The x-axis is the energy savings cumulative over projects, either as an absolute annual rate (e.g., $\mathrm{kWh} / \mathrm{yr}$ ) or as a percentage. Alternatively, analysts often convert the project's capital costs into a stream of annual payments divided by the annual energy savings, so that the y-axis is in the same units as the energy price (Meier 1983). This $y$-axis is often called the cost of conserved energy (CCE). The use of CSCs in a model introduces variables besides price that provide useful policy-analysis handles.

The derivation of the conservation suppiy curve from an economic perspective is shown in Figure 2.3. Part (a) of this figure shows total capital expenditures versus total energy savings per year. Part (b), the CSC, depicts the marginal capital cost as a function of energy savings per year. The CSC yields the capital expenditures required to save an

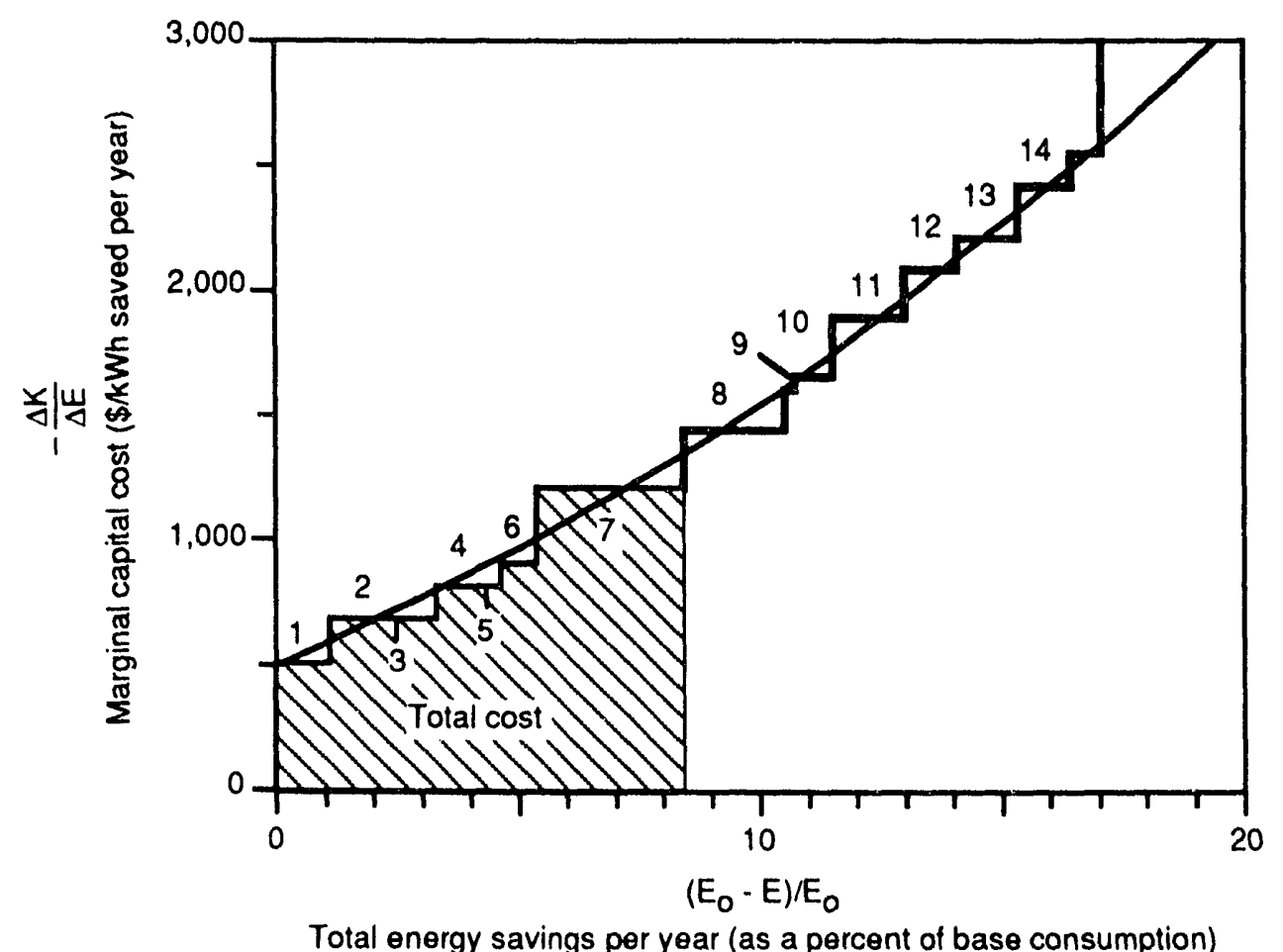

Note: Numbers on curve correspond to hypothetical project number.

FIGURE 2.2 Conservation Supply Curve - Engineering Perspective 
Consider two types of lighting: high efficiency and very high efficiency. Base energy use is $150 \mathrm{kWh} / \mathrm{yr}$ per bulb.

\begin{tabular}{|c|c|c|c|}
\hline $\begin{array}{c}\text { Lighting } \\
\text { Types }\end{array}$ & Cost per Bulb & $\begin{array}{c}\text { Energy Savings } \\
\text { (kWh/yr) Percent } \\
\text { Reduction }\end{array}$ & $\begin{array}{c}\text { Total Cost of } \\
\text { Measure (Assuming } \\
\text { Replacement of 100 Bulbs) }\end{array}$ \\
\hline HiEFF & $\$ 10$ & $45 \%$ & $\$ 1,000$ \\
\hline VHIEFF & $\$ 30$ & $69 \%$ & $\$ 3,000$ \\
\hline
\end{tabular}

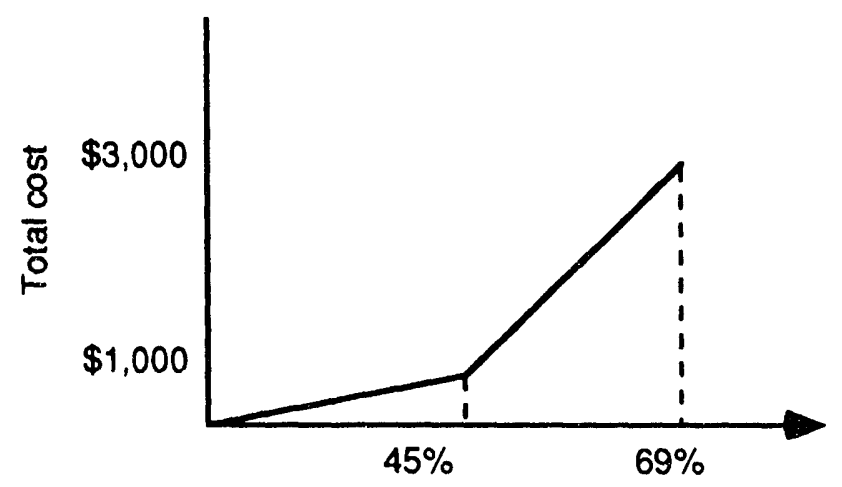

$\%$ of lighting energy saved per year

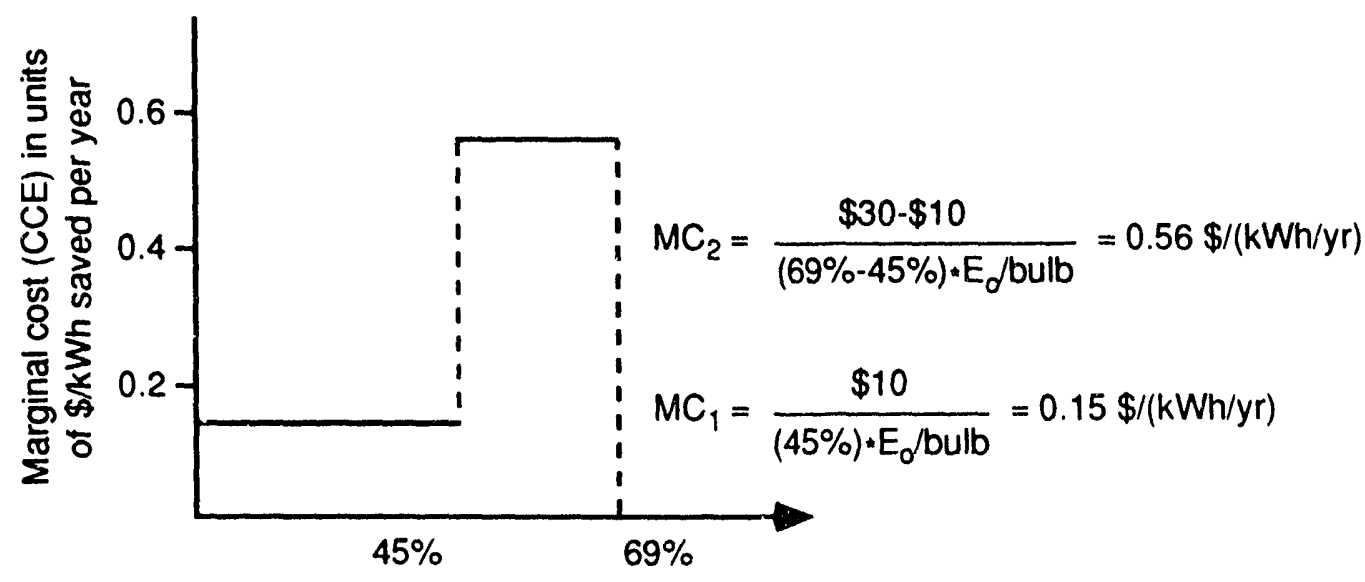

$\%$ of lighting energy saved per year

Hence, the two steps, at $15 \varnothing$ and $56 c$, are capital investments to save $1 \mathrm{kWh} / \mathrm{yr}$.

Exhibit 2.1 Example of Marginal Capital Costs of Conservation Projects 


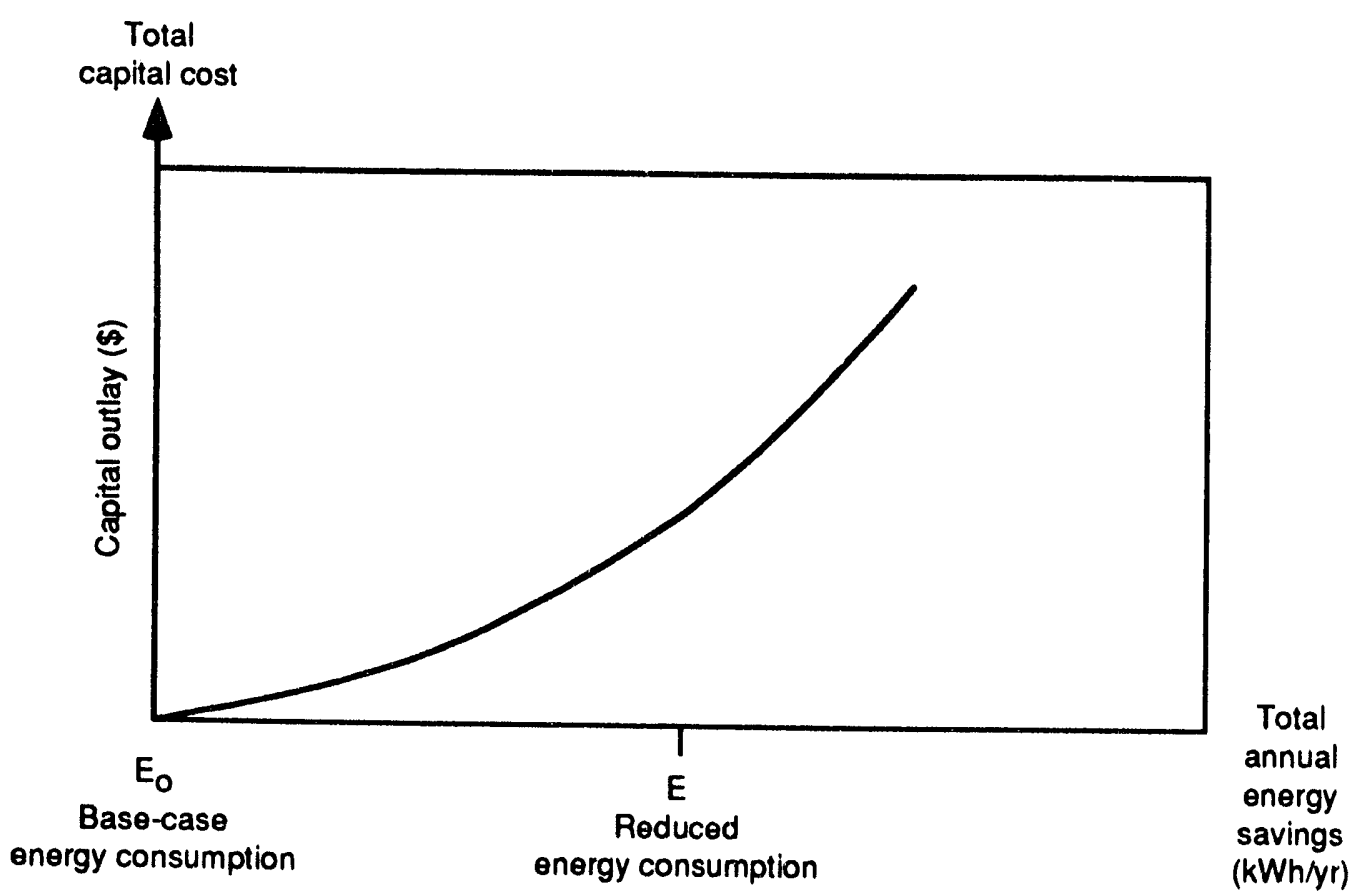

(a) Capital expenditure as a function of energy saved per year

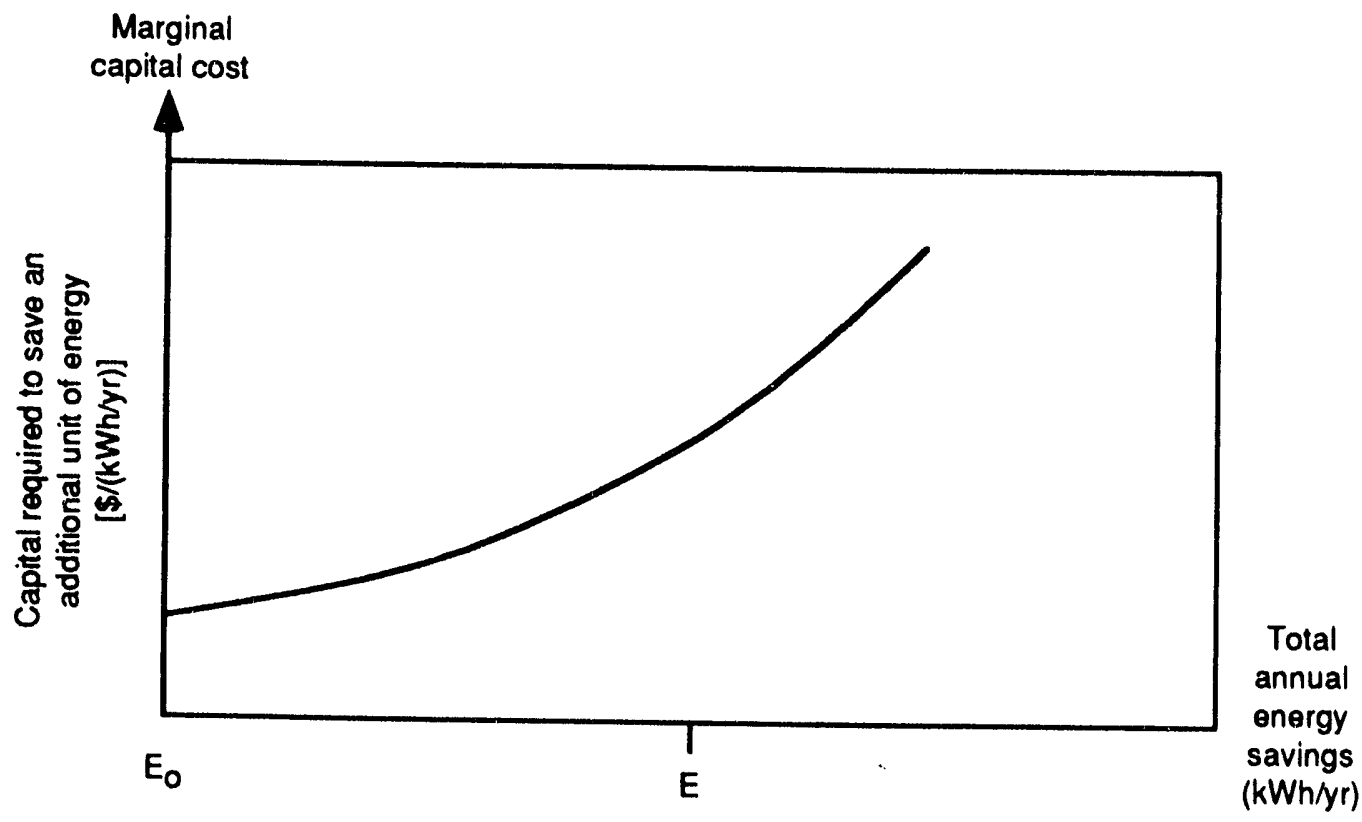

(b) Conservation supply curve (slope of capital outlay curve above)

FIGURE 2.3 Conservation Supply Curve - Economic Perspective 
additional unit of energy, given an existing level of energy savings, $\mathrm{E}_{\mathrm{o}}-\mathrm{E}$. The CSC rises because conservation opportunities should be taken in order, with the least cost first, and at high levels of existing energy savings it becomes more costly to save an additional unit of energy.

Severe data problems face the construction of CSCs for industry. The CSCs constructed by using the engineering, or bottom-up, approach are lists of identified conservation projects, ordered in terms of increasing cost. This method of construction is common for modeling the residential and commercial sectors. Some energy forecasting models with broad industrial coverage are essentially based on this approach (ISTUM 1982; EGUMS 1991). However, the vast heterogeneity of the industrial sector, the often proprietary nature of industrial process technology, and the lack of experience at high energy prices create severe data problems, particularly for cost information (Ross 1990b; DOE 1991; NRC 1991). Consequently, adequate CSCs constructed from the bottom-up are often limited to a few specific processes or plants. Examples include a conservation plan for a particular refinery (Larsen 1990) and a study of an integrated steel mill (Ross 1987).

The CSCs constructed by analogy extend the applicability of CSCs developed for specific industries or plants to analogous facilities. In this way, broader sector coverage can be obtained. In our opinion, this is a practical approach for constructing adequate CSCs for the entire manufacturing sector. Curves constructed in this manner have been used in some recent studies (DOE 1991; DOE 1991/1992b; NRC 1991).

LIEF characterizes the conservation opportunities through two parameters, $A_{i j}$ and $\mathrm{Gap}_{\mathrm{ij}}$, which roughly correspond to the slope and intercept of the CSC, respectively (Table 2.2). Statistical analysis of historical data and engineering case studies are used to estimate CSC parameters for each sector and fuel type without specifying the technologies (Ross and Hwang 1992). This method is less detailed than the approaches just discussed. However, detailed information is not as relevant for long-term forecasting.

In LIEF, a firm finds a conservation project cost-effective if the annualized cost of the measure is less than the energy cost avoided. The project's capital costs are annualized by using the firm's implicit discount rate as expressed in the capital recovery factor, CRF. A project's attractiveness is then directly proportional to the energy price expected and inversely proportional to the implicit CRF. Energy prices and the CRF determine the "ideal energy intensity," which is the energy intensity if all firms immediately adopted the most cost-effective projects (while retaining their implicit CRF). Raising price expectations or lowering implicit CRFs increases the ideal level of conservation (Figure 2.4). Figure 2.4 shows the extent of conservation that is economic at a given price of energy and at the CRF. The last unit of energy saved that is economic satisfies the condition that the annualized cost of conserving the energy just equals the price of purchasing the energy.

The penetration rate, pen(t), is a measure of the rate at which industry adopts conservation projects. Firms do not immediately adopt all cost-effective projects for several reasons, such as lack of capital, other business concerns (opportunity costs), or scheduling of 


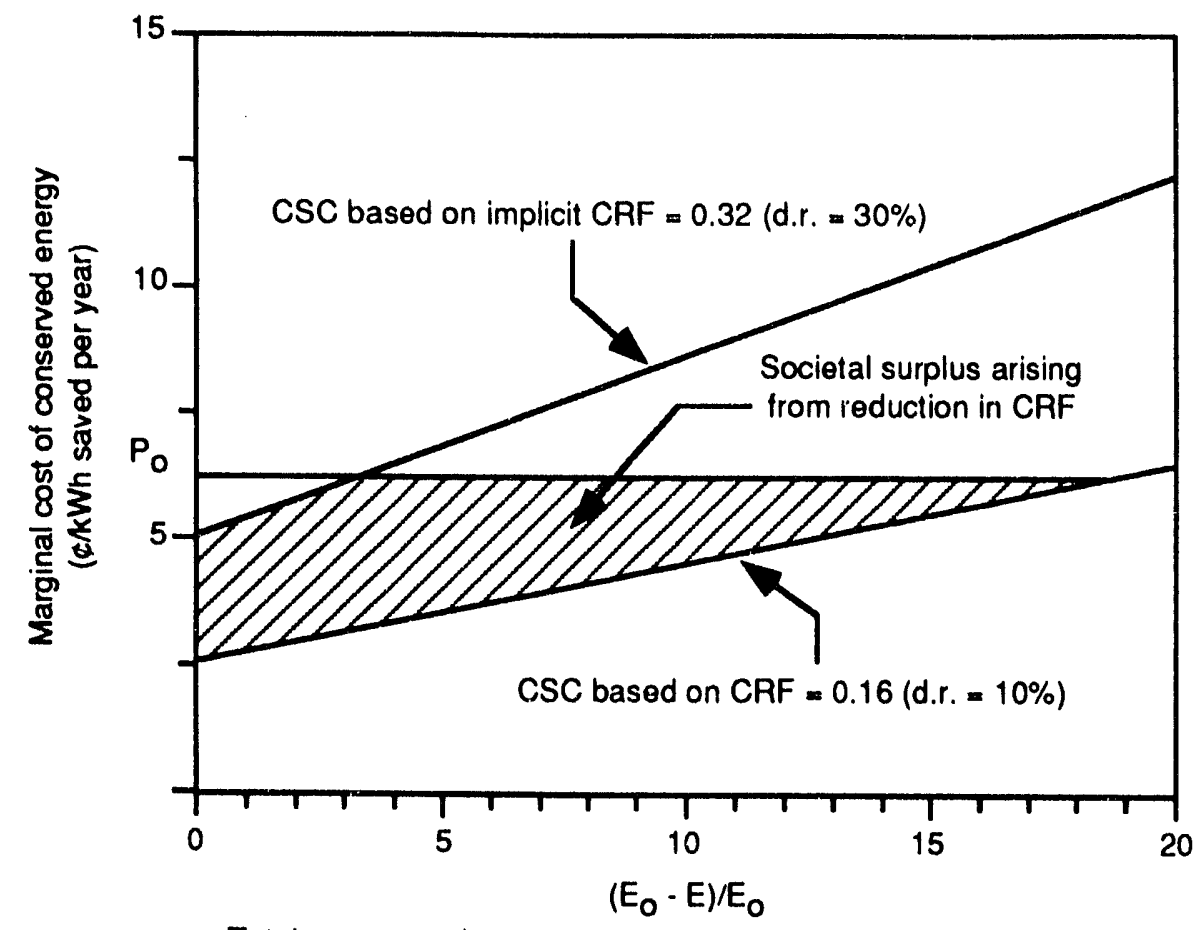

Total energy savings per year (as a percent of base consumption)

Note: CCE calculated assuming project life $=10 \mathrm{yr}$.

FIGURE 2.4 Dependence of Conservation Supply Curve on Capital Recovery Factor

production. Also, firms may simply be unaware of conservation opportunities, including new opportunities. An increase in penetration reflects a higher priority given to energy conservation by industry and better dissemination of information.

\subsubsection{Policy Analysis with LIEF}

Government policies may affect energy prices, financial criteria for equipment investment, rate of adoption of energy-efficient equipment, rate of technical innovation, criteria for investment other than financial, and recycling behavior. As shown in Table 2.3, LIEF can be used to forecast the effect of some, but not all, of these policy instruments. With microeconomic-based CSCs, LIEF provides handles for forecasting the effect of policies that modify:

- Energy prices $\left(p_{e}\right.$ and $\left.p_{f}\right)$,

- Implicit discount rate (CRF),

- Penetration rate of conservation investments (pen),

- Conservation supply curve shape $\left(\mathrm{A}_{\mathrm{ij}}\right)$, 
TABLE 2.3 Policy Handles in LIEF

\begin{tabular}{|c|c|}
\hline Area of Impact & Policy II andle \\
\hline $\begin{array}{l}\text { Energy prices } \\
\text { Taxes } \\
\text { Energy taxes } \\
\text { Carbon tax } \\
\text { Emission of greenhouse gases } \\
\text { Greenhouse gas emission limits } \\
\text { Tradeable } \mathrm{CO}_{2} \text { emission rights }\end{array}$ & Electricity and fuel prices, $p_{e}$ and $p_{f}$ \\
\hline $\begin{array}{l}\text { Financial criteria for equipment investment } \\
\text { Equipment subsidies by utility (via rate-of-return regulation) } \\
\text { Rebates } \\
\text { Low-interest loans } \\
\text { Installation at utility cost } \\
\text { Audits } \\
\text { Equipment subsidies by government } \\
\text { Performance-based tax rebates } \\
\text { Investment tax credits } \\
\text { Direct government purchases }\end{array}$ & Capital recovery factor, CRF \\
\hline $\begin{array}{l}\text { Rate of adoption of energy-efficient equipment } \\
\text { Equipment subsidies by utility (via rate-of-return regulation) } \\
\text { Equipment subsidies by government } \\
\text { Technology standards } \\
\text { Equipment design standards } \\
\text { Process standards } \\
\text { Performance standards } \\
\text { Data collection } \\
\text { Information dissemination } \\
\text { Audit programs } \\
\text { Extension services } \\
\text { Advertising and labeling } \\
\text { Training } \\
\text { Patent law }\end{array}$ & Penetration rate, pen \\
\hline $\begin{array}{l}\text { Rate of technical innovation } \\
\text { Research and development programs } \\
\text { Demonstration programs } \\
\text { Patent law }\end{array}$ & $\begin{array}{l}\text { Conservation supply curve } \\
\text { parameter, } A_{i j} \text {, and autonomous time } \\
\text { trend parameter, } B_{i j}\end{array}$ \\
\hline $\begin{array}{l}\text { Criteria for investment other than financial } \\
\text { Behavior modification } \\
\text { Goal setting and reporting of performance } \\
\text { Training and education } \\
\text { Moral suasion } \\
\text { Signaling }\end{array}$ & $\begin{array}{l}\text { Implicit capital recovery factor, CRF, } \\
\text { and penetration rate, pen }\end{array}$ \\
\hline $\begin{array}{l}\text { Recycling behavior } \\
\text { Recycle content standards } \\
\text { Deposit-refund systems }\end{array}$ & Recycling rate, $\mathrm{R}$ \\
\hline
\end{tabular}

Source: Ross and Hwang (1992). 
- Autonomous time trends $\left(\mathrm{B}_{\mathrm{ij}}\right)$, and

- Recycling rate $(\mathrm{R})$.

All these parameters, except A and B, can be freely adjusted in the model as functions of $t$.

The inclusion of factors other than price, especially the effect of alleviating capital constraints, is a major advantage of the approach in LIEF over the simplest econometric models. For example, the DSM program considered below is assumed to affect energy prices, implicit discount rates, and penetration rates.

\subsubsection{LIEF Outputs}

In addition to forecasting electricity and fossil-fuel intensities, LIEF reports production, relative to base-year levels, and absolute electricity and fuel consumption. For electricity, total usage is modeled (i.e., purchased electricity plus electricity that is selfgenerated and used [SGUE] on-site), but the purchased electricity and SGUE are also reported. Some of the fossil fuel is used for self-generation of electricity, which results in double counting if the total electricity and fossil fuel are combined. The base-year energy consumption determined from bottom-up analysis may not agree with the nominal totals of the Energy Information Administration from the State Energy Data System (SEDS). If the LIEF user inputs the discrepancies, totals consistent with SEDS are reported.

On the basis of forecast results, LIEF reports a Divisia analysis for industry total fuel and electricity. The index for total energy $I_{E}(t)$ is expressed as the product of indices for the aggregate production, $I_{Q}$; for the effect of shifting sectoral composition of production, $I_{S}$; and for the real intensity change, $I_{I}$ (Boyd et al. 1987). Thus, the aggregate $E(t)=I_{E}(t) E\left(t_{0}\right)$, and

$$
I_{E} \approx I_{Q} I_{S} I_{I}
$$

(The relationship is approximate because the sectoral shift and real intensity effects interact, but the interaction is small with the Divisia approach. Differences in the indices are a few parts per thousand or less, and differences in the corresponding percent-per-year growth rates are a few parts per hundred or less.)

LIEF also reports estimates of capital expenditures on energy conservation, $\mathrm{KC}$, for electricity and fuel. These investments are associated with the CSC, rather than with the autonomous trend. Since firms do not systematically and uniformly move up the CSC as penetration occurs, these capital expenditures are approximated and probably somewhat overestimate actual costs (given the CSC parameters A and Gap0). Details are specified in Appendix B. 


\subsection{THE DEMAND-SIDE MANAGEMENT REPRESENTATION}

Demand-side management (DSM) is the planning, implementation, and monitoring of utility activities designed to influence customer use of energy in ways that produce desired changes in a utility's load shape and energy consumption (Edison Electric Institute 1988; Krause and Eto 1988). The cost to utilities of facilitating energy savings can be competitive with the cost of rew supply capacity. The DSM aimed at conservation is the subject here, as well as in several other studies (Faruqui and Haites 1991; Gellings and Yau 1991; Hirst 1991).

Industrial DSM programs are often in the form of free technical assistance or subsidized analyses of energy-saving opportunities. More relevant here are programs offering financial inceritives, such as rebates per kilowatt or kilowatt-hour of savirigs, grants, loans, and sharec savings (ACEEE 1990b; OTA 1991). In practice, a nationwide manufacturing DSM effort would be a heterogeneous mixture of program types. For example, a DSM plan prepared for the New "York State Energy Research and Development Authority included over 20 different kinds of programs for the commercial/industrial sector (ACEEE 1990b).

The DSM program is assumed to begin in 1995 and extend until the end of this analysis in 2030. Thiz analysis models a single "stylized" DSM program that affects two LIEF parameters: reducing the implicit CRF of the customer and increasing the penetration rate for conservation. Reducing the implicit CRF does not change the customer's financial criterion as such: instead, the rebates reduce the payback time of energy savings projects so that more projects meet the payback criterion, which is assumed to be fixed. In addition, utility information programs, technical assistance, and persuasive efforts increase pen, or the rate at which firms adopt cost-effective conservation projects.

Energy conservation projects adopted under this program must meet the financial criteria of both customers and society. The rebate must be able to "buy down" the customer's payback time to roughly three years or less. The rebate is taken to be 50\% of the measures' costs. Typical industrial and commercial rebate programs provide customer incentives of 25-50\% of the installed cost (ACEEE 1990a,b). A plan for New York State suggests the incentive level be set at $80 \%$. Hence, $50 \%$ is not unreasonable for an aggressive program.

Society's criterion is that the total expenciture on conservation investments should be no more than would have been spent on new energy supply. Total prograrn cost to society includes measure costs and program administration costs. Averaging 46 commercial and industrial programs surveyed, ACEEE (1990b) found the average ratio of program administration costs to total installed costs to be 0.25 to 0.35 (Berry 1991). With a $50 \%$ rebate level, the effective CRF for customers drops from 0.33 to 0.17 . The criterion of society is essentially the same as tbat of the customer if the ratio of program administration costs to total installed costs is about 0.20 (Ross and Hwang 1992). We adopt this ratio.

Little is known about penetration rates for industrial DSM programs. The penetration rate is different from the commonly used participation rate, where the unit of analysis is participating customers (Berry 1990). Participation rates can be considered a 
proxy for penetration rates. A participation rate of 5\% per year appears reasonable (ACEEE 1990b; Berry 1990). On this basis, during the start-up phase (1995-2000) the penetration rate is assumed to be $3 \%$ per year, increasing to $5 \%$ per year starting in 2000 . After 2010, the penetration rate declines to $3 \%$ per year as the program begins to involve the more resistant portion of the market.

Modeling of the DSM policy requires modification of two key parameters: the penetration rate (pen) and the CRF. As discussed above, lowering the CRF increases the ideal level of conservation (i.e., the economically achievable energy intensity is smaller), and raising the penetration rate increases the rate at which ideal conservation measures penetrate the market.

A great deal of abstraction occurs in the transition from actual DSM programs to the two parameter series, pen(t) and $\operatorname{CRF}(t)$. The program described here is simple and successful. Some of the issues confronting DSM programs - if they are to be successful are discussed in Section 8 of Ross and Hwang (1992). 


\section{HISTORICAL PATTERNS OF ELECTRICITY AND FOSSIL FUEL USE}

\subsection{GENERAL CHARACTERISTICS*}

The aggregate energy intensity, that is, the ratio of the energy used by all of industry to total industrial production, was steady in the period from 1958 to 1972 and then fell by more than 33\% from 1972 to 1985.

The different sources of energy had quite different histories, however. From 1958 to 1985 , the aggregate coal and oil intensities fell $70 \%$ and $60 \%$, respectively. During this period, coal was being eliminated, except at large facilities and in very heavy industries. Petroleum was gradually losing share, and after the second oil shock its use was drastically curtailed. Between 1958 and 1971, the aggregate natural gas intensity rose $30 \%$ and, by 1985 , dropped from its peak by more than $50 \%$. Natural gas was favored for its low price and convenience until shortages occurred in 1971, shortly before the first oil shock.

The combined result of these developments was that the aggregate fossil fuel intensity fell $15 \%$ from 1958 to 1971 because of fuel-efficiency improvement in energyintensive sectors, even though real (i.e., inflation-corrected) fuel prices were low and falling. Beginning in 1971, the decline quickened and, by 1985, the aggregate fossil fuel intensity declined by another $50 \%$. Part of the reason for this accelerated decline was a relative shift in production away from energy-intensive production.

The pattern for electricity consumption is similar, except that continuing electrification (new uses of electricity) overshadows the other developments. Thus, the aggregate electricity intensity grew rapidly between 1958 and 1970, even though the efficiency of electricity-intensive processes, such as electrolysis of brine to produce chlorine and smelting of aluminum, was being improved. Real electricity prices fell during this period. Since 1970, electricity prices have mostly been rising, and the aggregate electricity intensity has gri ually declined. The two forces for decline, efficiency improvement and the relative decline in electricity-intensive production, have slightly outweighed ongoing electrification.

In 1958 , more than $20 \%$ of the total electricity used was generated and used on-site by manufacturers. On-site generation was falling, however, dropping to less than $8 \%$ of the total by 1981. With the Public Utilities Regulatory Policy Act (PURPA) of 1978, on-site generation has begun a comeback, rising to $10 \%$ of the manufacturing total in 1986 and to $11.4 \%$ in 1990 . These findings indicate that, up to 1981 , utility sales of electricity to

\footnotetext{
* The main data sources are, for energy, the NEA (NEA 1988) and, for output, the deflated value of shipments from the BLS (BLS 1989). Alternative sources of information are, for energy, the Annual Survey of Manufactures (ASM 1990 and earlier years), Census of Manufactures (DOC 1990a), Census of Construction-Industry Series (DOC 1990b), Census of Mineral Industries (DOC 1990c), and Census of Agriculture (DOC 1990d); and, for physical output, the Survey of Current Business (SCB 1991) and compendia of the same data in Business Statistics (DOC 1990e).
} 
manufacturers were growing about $0.7 \%$ per year faster than total electricity use. Utility sales growth is now slower than the growth of total electricity use.

In every sector, energy intensity histories roughly follow the same general pattern as for aggregate intensity. The typical pattern for fuel intensity (Figure 3.1) shows a slow decline from (before) 1958 to the early 1970s, when prices were constant or falling, and a rapid decline from the early 1970s, when the natural gas shortage and first oil-price shock occurred. (Data have not been analyzed beyond 1985.) The typical pattern for electricity intensity (Figure 3.2) shows a rapid increase from (before) 1958 to the early 1970s, when prices were falling. Electricity intensities have been roughly constant since the early 1970 s. In several industries, local increases in electricity intensity during the 1970, 1975, and 1982 recessions can be seen. Operations are apparently very inefficient with respect to electricity use when production is well below capacity.

Although all sectors for which there are adequate time series data (the 12 manufacturing sectors' energy use for heat and power) have had energy intensity patterns that resemble these typical patterns, several sectors exhibit important differences and present important accounting issues.

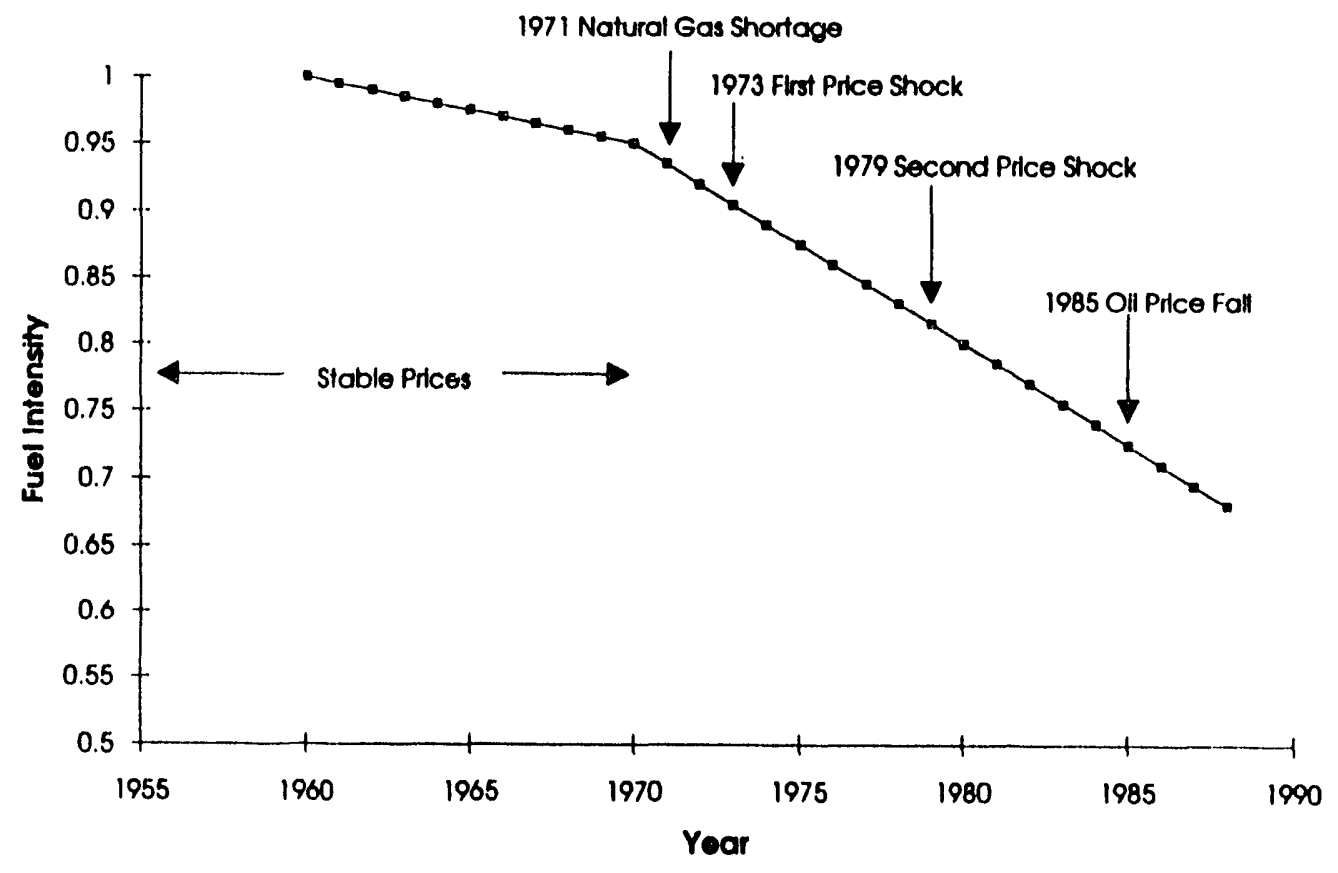

FIGURE 3.1 Typical Fuel Intensity History 


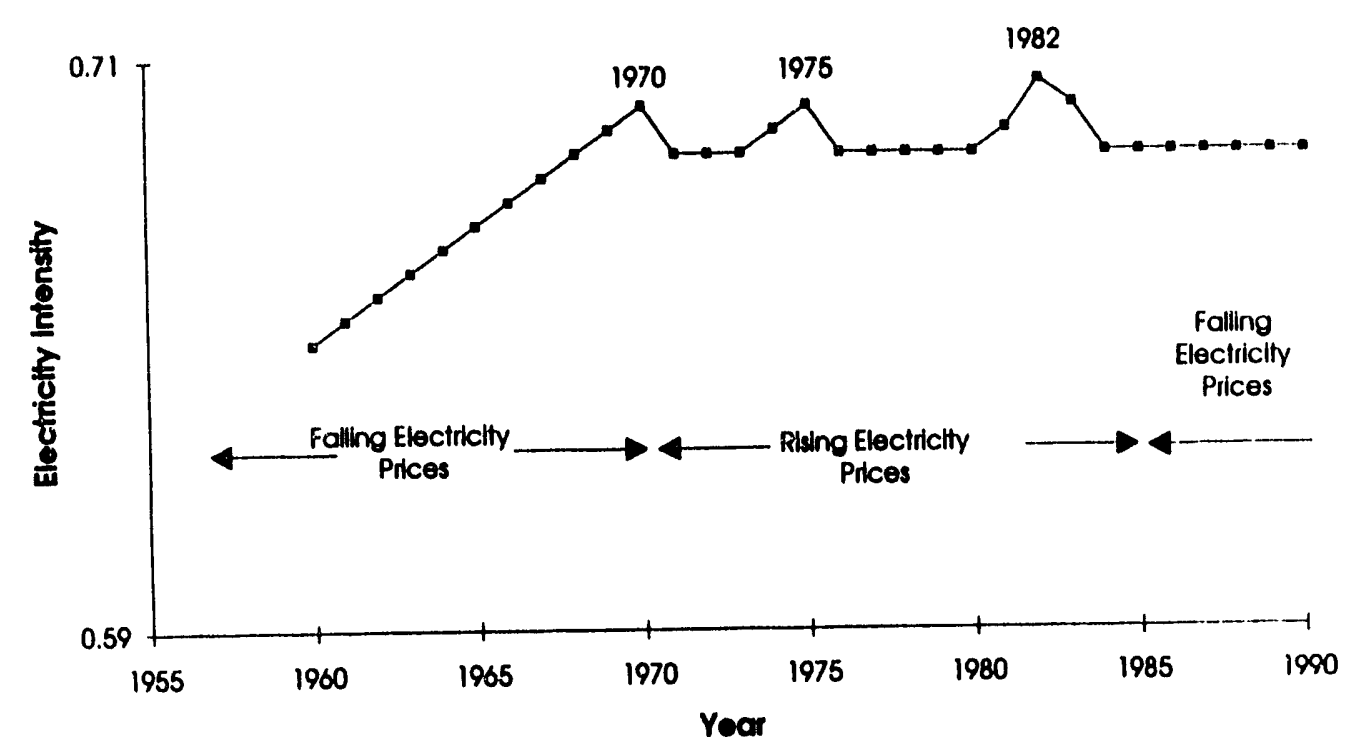

FIGURE 3.2 Typical Electricity Intensity History

\subsection{SECTORAL ENERGY INTENSITY PATTERNS}

\subsubsection{General Manufacturing}

The general manufacturing sector shows the typical pattern (Figure 3.3). Peak electricity intensities can be seen in 1970, 1975, and 1982 in association with those recession years. Peak fuel intensities can be seen in 1958, 1975, and 1983 in association with those recession years.

\subsubsection{Fast-Growing Manufacturing}

The fast-growing high-technology sector also shows the typical pattern, except for the important characteristic of falling electricity intensity after 1970 (Figure 3.4). Characteristics of this sector have been discussed by Ross and Fisher (1991), where it is argued that the falling electricity intensity is probably due to rapid product innovation, which increases real product values more than the increase in electricity of manufacture. Moreover, it is strongly argued that this sector changed in character during the 1960s and took its modern form only by around 1970 .

\subsubsection{Pulp and Paper Mills}

The purchased electricity intensity (not shown) rises extremely rapidly through most of the period, but as an indicator of electricity use, this fact is misleading. The paper industry is, by far, the largest user of self-generated electricity. Electricity that was 


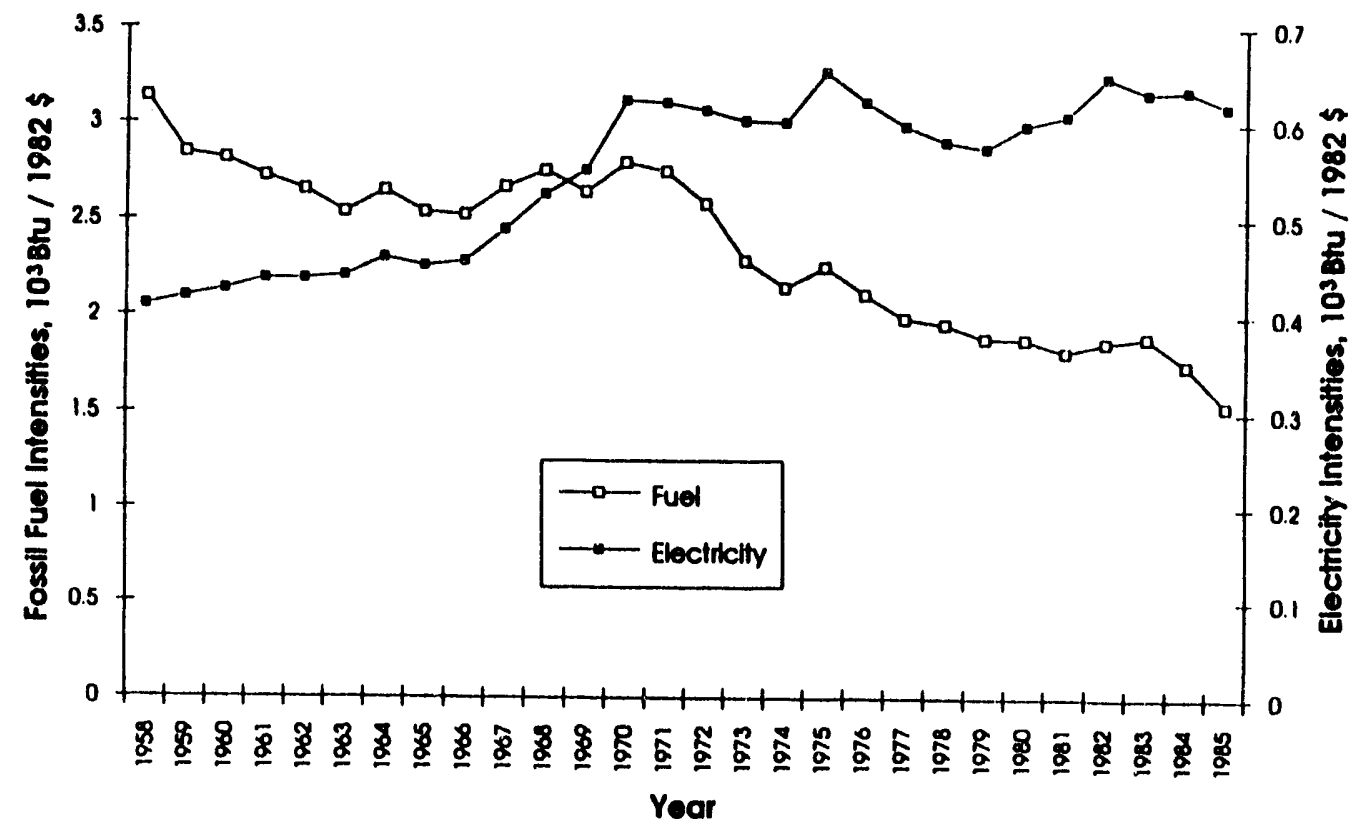

FIGURE 3.3 Energy Intensities: General Manufacturing

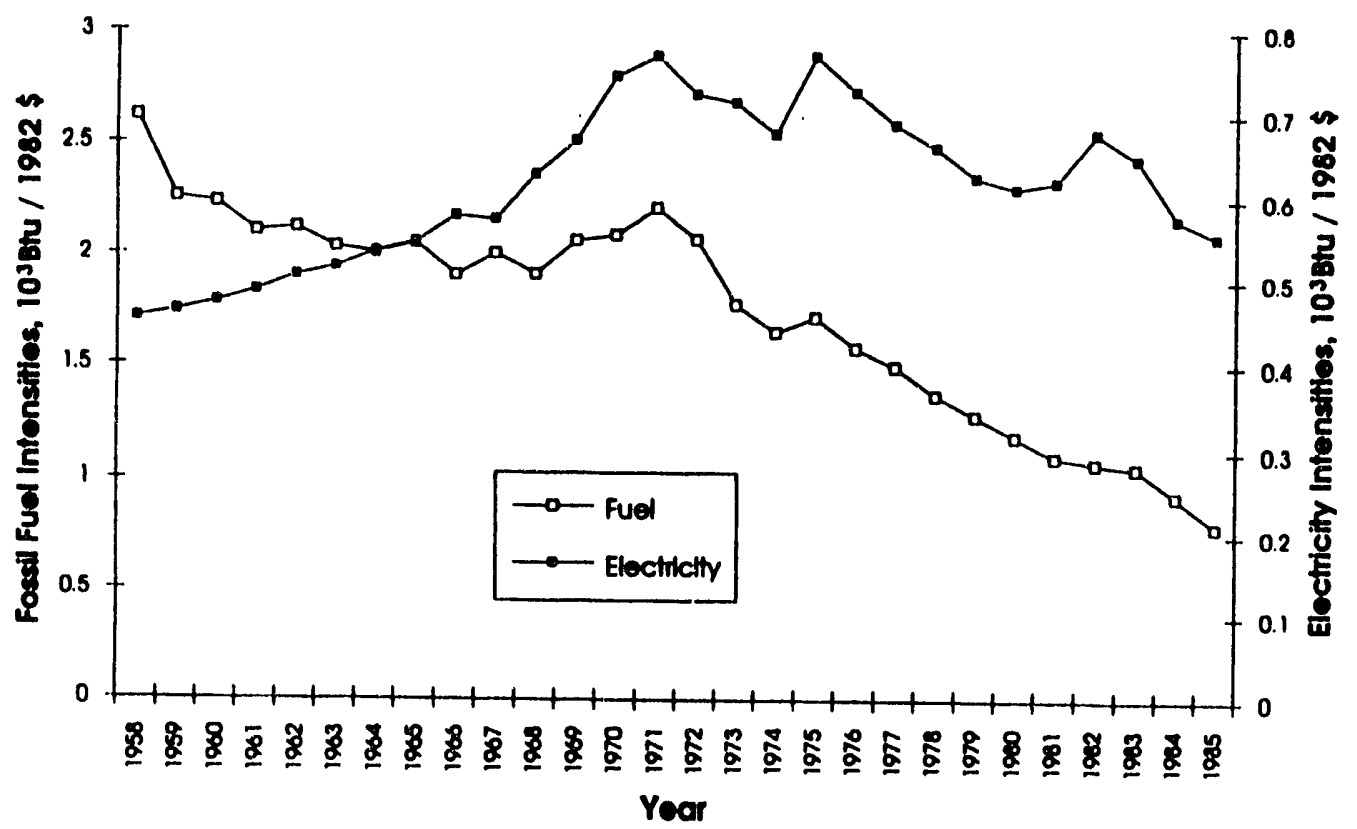

FIGURE 3.4 Energy Intensities: Fast-Growing Manufacturing 
self-generated and used on-site comprised $63 \%$ of total electricity use in 1958. This fraction fell steadily to $38 \%$ by 1981 and, partly as a result of PURPA, climbed back in the 1980s to reach $44 \%$ in 1990 . The total electricity intensity and fossil fuel intensity are shown in Figure 3.5.

The fossil fuel intensity (Figure 3.5) should not be interpreted too closely because of the heavy use of wood by-product fuels and the major use of fuel for in-plant generation of electricity. Attempts to correct for these uses to obtain a better fuel series are not promising, since there have been substantial changes in the use of by-product fuels, and are beyond the scope of this report. (In terms of Btu values, biomass constituted $42 \%$ of the fuel input in 1972 and $60 \%$ in 1985.$)$

\subsubsection{Industrial Inorganic Chemicals}

The energy-intensity pattern for the industrial inorganic chemicals sector is not studied in this report.

\subsubsection{Industrial Organic Chemicals}

The energy-intensity pattern for the industrial organic chemicals sector is not studied in this report.

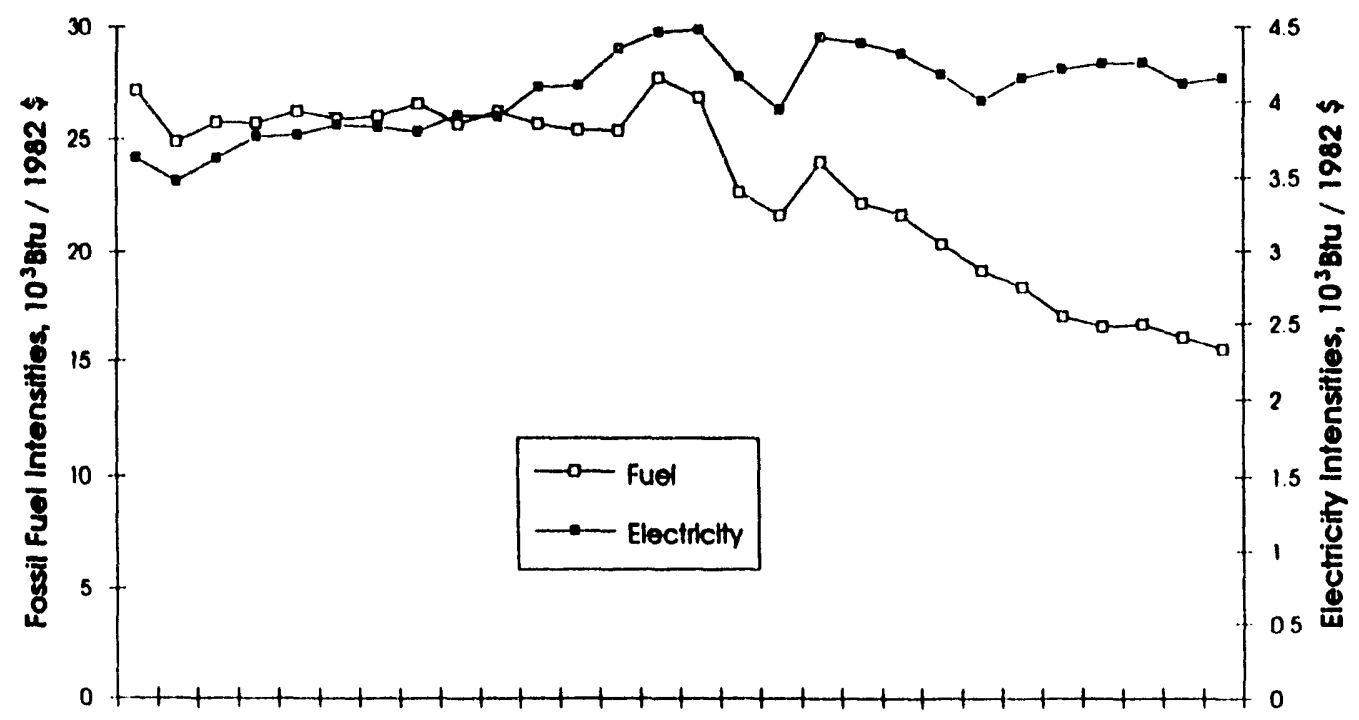

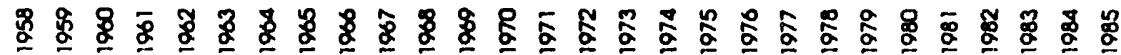

Year

FIGURE 3.5 Energy Intensities: Pulp and Paper Mills 


\subsubsection{Petroleum Refining}

The electricity and fuel intensities in the petroleum refining sector correspond roughly to the typical patterns, but careful examination leads to important discrepancies. The electricity intensity reaches a plateau or drops in the late 1970s and then rises rapidly in the early 1980s. The fuel intensity falls steadily throughout the period, showing little response to the price shocks. There are a number of explanations for this situation - an attractive one being the increased energy intensities (relative to what they would have been) in the 1980s associated with conversion of much more of the barrel into gasoline and distillate, with a reduction in the fraction of crude going into resid. We tried to partially represent this shift in refinery effort by using barrels of gasoline produced as the output measure, rather than deflated gross output or barrels of input to crude distillation (which we also tried). Intensities calculated in this way (Figure 3.6) have the problems just discussed, but they are less marked.

\subsubsection{Glass}

The electricity and fuel intensities of glassmaking based on gross output (Figure 3.7) do not show the shift toward less growth, or negative growth, starting in the early 1970s. This pattern might be explained by the tonnage of glass production not rising as fast as the BLS deflated value of gross output.

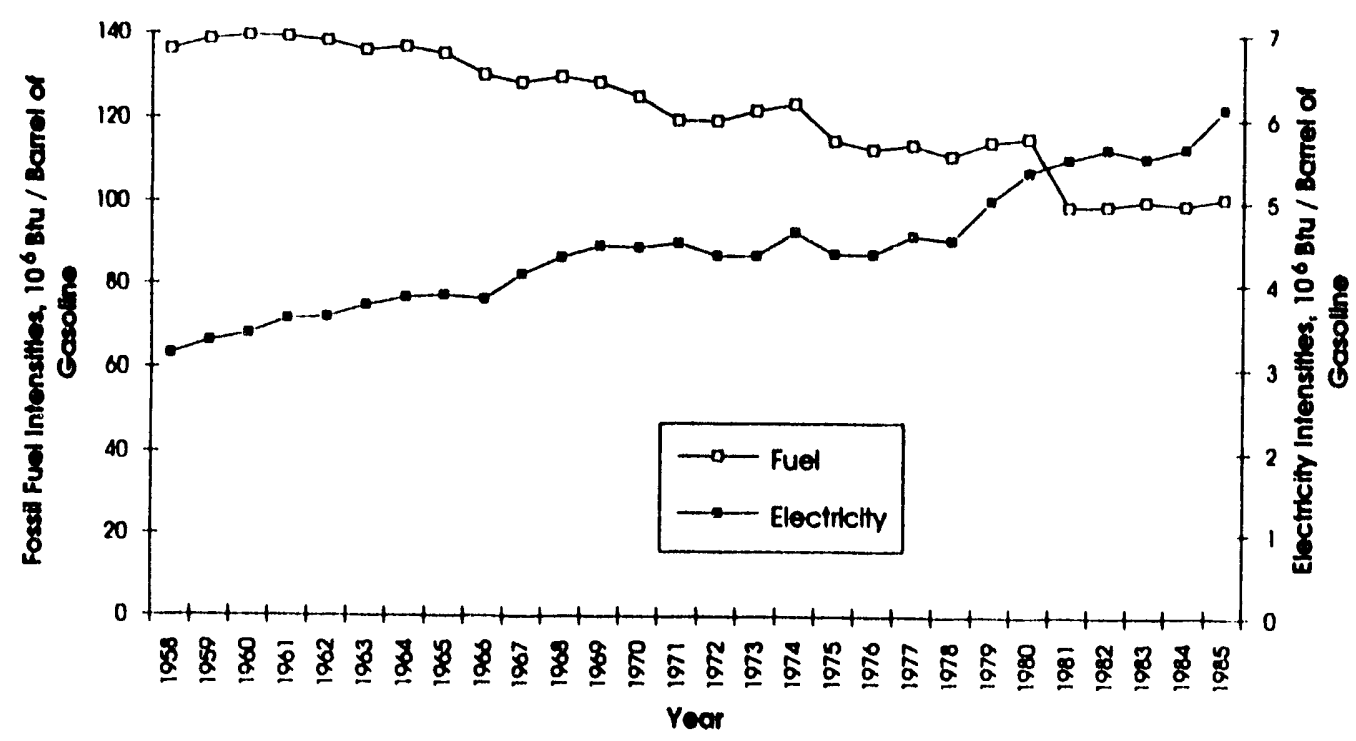

FIGURE 3.6 Energy Intensities: Petroleum Refining 


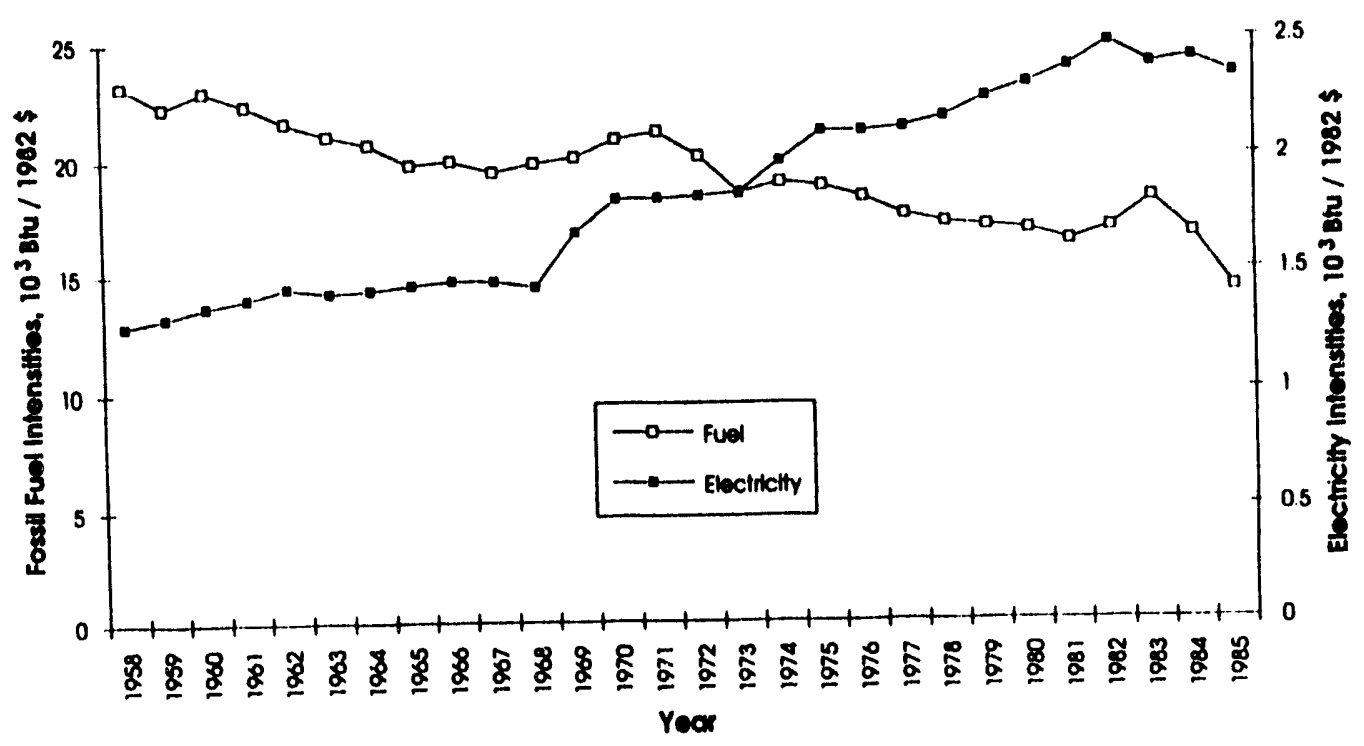

FIGURE 3.7 Energy Intensities: Glass

\subsubsection{Cement}

The energy intensities for cement (Figure 3.8) show the typical behavior, although the fossil intensity is rising slightly in the early 1960s. In this case, a good physical measure - barrels of Portland cement - is available from the Survey of Current Business (SCB 1991). Figure 3.9 shows that the deflated shipments trends (BLS) differ somewhat from the physical series (SCB). We believe that such differences are common for all products because the price deflators used by BLS to create the deflated value-of-shipments series are not necessarily accurate in detail, since they are obtained from limited surveys that primarily involve spot prices.

\subsubsection{Stone and Clay Products}

Although data problems clearly exist, as with electricity consumption in 1966 and 1985 (Figure 3.10), the stone and clay products sector (similar to sectors 1 and 2) represents a rather diverse group of industries where results for the general patterns of electricity and fuel intensity trends show the typical behaviors.

\subsubsection{Iron and Steel}

The electricity intensity shows continued increase in the post-price-shock period associated with the growth of scrap-based steel production using electric arc furnaces. In Figure 3.11, a physical series (rolled) steel mill product is the measure of output. 


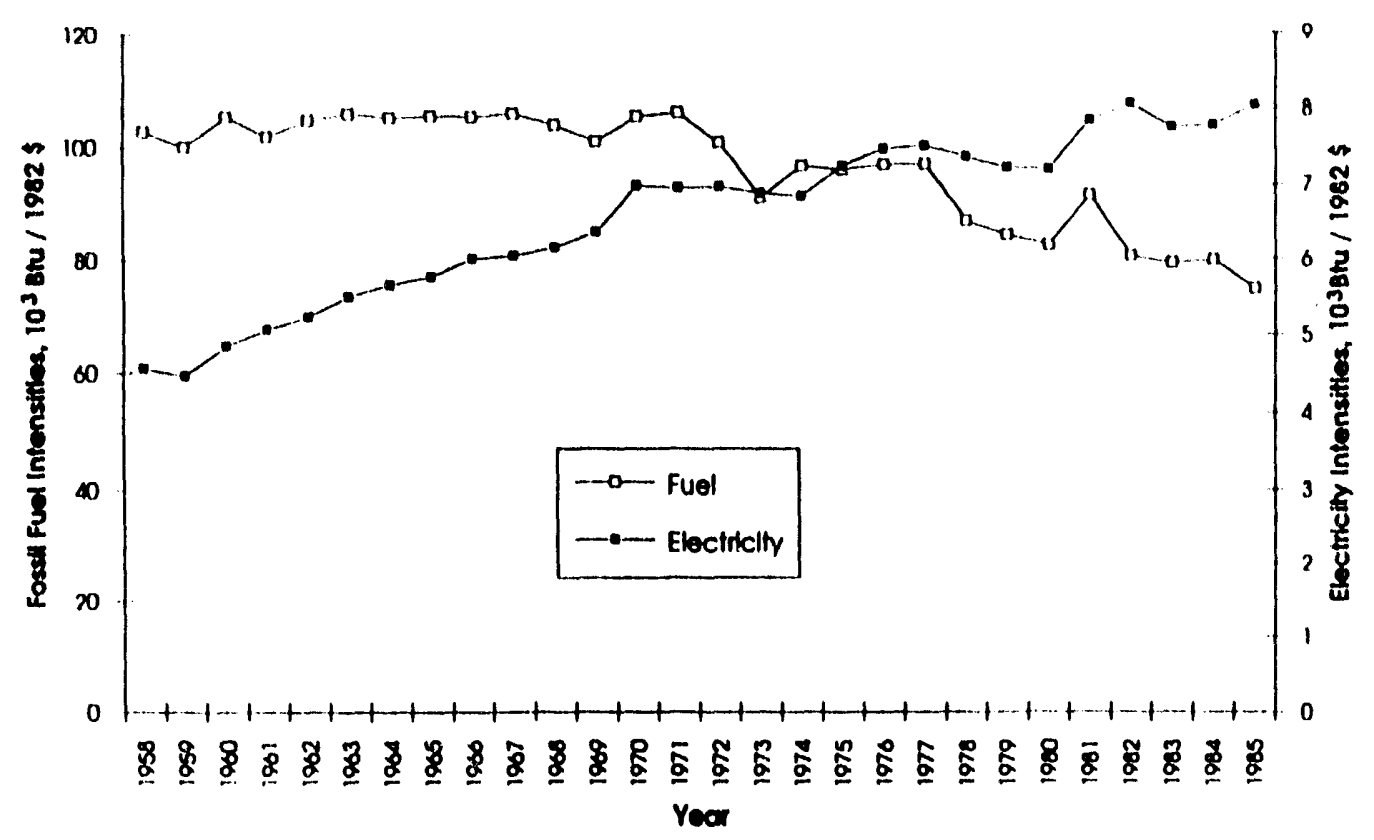

FIGURE 3.8 Energy Intensities: Cement

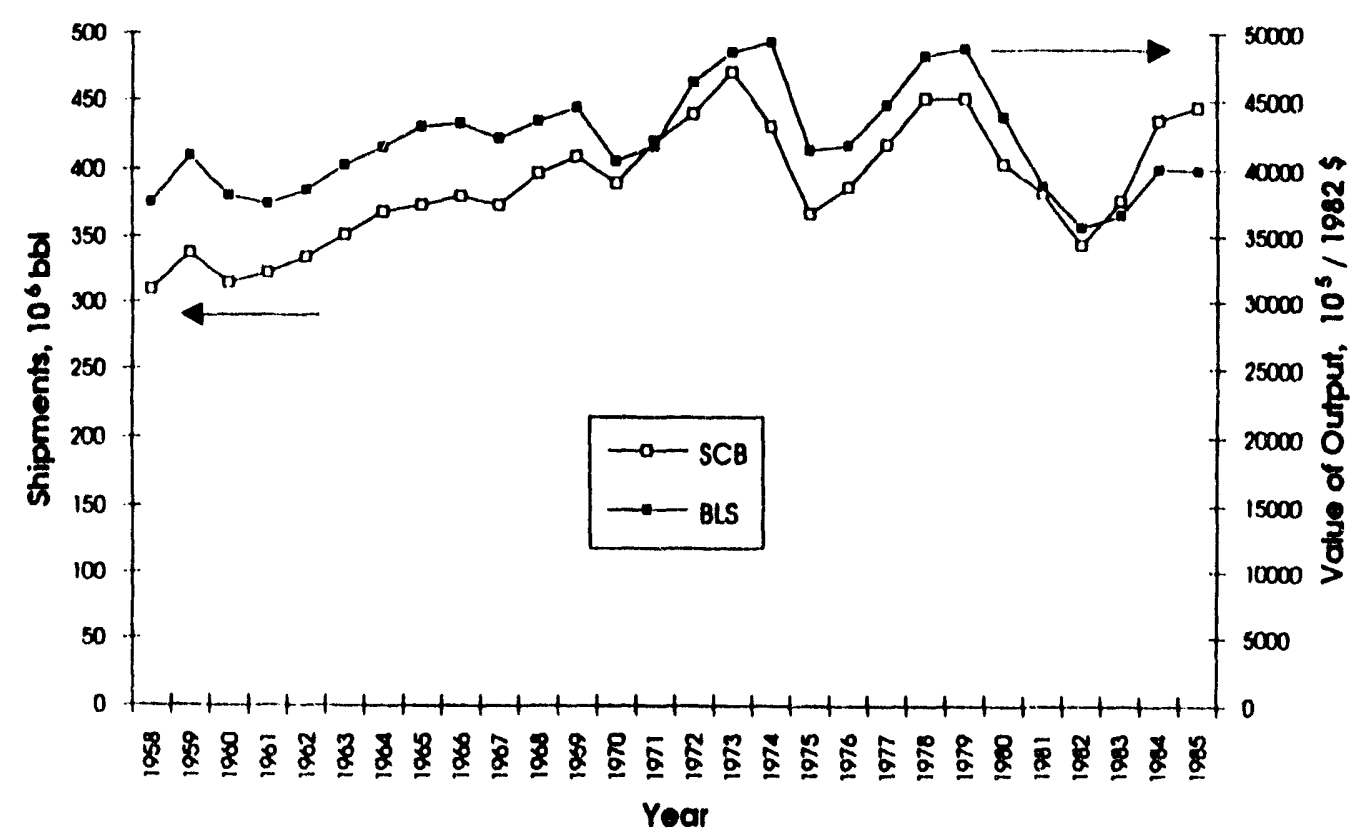

FIGURE 3.9 Comparison of BLS and SCB for Cement, Sector 8 


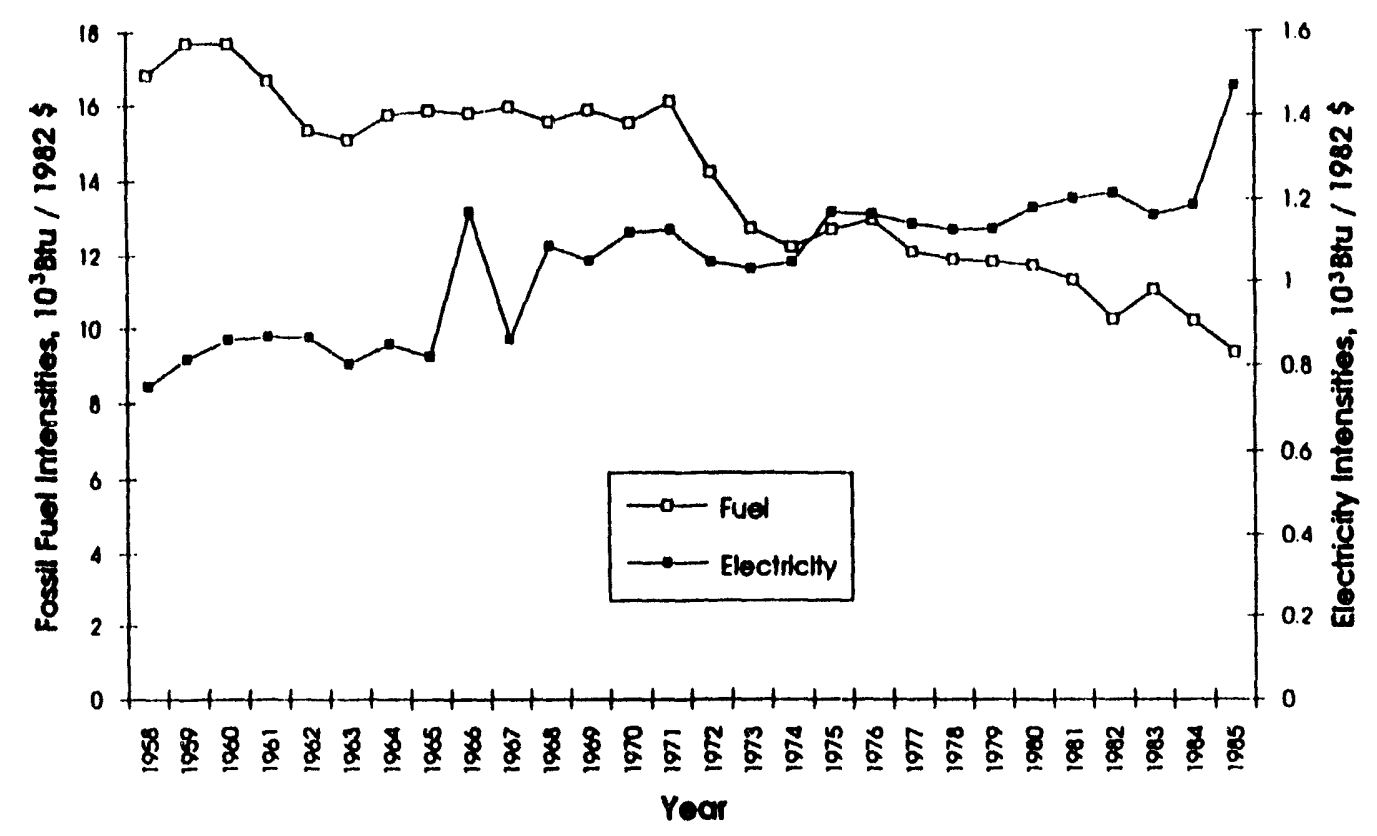

FIGURE 3.10 Energy Intensities: Stone and Clay Products

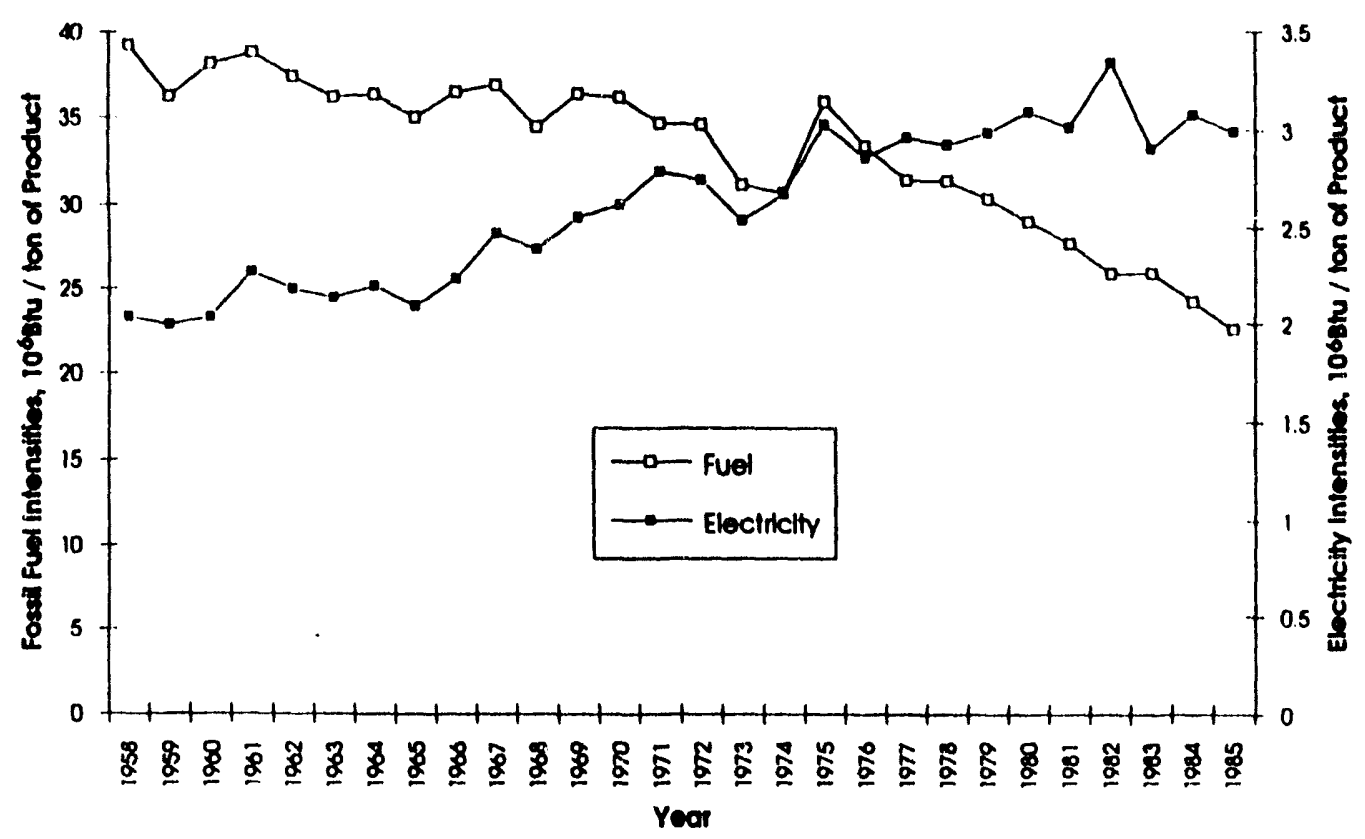

FIGURE 3.11 Energy Intensities: Iron and Steel Actual (with recycling) 
In Figure 3.12, the intensities are shown corrected approximately for the effect of scrap usage. That is, these would be the intensities assuming the entire industry were based on ore and internal scrap, with relative energy intensities obtained from a comparison of integrated and scrap-based mills. In this hypothetical regime, the electricity intensity peaks in the mid-1970s, and the fuel-intensity decline is only slightly faster after the price shock than before. (The energy intensities without recycling are modeled in LIEF, and the observed recycling rates are imposed with the corresponding energy-intensity changes.)

The reason we choose the physical series for output is that the BLS deflated gross output declines more rapidly in recent years than tonnage (thus suggesting that real value per ton is declining), incorrectly implying that fuel intensities have not declined rapidly in spite of a major increase in recycling, as well as major continuing efforts to improve fuel efficiency.

\subsubsection{Primary Aluminum}

Considerable data problems affect both the electricity and deflated shipments series for primary aluminum (Figure 3.13). The high level of noise in the energy intensity, calculated from NEA for energy and from BLS for output, is deeply disturbing because primary aluminum is, in some ways, the simplest sector in all industry. Do other data series

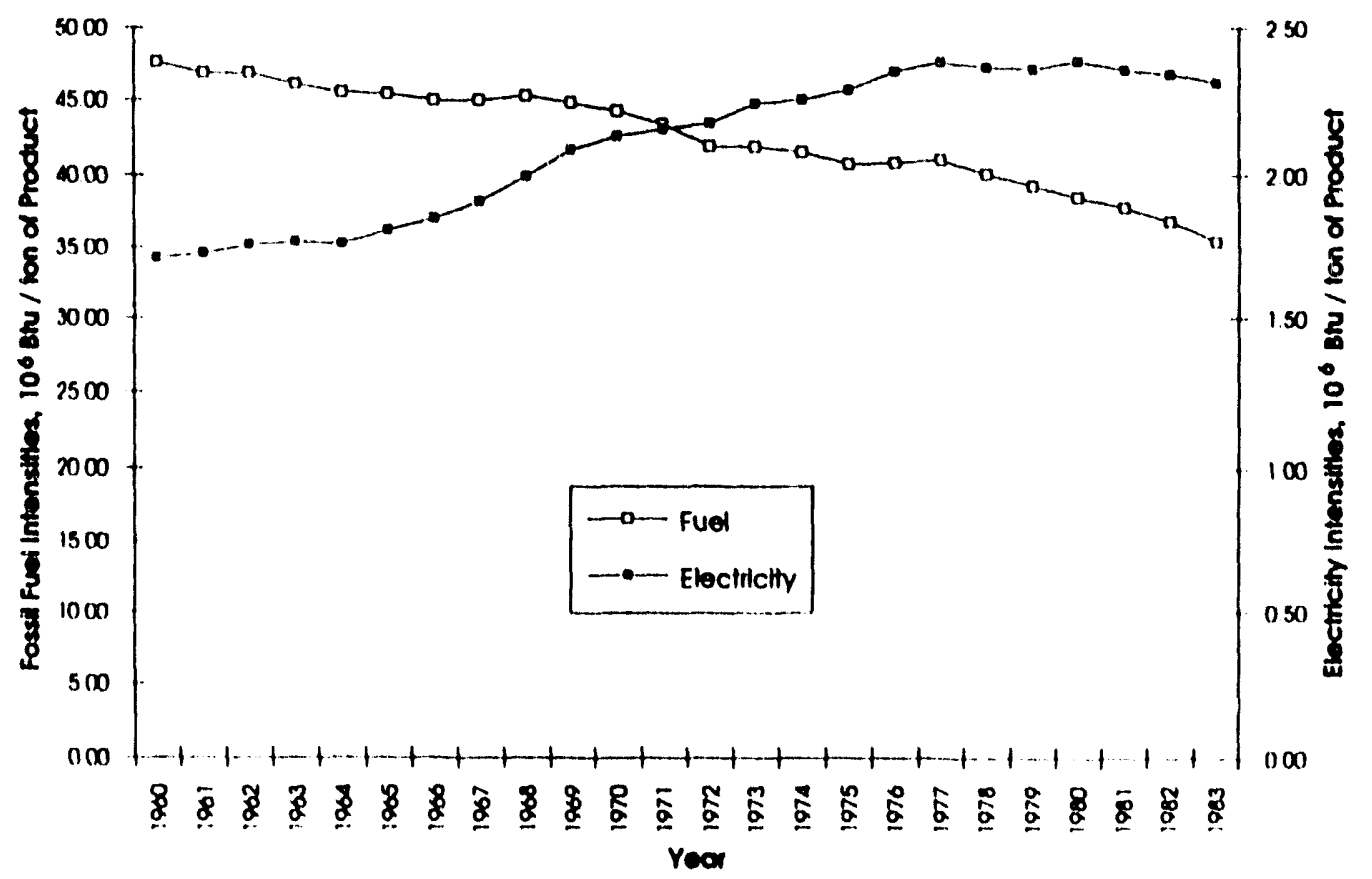

FIGURE 3.12 Energy Intensities: Iron and Steel Hypothetical (without recycling) 


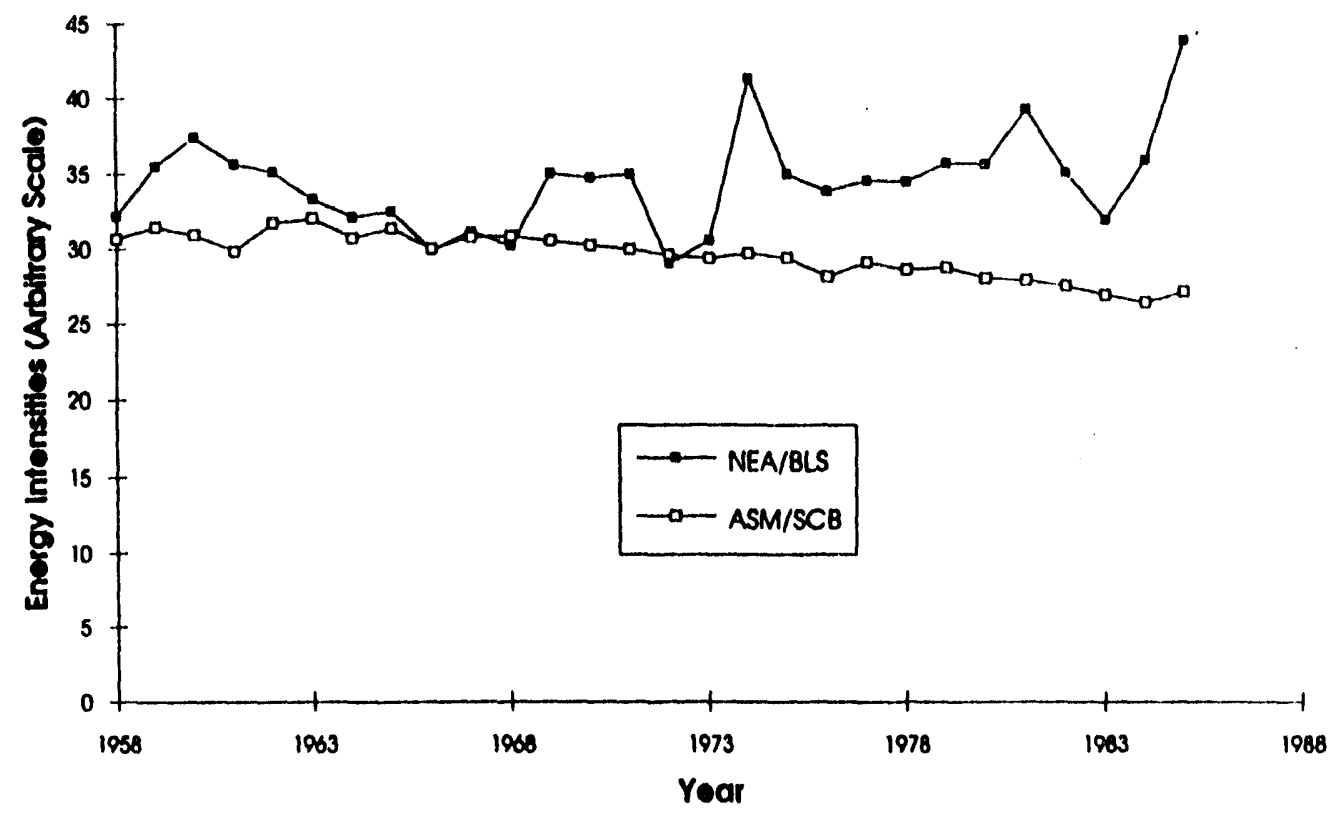

FIGURE 3.13 Comparison of Electricity Intensities in the Primary Aluminum Industry as Found in Two Data Sets

look better because most of them combine a variety of subindustries and the noise is relatively less in the sum? We went back to the original ASM data for total electricity (including that from on-site) and to SCB for production of primary aluminum in tons. One point in the electricity series (1972) is known at the Census to be low, and we adjusted it to fit smoothly with its neighbors. (Note that for many of the other years, energy usage in NEA, as well as here, is found by interpolation or is estimated by disaggregating the energy reported for the SIC 333 sector.) The adjusted intensity series is shown in Figure 3.14.

\subsubsection{Nonferrous Metals (except primary aluminum)}

The energy-intensity pattern for the nonferrous metals (except primary aluminum) sector is not studied in this report.

\subsection{SECTORAL ENERGY PRICES}

A typical pattern of price change occurred during the 1958-1985 period. Fossil fuel prices were stable in the period to 1969 or 1970; they then rose, with a major step being the first price shock in 1973-1974. At that point, prices hesitated, then rose sharply again in 1978-1980 during the second price shock. In the 1983-1985 period, fuel prices tended to decline. The price rise from the late 1960 s to the peak around 1980 varied considerably with industry sector. (This trend suggests that sectoral dependence of prices should be considered in future forecasting.) This sectoral dependence involved factors such as the ability of an industry to switch fuels and the existence of specially arranged low prices (in the period 


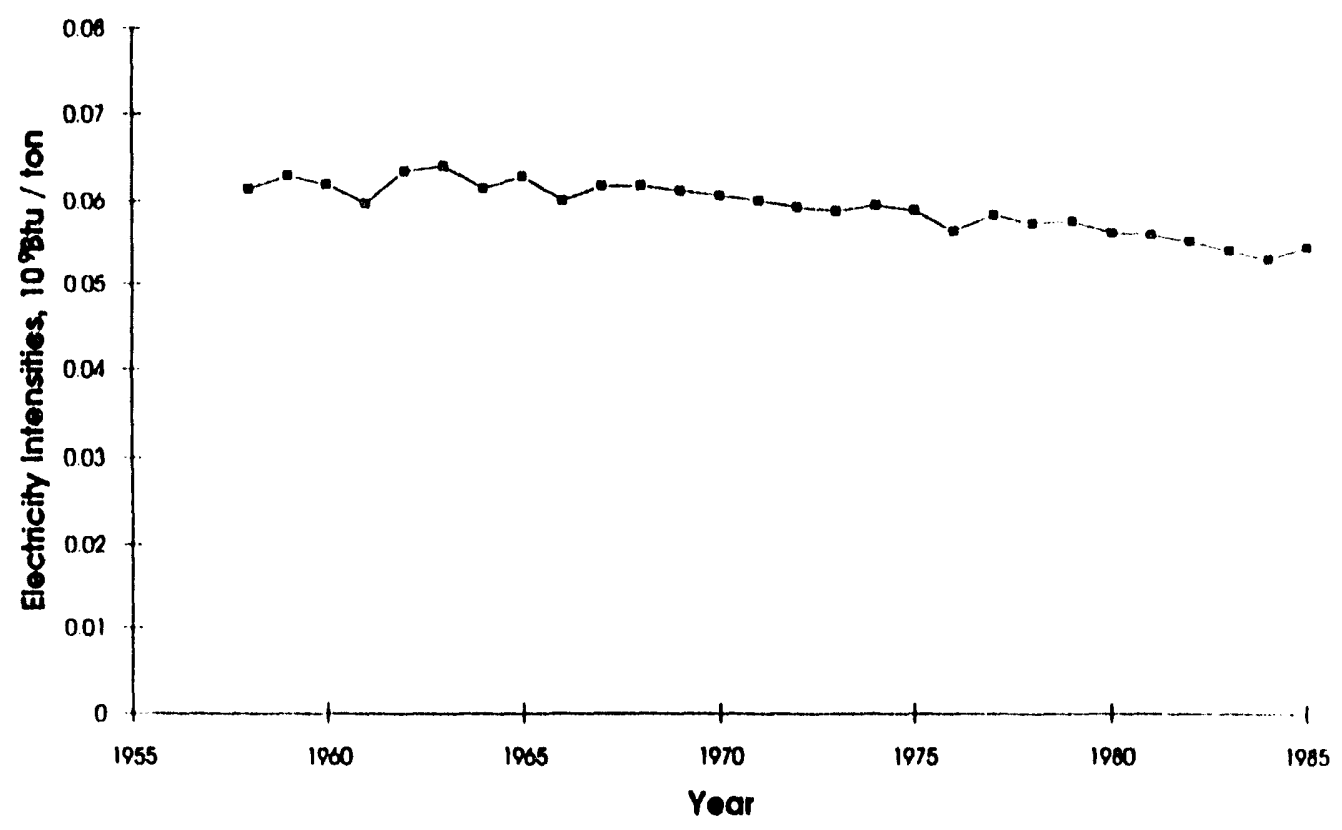

FIGURE 3.14 Energy Intensities: Primary Aluminum

before the price shocks) for some large energy-intensive industries like organic chemicals. Figure 3.15 shows a sample price pattern for cement, which achieved a relatively small price increase.

Electricity prices were still undergoing their historic decline at the beginning of the period under study. The prices bottomed out around 1969-1970 and began to rise slowly and then more rapidly through the early $1980 \mathrm{~s}$, followed by a slight decline in some sectors. Thus, the electricity price rise continued longer into the 1980s than that for fuel. The relative price increase from the trough of the late 1960 s to the early 1980 s was smaller than the price increase for fuels but was still substantial, especially for some electricity-intensive industries. For both energy forms, the extreme pressure of the energy crisis appeared to force the energy industry to raise its prices more in percentage terms to energy-intensive customers than to typical customers.

\subsection{CONCLUSIONS}

Historical time series on electricity and fuel intensities by industrial sector behave in a relatively simple and consistent manner for the most part: the fossil fuel intensity declines gradually until the early 1970 s and then declines rapidly. The electricity intensity rises rapidly until the early 1970 s and then is relatively steady. There are, however, important complications: the data series that might initally be selected may need modifications or require substitutions. Capacity utilization effects (e.g., in 1975 and 1980-83) may be large. In a few cases, major changes in the industry have changed the pattern of energy intensity so that a simple picture could be misleading. (See, especially, comments for LIEF sector 2, fast-growing manufacturing; sector 3, pulp and paper mills; and sector 6, petroleum refining.) 


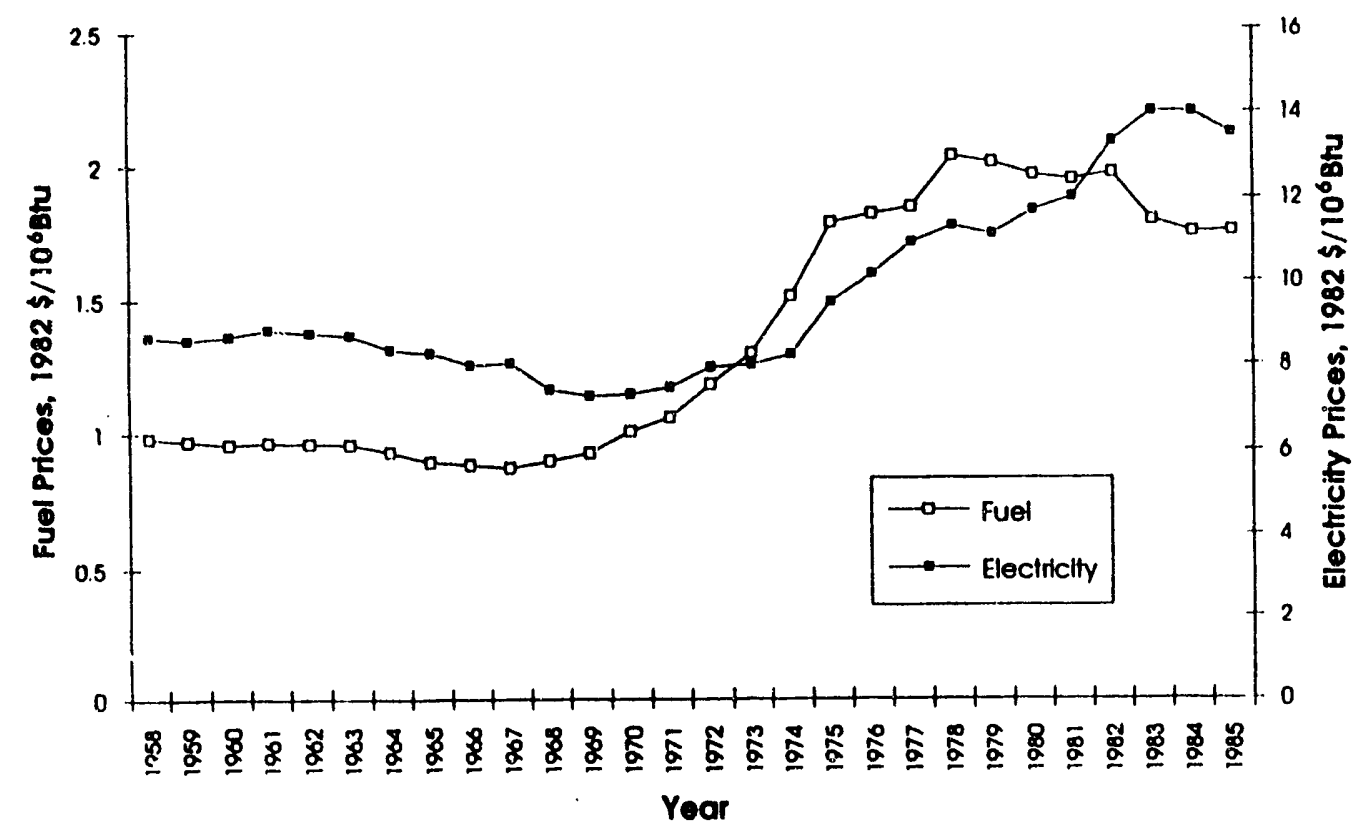

FIGURE 3.15 Prices of Fossil Fuel and Electricity: Cement Example

During periods of energy price volatility, price changes were substantially different in different sectors even if qualitative changes were uniform across sectors. These differences strongly suggest that, in the future, forecasting models should account for likely sectoral dependence of prices. (Industrywide prices are used in the present version of LIEF.) 


\section{HISTORICAL PARAMETERS: CONSERVATION SUPPLY CURVES AND PENETRATION RATES}

\subsection{GENERAL COMMENTS}

In this section, parameters in LIEF, which describe autonomous technical change, CSCs, and market penetration rates, are determined from historical analysis of the sectoral energy intensities. In a previous analysis of this kind with the four-sector model, parameter ranges were determined because the aggregate historical series do not allow for narrowly defined, or point, estimates (Ross and Hwang 1992, Table 5.5). Howeve1, relationships among the parameters are lost when ranges for each are presented separately. In this section, point estimates are presented that preserve those relationships, and parameter ranges are briefly discussed.

As shown in Section 3, disaggregation of the energy-intensive industries involves data with many problems - problems that are hidden when the sectors are aggregated. Therefore, we have selected data series that differ from the standard energy (NEA) and output (BLS) series in several cases where improved agreement could be obtained, as indicated in Section 3.2.

The parameters to be determined for each sector are CSC parameters, $G a p 0_{i}$ and $A_{i}$; autonomous trends, $B_{i}$; and penetration rates, pen $(t)$. The penetration is a function of period but not energy form, while the others depend on energy form, but not period. The exact roles of these parameters are defined in the documentation in Appendix B.

\subsection{THE CONSERVATION SUPPLY CURVE - GENERAL PROPERTIES}

The CSC parameterization merits more exposition. The unit capital cost of a conservation project, $k$, is $K_{k} / S_{k}$, and

$$
K_{k} / S_{k}=p_{k} / C R F \text {, }
$$

where $p_{k}$ is the price of energy at which project $k$ may be marginally undertaken, CRF is the implicit capital recovery factor, $S_{k}$ is the annual energy savings rate associated with the project, and $K_{k}$ is its capital cost. (If there are multiple benefits, $K_{k}$ is the energy-related part of the capital cost, as determined, for example, from the present values of the energy and nonenergy benefits.) The $y$-axis of the CSC is unit capital cost or $p / C R F$. The $x$-axis is the cumulative energy savings of projects put in order of economic attractiveness, $p_{k}$. Thus, $\mathrm{S}=\Sigma \mathrm{S}_{\mathrm{k}}$. Typically, one plots $\mathrm{x}=\mathrm{S} / \mathrm{E}_{\mathbf{0}}$. From the LIEF relationships we have:

$$
p / C R F=\left\{(1-G a p 0)^{1 / A} /\left[1-\left(S / E_{\alpha}\right)\right]^{1 / A} /\left(p o / C R F_{\sigma}\right) .\right.
$$

(See Hwang and Ross 1992, Eq. A.7.) The intercept depends sensitively on the base-year parameter, Gap0, and the slope depends on A. Some CSCs are shown for typical parameter values in Figure 4.1 . 


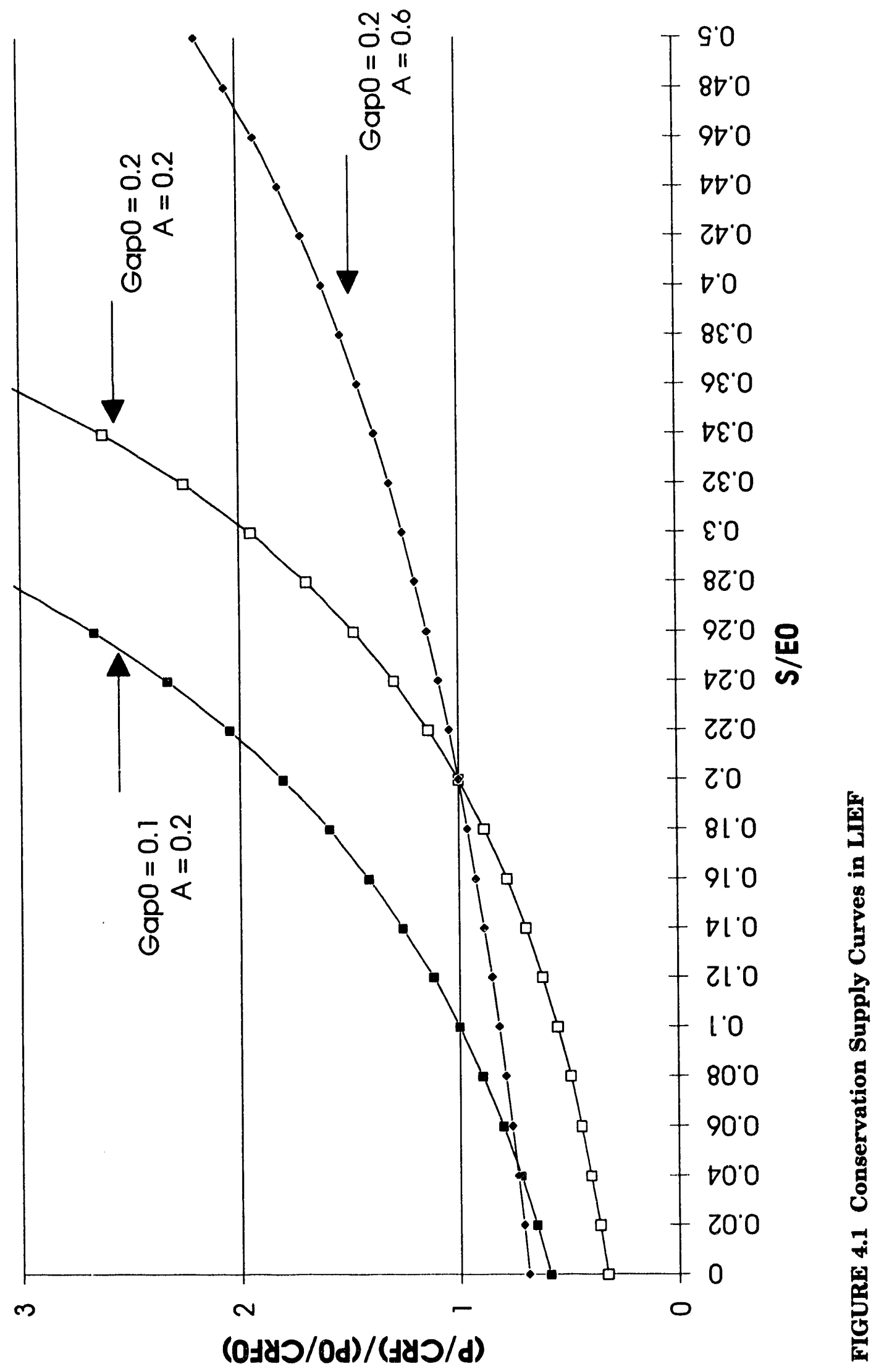


The extent of savings opportunity available with a doubling of $\mathrm{p} / \mathrm{CRF}$ depends on Gap0 and $\mathrm{A}$ - parameters that are seen to work together (Figure 4.1). In the statistical analysis, one combination of the parameters is well identified, or determined, as roughly $0.5 \mathrm{~A}+\mathrm{Gap0}$, and the orthogonal combination is poorly identified. In order to cope with this difficulty, we adopt engineering and theoretical insights, putting floors and ceilings on $\mathrm{A}$ and Gap0. Upper bounds of Gap0 $=0.5$ and $A=1.0$ are imposed, with lower bounds for Gap0 and A of 0.30-0.05, depending on the energy intensity of the sector (with smaller lower bounds for the most intensive sectors, such as electricity in primary aluminum). As will be seen in Section 4.3, these bounds are often not needed; they do not come into play.

For highly energy-intensive processes, , uch as reduction of metal ores or glassmaking and cement making, the opportunity for energy savings is small. We expect and the historical analysis shows that both Gap0 and A are small, especially for the most intensive energy forms like electricity in aluminum and fuel in cement. Meanwhile, for general manufacturing (sector 1), we expect and find large Gap0 and A values; for fast-growth manufacturing, which is lighter and less mature, we expect and find even larger Gap 0 and A values. For general manufacturing industries, doubling $\mathrm{p} / \mathrm{CRF}$ is expected on engineering grounds to provide an opportunity to roughly halve the energy intensity $\left(\mathrm{S} / \mathrm{E}_{\mathrm{o}}=0.5\right)$.

Another feature of the CSC occurs when $\mathrm{S}=0,(\mathrm{p} / \mathrm{CRF})<(\mathrm{p} / \mathrm{CRF})_{0}$, which results in the controversial negative cost phenomenon associated with conservation. That is, the cost of some conservation investments per unit of saved energy, $\mathrm{K}_{k} / \mathrm{S}_{k}$, is less than the cost of energy supply. These low-cost opportunities are present in LIEF. They will not be realized in a net sense, however, unless penetration occurs; and the penetration is zero in the status quo (i.e., without rising prices or adoption of policies to induce investment). The motivation to realize these low-cost opportunities can also be increased if policies are introduced (or changes in financial markets occur) that reduce the implicit CRF. However, these kinds of policies may have substantial administrative costs.

\subsection{SECTORAL RESULTS}

Only the 12 manufacturing sectors (sectors 1-12) with energy used for heat and power (i.e., excluding nonmanufacturing, feedstocks, and uranium enrichment) have historical data series suited for modeling. Nine of these sectors have been analyzed for this report (Table 4.1). In most cases, the analysis includes examining alternate time series for energy or output.

\subsubsection{Sector 1: General Manufacturing}

In this section, general concepts of interest for all sectors will be developed in terms of the general manufact,uring sector. The fit to general manufacturing (minimizing $\mathrm{R}^{2}$ ) shows substantial electricity and fuel elasticities (i.e., relatively large Gap0 and A values) (Table 4.2). 
TABLE 4.1 Data Series Analyzed

\begin{tabular}{llcc}
\hline & & \multicolumn{2}{c}{ Data Series Analyzed } \\
\cline { 3 - 4 } & \multicolumn{1}{c}{ Sector } & Energy & Output \\
\hline 1 & General manufacturing & NEA & BLS \\
2 & Fast-growing manufacturing & NEA & BLS \\
3 & Pulp and paper & NEAASM $^{\mathrm{a}}$ & BLS \\
6 & Petroleum refining & NEAASM & Physical $^{\mathrm{b}}$ \\
7 & Glass & NEA & Physical $^{\mathrm{c}}$ \\
8 & Cement & NEA & Physical $^{\mathrm{d}}$ \\
9 & Stone and clay & NEA & BLS $^{2}$ \\
10 & Iron and steel & ASM $^{\mathrm{a}}$ & Physical $^{\mathrm{e}}$ \\
11 & Primary aluminum & ASM $^{\mathrm{a}}$ & Physical $^{\mathrm{f}}$ \\
\hline
\end{tabular}

a For electricity, purchased and generated on-site less sold are combined.

b Production of gasoline.

c Preliminary index based on bottle production.

d Barrels of portland cement, SCG.

e Tons of steel mill products.

f Tons of primary aluminum, SCG.

The potential for satisfactorily fitting the available 1958-1985 historical data depends on the regularity of the data. That is, LIEF contains smooth relationships such that only the price rises starting in the early 1970 s can alter the time dependence of the energy intensities. Moreover, the price rise must cause the time dependence of the intensities to be more negative (e.g., to rise less rapidly) after the early 1970s than before. In addition, the philosophy adopted is not wholly that of statistical analysis of historical data. We adopt engineering and theoretical insights where available in order to limit the parameter ranges allowed by fits to the historical data series. (See notes to Table 4.2.)

The historical forecast approach can be seen for electricity intensity in Figure 4.2. There are, in fact, five forecasts with base years 1960-1964. The actual energy-intensity series attempted to be fit (open squares) consists of a five-year running average, in order to smooth the effects of recessions. (The model typically forecasts in five-year periods and does 
TABLE 4.2 Parameters from Historical Analysis

\begin{tabular}{lcccccccc}
\hline \multicolumn{1}{c}{ Sector } & $\mathrm{Gap0}_{\mathrm{e}}$ & $\mathrm{A}_{\mathrm{e}}$ & $\mathrm{B}_{\mathrm{e}}$ & $\mathrm{R}_{\mathrm{e}}^{2}$ & $\mathrm{Gap0}_{\mathrm{f}}$ & $\mathrm{A}_{\mathrm{f}}$ & $\mathrm{B}_{\mathrm{f}}$ & $\mathrm{R}_{\mathrm{f}}^{2}$ \\
\hline General & 0.40 & 0.55 & -3.5 & 0.87 & 0.30 & 0.19 & 0.4 & 0.94 \\
Fast growing & 0.57 & $1.0^{\mathrm{a}}$ & -4.5 & 0.87 & 0.16 & 0.8 & 0.7 & 0.93 \\
Pulp and paper & 0.26 & 0.24 & -1.9 & 0.90 & $0.20^{\mathrm{b}}$ & $0.36^{\mathrm{b}}$ & $0.0^{\mathrm{b}}$ & $0.96^{\mathrm{b}}$ \\
Petroleum refining & 0.23 & $0.2^{\mathrm{c}}$ & -2.4 & 0.81 & $0.10^{\mathrm{c}}$ & $0.10^{\mathrm{c}}$ & 0.6 & 0.89 \\
Glass & & & & & & & & \\
d & $0.10^{\mathrm{c}}$ & 0.26 & -2.5 & 0.95 & $0.10^{\mathrm{c}}$ & 0.25 & 1.2 & 0.98 \\
Cement & 0.32 & $0.20^{\mathrm{c}}$ & -3.2 & 0.94 & $0.10^{\mathrm{c}}$ & 0.19 & $0.3^{\mathrm{c}}$ & 0.93 \\
Stone and clay & $0.30^{\mathrm{c}}$ & $0.20^{\mathrm{c}}$ & -2.6 & 0.87 & $0.30^{\mathrm{c}}$ & $0.20^{\mathrm{c}}$ & 0.7 & 0.94 \\
Iron and steel & 0.11 & 0.31 & -1.9 & 0.97 & $0.10^{\mathrm{c}}$ & $0.10^{\mathrm{c}}$ & 0.5 & 0.90 \\
Primary aluminum & 0.09 & 0.08 & 0.24 & 0.97 & & & & \\
\hline
\end{tabular}

a Upper bound imposed.

b The fuel analysis for the paper sector is suspect, as discussed in Section 3.

c Lower bound imposed.

d Based on preliminary output series.

not account for short-run changes in capacity utilization.) The series of diamonds are the ideal electricity intensities, or the long-run intensity that is economic at the manufacturers' implicit discount rate. In the particular mode of fitting, the model exactly reproduces the base-year intensities. The model forecasts smooth energy-intensity trends, unless there are price or other changes, and therefore cannot fit the curvature seen here between the early and late 1960s, as shown by the positions of the forecast intensities (black squares) in the mid and late 1960s. (This curvature may be associated with the boom in electricity consumption in the late 1960s.)

The fuel intensity is less elastic than the electricity intensity. This distinction is typical for all sectors, except for those where electricity use is very intensive. The engineering explanation for this condition is that fuel use is more mature than electricity use. The economic explanation is associated, in part, with the fact that the CSC in LIEF is longrun. (Short-run effects are associated with penetration and the gap.) The large long-run opportunities for more efficient use of electricity in response to price increases have been somewhat obscured by the autonomous trend toward new appplications of electricity. 


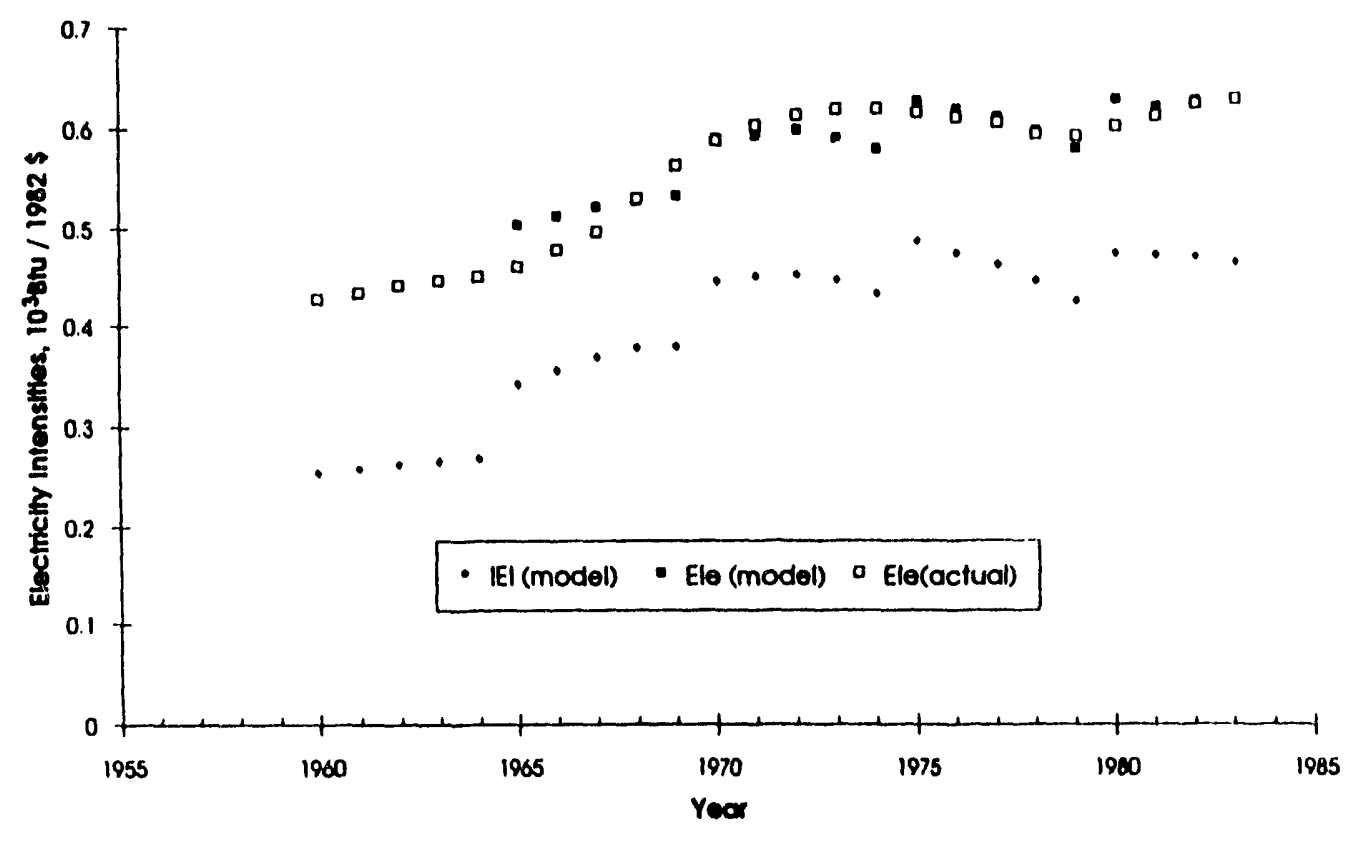

FIGURE 4.2 Historical Forecast of Electricity Intensity, General Manufacturing, Sector 1

The penetration rate, pen(t), used for this sector is shown in Table 4.3. Typical shapes for pen $(t)$ are shown in Figure 4.3. The penetration rate is zero when prices are steady or falling and is positive if prices rise, with a maximum penetration rate of roughly $15 \%$ per year. The penetration rate series used is shown in Figure 4.4, along with the price change over each past-five-year period, normalized to the pre-price-shock level: $[p(t)-p(t-5)] / p_{0}$. (The relationship between the right- and left-hand scales has been adjusted for purposes of presentation.) Slightly different penetration sets could have been selected without violating the general concept represented by pen $(t)$. This particular penetration set provides a good fit, but use of a similar set, such as another of those shown in Table 4.3, does not much affect the values of the other parameters. Because of the structure of decision making in firms, the same set of penetration rates is used for fuel and electricity.

\subsubsection{Sector 2: Fast-Growing Manufacturing}

The energy intensities in this sector are more elastic than those for sector 1 , as would be expected (Table 4.2). However, since the character of the sector was established only around 1970, the values of $B$ have little or no meaning, and the other parameters may be suspect. For forecasts, we suggest not using $B_{e}$ from the historical analysis here. (See Section 5.1 and Ross and Fisher [1991] for another approach.) 
TABLE 4.3 Penetration Rates (\% per year) Used in Historical Forecasts

\begin{tabular}{ccccccccc}
\hline Year & Sector 1 & Sector 2 & Sector 3 & Sector 6 & Sector 8 & Sector 9 & Sector 10 & Sector 11 \\
\hline 1969 & 0 & 0 & 0 & 0 & 0 & 0 & 0 & 5 \\
1970 & 0 & 0 & 0 & 0 & 0 & 0 & 0 & 5 \\
1971 & 0 & 5 & 5 & 5 & 0 & 0 & 5 & 5 \\
1972 & 0 & 5 & 5 & 10 & 0 & 0 & 5 & 5 \\
1973 & 5 & 5 & 5 & 10 & 5 & 5 & 5 & 5 \\
1974 & 5 & 10 & 10 & 15 & 5 & 5 & 10 & 5 \\
1975 & 10 & 10 & 10 & 15 & 10 & 10 & 10 & 5 \\
1976 & 10 & 10 & 10 & 15 & 10 & 10 & 10 & 5 \\
1977 & 10 & 10 & 10 & 15 & 10 & 10 & 10 & 5 \\
1978 & 10 & 10 & 10 & 15 & 10 & 10 & 10 & 5 \\
1979 & 10 & 15 & 10 & 15 & 10 & 10 & 10 & 10 \\
1980 & 10 & 15 & 10 & 10 & 10 & 10 & 10 & 10 \\
1981 & 10 & 15 & 10 & 10 & 10 & 10 & 10 & 10 \\
1982 & 10 & 15 & 10 & 5 & 10 & 10 & 10 & 10 \\
1983 & 10 & 10 & 10 & 0 & 10 & 10 & 10 & 10 \\
1984 & 0 & 5 & 10 & 0 & 0 & 0 & 10 & 10 \\
1985 & 0 & 5 & 5 & 0 & 0 & 0 & 5 & 0 \\
\hline
\end{tabular}

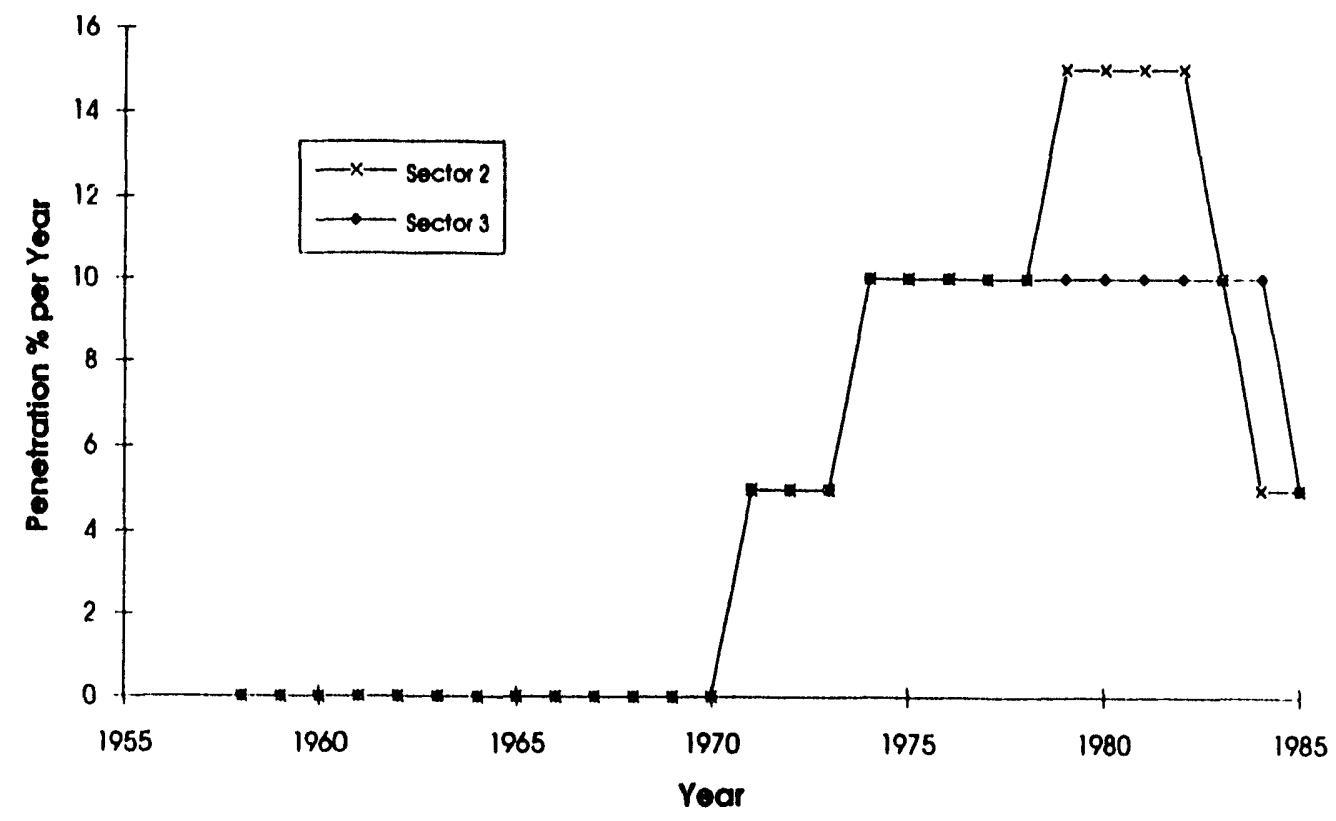

FIGURE 4.3 Sample Penetration Rates Used in Historical Fits 


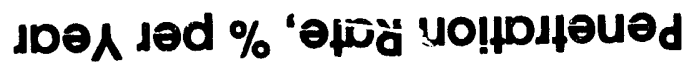

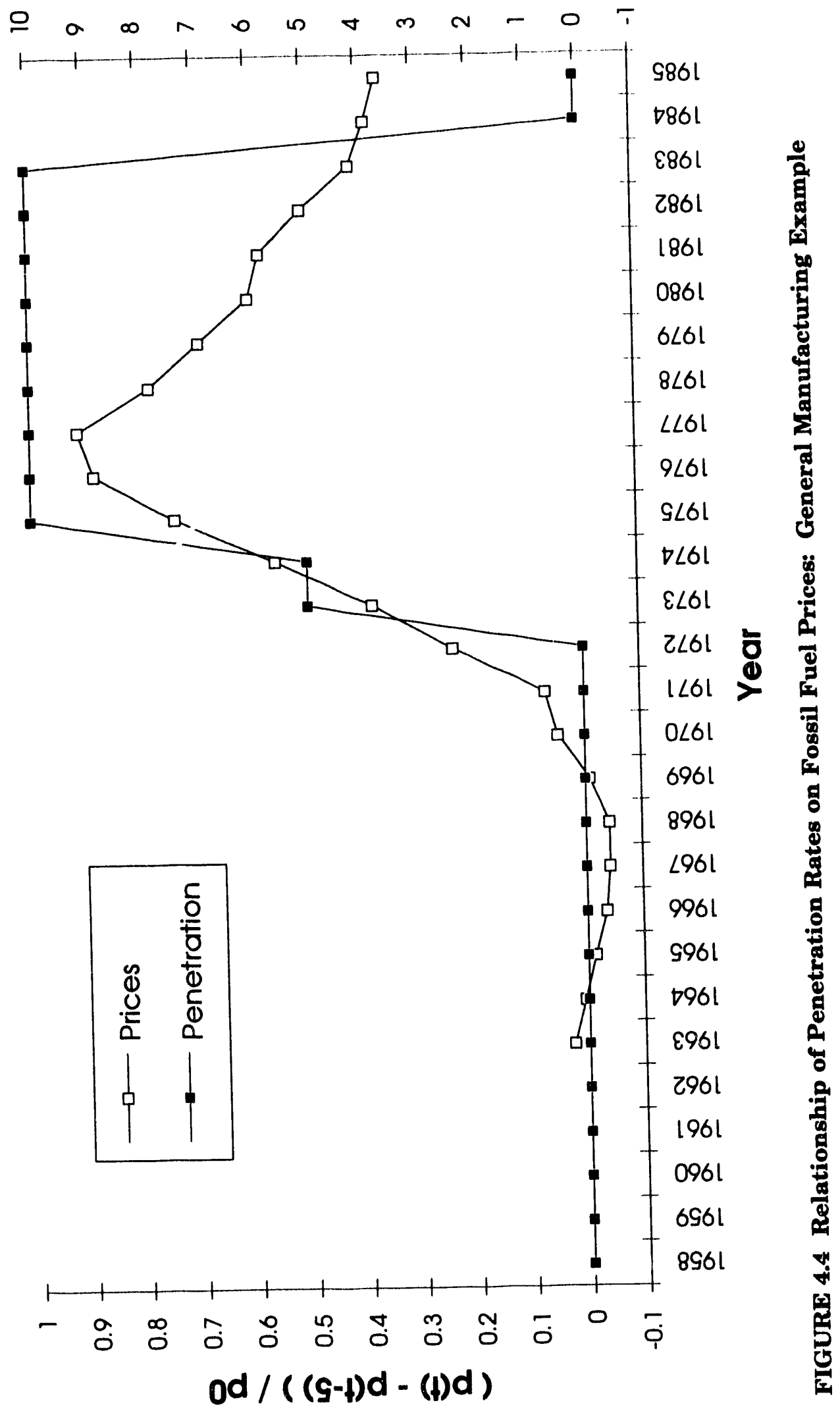




\subsubsection{Sector 3: Pulp and Paper}

As with other energy-intensive industries, the paper industry is much less elastic than sector 1, as would be expected (Table 4.2). The electrification trend is slower than for sector 1 because heavy use of electric motors already existed at the beginning of this period. Therefore, new uses, such as environmental controls and process controls, have had less of an impact.

\subsubsection{Sector 6: Petroleum Refining}

It is not possible to accurately fit the detailed structure of the electricity intensity from the mid-1970s on, as discussed in Section 3.2. (The electricity fit described in Table 4.2 involves considerable effort, relative to that for other sectors, at adjustment of minor parameters not shown, such as C.) The major parameters determined in the fits are nevertheless consistent with those for the other sectors. Petroleum refining is a high-energyintensity sector, so the $A$ and Gap0 parameters are relatively small for both fuel and electricity. Because the fuel intensity is much higher than that for electricity, it is gratifying that $A$ and Gap0 values for fuel are smaller. Much of the fuel use involves by-products of the process, especially petroleum coke and light ends. Thus, the average fuel price is not well defined, so the fuel parameter, $A_{f}$, is only roughly determined.

\subsubsection{Sectors 7-9: Stone, Clay, and Glass}

In these historical fits, low elasticities are expected and found with intensive process energy use, as with high-temperature furnaces. This fact is especially so for the highestintensity process of fuel use in the cement sector. As shown in Figure 4.1, with Gap0 $=0.1$ and $A=0.2$, and at present energy prices, the long-run energy intensity involves only about $10 \%$ savings compared with current average practice. At double present energy prices, longrun savings are $22 \%$ of current average practice. As indicated by the parameters in Table 4.2, the likely potential is less than this for fuel in the cement industry. (Some savings will, however, also come from long-term improvement in the technology that is autonomously adopted by the industry, as reflected by the $\mathrm{B}$ term.)

The parameters shown in Table 4.2 are for best fits to the data, except in the cases indicated, where lower bounds are imposed to keep parameters in ranges judged to be desirable. (The ranges permitted for the parameters were briefly discussed in Section 4.2.)

\subsubsection{Sector 10: Iron and Steel}

The fuel-intensity elasticity parameters for the steel industry are small in keeping with the industry's very high fuel intensity. The corresponding electricity parameters are not as small. In a study of electric arc furnace technology, it was found that, while adoption of the technology is not energy price dependent, furnace characteristics depend on price and there is a substantial range in electricity intensity (Karlson 1990). The analysis of this 
industry is sensitive to recycling because recycling rates are high and fuel and electricity use are sensitive to recycling - fuel use strongly decreases and electricity use strongly increases with increased recycling. A careful analysis of recycling in the context of LIEF remains to be carried out.

\subsubsection{Sector 11: Primary Aluminum}

The electricity-intensity elasticity parameters for primary aluminum are very low. How does this compare with what is known about best practice in the industry? Where the industry average (SIC 3334) is an intensity of about $7.0 \mathrm{kWh} / \mathrm{lb}$, the U.S. best practice is, perhaps, $10-12 \%$ lower. This opportunity is somewhat larger than that suggested for current prices by the CSC with the parameters shown in Table 4.2, especially after taking into account that the Gap has probably declined since 1960. It is likely that the long-term CSC, revealed in this way by historical behavior, is somewhat less elastic than actual best practice suggests. Since the model does not separately describe CSCs for existing and new facilities, it does not fully capture the opportunity for increased efficiency offered by new facilities. New facilities are unlikely to be built in the United States by the primary aluminum industry. The CSC from LIEF may more accurately indicate the potential for retrofit.

\subsection{CONCLUSIONS}

The general structure of parameters Gap0, A, and pen has been suggested by the above discussion. The CSC characteristic embodied in the parameters Gap0 and A agrees with the notion that long-term opportunities for savings are excellent in the nonintensive industries but are strongly limited, in a percentage sense, in the energy-intensive industries, especially for the most intensive processes. Figure 4.5 shows the two elasticity parameters for each energy form and sector versus the log of the corresponding energy intensity. (The $A$ and Gap0 values are given in Table 4.2. The intensities are for 1990 and are given in Section 5, Table 5.1. Sector numbers are shown on the plot for identification.) The decline with increasing intensity is clear, although some of the behavior is imposed by setting floors for the parameters, where the floors are chosen so they decline with increasing intensity. The tendency for the electricity parameters to be greater than the fuel parameters is also evident.

The autonomous trend parameters, $\mathrm{B}$, vary from industry to industry and are sensitive determinants of the model. Thus, it is indicated that forecasters should use the values of $B$ found by historical fitting - although it must be said that the determinations arise largely from the long-ago period from 1958 to 1970, when energy prices did not influence the general trends. This situation will be greatly improved with extensive post1985 data (e.g., with the 1991 Manufacturing Energy Consumption Survey [MECS] and the corresponding BLS series). The parameters $B_{e}$ show ongoing electrification through the period to 1985, except in the primary aluminum sector (Table 4.2). Autonomous declines in electricity intensity would also be expected in other highly electricity-intensive sectors, such 


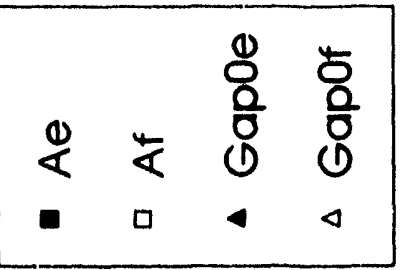

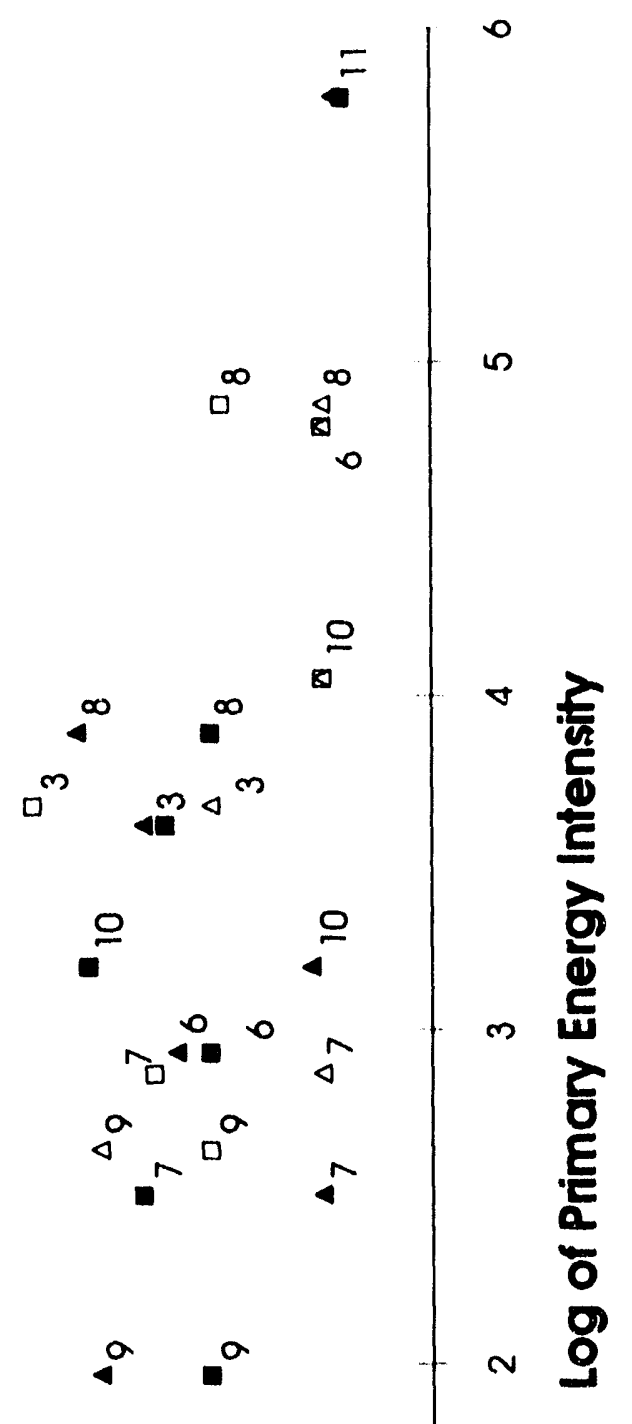

$n^{N}$

$4^{N}$

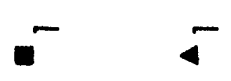

N
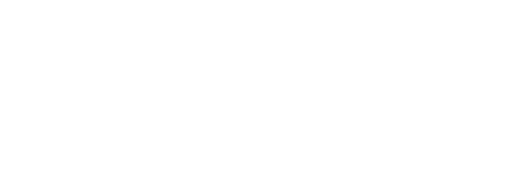
as chloralkali and phosphorous, if they were modeled explicitly. Similarly, the intensity of electric arc steelmaking has been declining (Boyd et al. 1992). The parameters $B_{f}$ show less variability. The fossil fuel intensities are declining autonomously about $0.5 \%$ per annum, except for minor deviations for cement and glass (Table 4.2).

The values of $B$ to use in a forecast are those given by the form used in the model:

$$
B(t)=B(1960) \times\left(1-(t-1960) / B^{\prime}\right),
$$

where $t$ is the base year for the forecast, and where $B^{\prime}=75$ years was found to improve the fits in most sectors and seems like a reasonable time period for sector process maturity. Thus, for the base year 1990, we propose that LIEF incorporate values of $B=0.6 \mathrm{~B}(1960)$ where $B(1960)$ is shown in Table 4.2. We propose using $B^{\prime}=50$ years for forecasts of 50 years or less.

As far as obtaining good historical fits is concerned, the B's are sensitively determined. However, considerable interaction occurs between Gap0 and $\mathrm{A}$. As discussed in Section 4.2, one can be increased while the other is decreased without strongly affecting the fit. In a typical case, a move from Gap0 $=0.2, A=0.2$ to $\mathrm{Gap} 0=0.15, \mathrm{~A}=0.3$ can occur while retaining what we judge to be a satisfactory fit. Thus, $A=A_{0}(1 \pm 0.5)$ with a corresponding modification of Gap0 is generally satisfactory, while much larger excursions from the best fits shown are not. Unfortunately, we do not have a solid statistical measure for satisfactoriness of fit since the model is nonlinear in the parameters. The $R^{2}$ values in the 0.90 and above range correspond to very good fits, and those in the 0.85 and above range correspond to good fits (as suggested by Figure 4.2). 


\section{SIMULATION RESULTS - EXERCISING THE MODEL}

\subsection{BASE-CASE SCENARIO}

The long-term future cannot be forecasted with any expectation of accuracy, although some aspects of the future can be forecasted with reasonable confidence. Other aspects of the future can be represented by interesting and important alternatives, or scenarios. LIEF was designed with the scenario approach to forecasting in mind. However, because the main purpose of this report is model documentation, we limit ourselves to two illustrative forecasts without extensive preparation or interpretation.

Parameters for the base case are shown in Table 5.1. (Note that this table includes all data in the model. All LIEF data are routinely input, although we recommend that baseyear data be left unchanged until the user is familiar with the model.) The sources for these parameters are given in Appendix B.

Some forecast parameters are based primarily on the authors' judgment. We call attention, in particular, to the autonomous trend for electricity in fast-growing manufacturing, sector 2 . We choose $B_{e}=0.0$ to describe a characteristic of this sector since 1970 (Ross and Fisher 1991). This choice generates quite a different electricity forecast than for the National Energy Strategy (NES) base case (EIA 1990; DOE 1991/1992b). Another parameter series that is controversial is the growth rate for all of industry. In exercises for the NES, this growth rate was taken to be faster than that for the GNP. In this model it is taken to be slower (Hwang and Ross 1992). The rationale for relatively slow industrial growth is that it has been slow in the last two decades. The contrary rationale for fast industrial growth in the NES exercises was that if GNP grows rapidly, as specified for NES by the Executive Office (White House), then very strong manufacturing growth is needed. In our opinion, both ends of this argument are dubious for a base case, although they could be reasonable for an alternative scenario.

The base-case forecast is shown in Table 5.2 (sectoral results) and Table 5.3 (summary results). The electricity intensity and electricity consumption forecasts for all industry are also shown in Figures 5.1 and 5.2. The growth rate for electricity use is predicted to be $1.9 \%$ per year for $1990-2010,1.1 \%$ per year for $2010-2030$, and $1.5 \%$ per year for 1990-2030.

After initially rising slowly over the second half of the forecast period, the aggregate industrial electricity intensity falls to essentially the 1990 value by 2030 (Table 5.3 and Figure 5.1). Since the electricity intensity is rising or constant in all but two sectors, this decline is associated with continued strong structural, or compositional, change in sectoral production.

Two structural effects occur: the move away from bulk materials and the move toward high-technology subsectors. The Divisia analysis (Table 5.4) shows that the decline 
TABLE 5.1 LIEF Input Parameters

a. Base-Year Sectoral Energy Demand and Production Rate

\begin{tabular}{|c|c|c|c|c|c|c|}
\hline \multirow{2}{*}{$\begin{array}{c}\text { Sector } \\
\text { No. }\end{array}$} & \multirow[b]{2}{*}{ Name } & \multirow{2}{*}{$\begin{array}{c}\text { Electricity } \\
\text { Demand } \\
\left(10^{12} \text { Btu }\right)\end{array}$} & \multicolumn{2}{|c|}{$\begin{array}{l}\text { Self-Generated and } \\
\text { Used Electricity, } \\
\text { by Year ( } \% \text { of total) }\end{array}$} & \multirow{2}{*}{$\begin{array}{c}\text { Fuel } \\
\text { Demand } \\
\left(10^{12} \text { Btu }\right)\end{array}$} & \multirow{2}{*}{$\begin{array}{c}\text { Sectoral } \\
\text { Production } \\
\text { Rate }\left(10^{9} \$\right) \\
\end{array}$} \\
\hline & & & 1990 & 2030 & & \\
\hline 1 & $\begin{array}{l}\text { General } \\
\text { manufacturing }\end{array}$ & 882.4 & 3.30 & 3.30 & $1,775.9$ & 685.40 \\
\hline 2 & $\begin{array}{l}\text { Fast-growing } \\
\text { manufacturing }\end{array}$ & 385.7 & 0.00 & 0.00 & 449.9 & 430.09 \\
\hline 3 & Pulp and paper & 316.7 & 44.00 & 44.00 & $1,105.8$ & 28.13 \\
\hline 4 & Inorganics & 202.5 & 14.70 & 14.70 & $1,169.8$ & 19.01 \\
\hline 5 & Organics & 237.2 & 29.60 & 29.60 & 740.4 & 48.98 \\
\hline 6 & $\begin{array}{r}\text { Petroleum } \\
\text { refining }\end{array}$ & 154.8 & 22.30 & 22.30 & $3,326.9$ & 27.21 \\
\hline 7 & Glass & 37.4 & 1.50 & 1.50 & 177.6 & 10.07 \\
\hline 8 & Cement & 32.5 & 1.50 & 1.50 & 287.5 & 2.19 \\
\hline 9 & Stone and clay & 47.3 & 1.50 & 1.50 & 306.1 & 21.86 \\
\hline 10 & Iron and steel & 241.8 & 10.30 & 10.30 & $1,889.3$ & 32.61 \\
\hline 11 & $\begin{array}{l}\text { Primary } \\
\text { aluminum }\end{array}$ & 219.6 & 1.10 & 1.10 & 30.6 & 2.20 \\
\hline 12 & Nonferrous & 74.3 & 1.10 & 1.10 & 218.5 & 18.54 \\
\hline 13 & Agriculture & 100.8 & 0.00 & 0.00 & 758.8 & 113.50 \\
\hline 14 & Mining & 152.9 & 5.00 & 5.00 & 505.4 & 24.60 \\
\hline 15 & Oil and gas & 96.8 & 5.00 & 5.00 & $1,288.1$ & 55.70 \\
\hline 16 & Construction & 45.4 & 0.00 & 0.00 & 422.5 & 247.70 \\
\hline 17 & Feedstocks & 0.0 & 0.00 & 0.00 & $4,974.2$ & 10.00 \\
\hline 18 & Uranium & 92.0 & 0.00 & 0.00 & 0.0 & 10.00 \\
\hline Total & & $3,320.6$ & & & $19,428.2$ & $1,787.85$ \\
\hline
\end{tabular}

\section{b. Discrepancy in Total}

Energy Demand (SEDS Basis)

\begin{tabular}{ccc}
\hline & \multicolumn{2}{c}{$\begin{array}{c}\text { Discrepancy in Demand } \\
\left(10^{12} \text { Btu }\right)\end{array}$} \\
\cline { 2 - 3 } Year & Electricity $^{b}$ & Fuel \\
\hline 1990 & 250.6 & 150.7 \\
2030 & 250.6 & 150.7 \\
\hline
\end{tabular}

a SEDS less quantity, as modeled.

b For electricity, the discrepancy is based on purchased electricity only. 
TABLE 5.1 (Cont.)

c. Heat Rates

\begin{tabular}{ll}
\hline & $\begin{array}{l}\text { Heat } \\
\text { Rate }\end{array}$ \\
\hline 1990 & 3.33 \\
2030 & 3.33 \\
\hline
\end{tabular}

d. LIEF Forecast Parameters

\begin{tabular}{clcccccc}
\hline $\begin{array}{c}\text { Sector } \\
\text { No. }\end{array}$ & \multicolumn{1}{c}{ Name } & Gap0e & Gap0f & Ae & Af & Be & Bf \\
\hline & General & 0.30 & 0.20 & 0.60 & 0.40 & -0.021 & 0.0025 \\
1 & $\begin{array}{l}\text { manufacturing } \\
\text { Fast-growing }\end{array}$ & 0.30 & 0.20 & 1.00 & 0.60 & 0.000 & 0.0040 \\
2 & $\quad$ manufacturing & & & & & & \\
& Pulp and paper & 0.15 & 0.15 & 0.25 & 0.20 & -0.011 & 0.0050 \\
3 & 0.15 & 0.15 & 0.25 & 0.22 & -0.018 & 0.0060 \\
4 & Inorganics & 0.15 & 0.15 & 0.25 & 0.20 & -0.018 & 0.0060 \\
5 & Organics & 0.15 & 0.15 & 0.25 & 0.20 & -0.018 & 0.0060 \\
6 & Petroleum refining & 0.10 & 0.10 & 0.25 & 0.25 & -0.018 & 0.0060 \\
7 & Glass & 0.20 & 0.20 & 0.20 & 0.20 & -0.019 & 0.0020 \\
8 & Cement & 0.20 & 0.20 & 0.20 & 0.20 & -0.016 & 0.0040 \\
9 & Stone and clay & 0.10 & 0.10 & 0.30 & 0.20 & -0.020 & 0.0060 \\
10 & Iron and steel & 0.05 & 0.10 & 0.10 & 0.20 & 0.001 & 0.0050 \\
11 & Primary aluminum & 0.15 & 0.15 & 0.25 & 0.20 & -0.018 & 0.0060 \\
12 & Nonferrous & 0.20 & 0.20 & 0.60 & 0.50 & -0.007 & 0.0070 \\
13 & Agriculture & 0.20 & 0.20 & 0.60 & 0.50 & -0.018 & 0.0040 \\
14 & Mining & 0.20 & 0.20 & 0.60 & 0.50 & -0.018 & 0.0040 \\
15 & Oil and gas & 0.20 & 0.20 & 0.60 & 0.50 & -0.018 & 0.0040 \\
16 & Construction & 0.00 & 0.00 & 0.00 & 0.00 & 0.000 & 0.0000 \\
17 & Feedstocks & 0.00 & 0.00 & 0.00 & 0.00 & 0.000 & 0.0000 \\
18 & Uranium & & & & & & \\
\hline
\end{tabular}


TABLE 5.1 (Cont.)

e. Energy Prices and Financial Parameters

\begin{tabular}{|c|c|c|c|c|c|c|}
\hline \multirow[b]{3}{*}{ Year } & & & \multicolumn{4}{|c|}{ Rate Change (\%/yr) } \\
\hline & \multicolumn{2}{|c|}{ Price $\left(1990 \$ / 10^{6} \mathrm{Btu}\right)$} & \multicolumn{2}{|c|}{ Base Case } & \multicolumn{2}{|c|}{ DSM Case } \\
\hline & Electricity & Fuel & Pen & CRF & Pen & CRF \\
\hline 1985 & 17.87 & 4.48 & & & & \\
\hline 1990 & 15.01 & 3.06 & & 33 & & 33 \\
\hline 1995 & 15.00 & 3.93 & 0.0 & 33 & 0.0 & 33 \\
\hline 2000 & 14.98 & 4.79 & 2.0 & 33 & 2.0 & 17 \\
\hline 2005 & 15.60 & 5.52 & 2.0 & 33 & 10.0 & 17 \\
\hline 2010 & 16.21 & 6.26 & 1.0 & 33 & 7.0 & 17 \\
\hline 2015 & 16.45 & 6.79 & 1.0 & 33 & 4.0 & 17 \\
\hline 2020 & 16.69 & 7.32 & 0.5 & 33 & 2.0 & 17 \\
\hline 2025 & 16.88 & 7.71 & 0.5 & 33 & 1.0 & 17 \\
\hline 2030 & 17.07 & 8.09 & 0.0 & 33 & 1.0 & 17 \\
\hline
\end{tabular}

\section{f. Production Growth Rates}

Production Growth Rate, by Year (\%/yr)

\begin{tabular}{|c|c|c|c|c|c|c|c|c|c|}
\hline $\begin{array}{l}\text { Sector } \\
\text { No. }\end{array}$ & Name & 1995 & 2000 & 2005 & 2010 & 2015 & 2020 & 2025 & 2030 \\
\hline 1 & $\begin{array}{l}\text { General } \\
\text { manufacturing }\end{array}$ & 1.00 & 1.00 & 1.00 & 1.00 & 1.00 & 1.00 & 0.60 & 0.60 \\
\hline 2 & $\begin{array}{l}\text { Fast-growing } \\
\text { manufacturing }\end{array}$ & 5.00 & 4.00 & 4.00 & 3.00 & 3.00 & 3.00 & 2.00 & 2.00 \\
\hline 3 & Pulp and paper & 2.00 & 2.00 & 1.50 & 1.50 & 1.00 & 1.00 & 0.50 & 0.50 \\
\hline 4 & Inorganics & 0.50 & 0.50 & 0.20 & 0.20 & 0.00 & 0.00 & 0.00 & 0.00 \\
\hline 5 & Organics & 1.50 & 1.50 & 1.00 & 1.00 & 1.00 & 1.00 & 0.50 & 0.50 \\
\hline 6 & $\begin{array}{r}\text { Petroleum } \\
\text { refining }\end{array}$ & 0.00 & 0.00 & 0.00 & 0.00 & -0.50 & -0.50 & -1.00 & -1.00 \\
\hline 7 & Glass & 0.00 & 0.00 & 0.00 & 0.00 & 0.00 & 0.00 & 0.00 & 0.00 \\
\hline 8 & Cement & 0.30 & 0.30 & 0.00 & 0.00 & 0.00 & 0.00 & 0.00 & 0.00 \\
\hline 9 & Stone and clay & 0.50 & 0.50 & 0.50 & 0.50 & 0.20 & 0.20 & 0.00 & 0.00 \\
\hline 10 & Iron and steel & 0.20 & 0.20 & 0.00 & 0.00 & 0.00 & 0.00 & 0.00 & 0.00 \\
\hline 11 & $\begin{array}{l}\text { Primary } \\
\text { aluminum }\end{array}$ & 0.00 & 0.00 & -0.50 & -0.50 & -1.00 & -1.00 & -1.00 & -1.00 \\
\hline 12 & Nonferrous & 0.00 & 0.00 & -0.50 & -0.50 & -1.00 & -1.00 & -1.00 & -1.00 \\
\hline 13 & Agriculture & 1.00 & 1.00 & 1.00 & 1.00 & 0.50 & 0.50 & 0.50 & 0.50 \\
\hline 14 & Mining & 0.00 & 0.00 & 0.00 & 0.00 & -0.50 & 0.50 & -1.00 & -1.00 \\
\hline 15 & Oil and Gas & 0.00 & 0.00 & -0.50 & -0.50 & -0.50 & -0.50 & -1.00 & -1.00 \\
\hline 16 & Construction & 0.50 & 0.50 & 0.50 & 0.50 & 0.50 & 0.50 & 0.00 & 0.00 \\
\hline 17 & Feedstocks & 1.50 & 1.50 & 1.00 & 1.00 & 1.00 & 1.00 & 0.50 & 0.50 \\
\hline 18 & Uranium & 0.00 & 0.00 & 0.00 & 0.00 & 0.00 & 0.00 & 0.00 & 0.00 \\
\hline Tot & triry & 1.80 & 1.80 & 1.70 & 1.60 & 1.50 & 1.40 & 1.30 & 1.20 \\
\hline
\end{tabular}


TABLE 5.1 (Cont.)

\begin{tabular}{|c|c|c|c|c|c|c|c|c|c|c|}
\hline \multirow{2}{*}{$\begin{array}{c}\text { Sector } \\
\text { No. }\end{array}$} & \multirow[b]{2}{*}{ Name } & \multicolumn{9}{|c|}{ Recycle Ratio, by Year (\%) } \\
\hline & & 1990 & 1995 & 2000 & 2005 & 2010 & 2015 & 2020 & 2025 & 2030 \\
\hline 3 & $\begin{array}{l}\text { Pulp and } \\
\text { paper }\end{array}$ & 26 & 29 & 31 & 33 & 35 & 37 & 39 & 40 & 40 \\
\hline 5 & Organics & 1 & 1.5 & 2 & 2.5 & 3 & 3.5 & 4 & 4.5 & 5 \\
\hline 7 & Glass & 11 & 12 & 12 & 13 & 13 & 14 & 14 & 15 & 15 \\
\hline 10 & $\begin{array}{c}\text { Iron and } \\
\text { steel }\end{array}$ & 42 & 44 & 46 & 48 & 50 & 50 & 50 & 50 & 50 \\
\hline 12 & Nonferrous & 50 & 51 & 52 & 53 & 54 & 55 & 55 & 55 & 55 \\
\hline
\end{tabular}

h. Relative Recycle Intensities

\begin{tabular}{clll}
\hline $\begin{array}{c}\text { Sector } \\
\text { No. }\end{array}$ & \multicolumn{1}{c}{ Name } & REIe & REIf \\
\hline 3 & Pulp and paper & 0.7 & 1.0 \\
5 & Organics & 0.5 & 0.5 \\
7 & Glass & 0.9 & 0.9 \\
10 & Iron and steel & 1.8 & 0.25 \\
12 & Nonferrous & 0.4 & 0.2 \\
\hline
\end{tabular}

\section{i. Global Economy}

$\mathrm{BPR}=10$ periods

Length of period, $\mathrm{T}=5$ years

Number of periods, $n=8$

Base year $=1990$

Fuel switching behavior, $\mathrm{C}=0.02$ 
TABLE 5.2 Base-Case Forecasts for Electricity Demand ${ }^{\text {a }}$

\begin{tabular}{|c|c|c|c|c|c|c|c|c|}
\hline Year & $\mathrm{Pe}$ & $\mathbf{Q}$ & $\mathrm{Ee}$ & EIe & PEIe & IEIe & SGUE & PURCHE \\
\hline \multicolumn{9}{|c|}{ Sector - 1. General Manufacturing } \\
\hline 1990 & 15.01 & 685.4 & 882.4 & 1.29 & 0 & 0.9 & 29.1 & 853.3 \\
\hline 1995 & 15 & 717.0 & $1,007.9$ & 1.41 & 1.28 & 1.06 & 33.2 & 974.7 \\
\hline 2000 & 14.98 & 755.1 & $1,131.7$ & 1.5 & 1.42 & 1.1 & 37.3 & $1,094.3$ \\
\hline 2005 & 15.6 & 788.7 & $1,247.1$ & 1.58 & 1.51 & 1.18 & 41.1 & $1,206.0$ \\
\hline 2010 & 16.2 & 830.0 & $1,383.7$ & 1.67 & 1.59 & 1.23 & 45.6 & $1,338.0$ \\
\hline 2015 & 16.45 & 868.7 & $1,510.8$ & 1.74 & 1.67 & 1.29 & 49.8 & $1,460.9$ \\
\hline 2020 & 16.69 & 901.7 & $1,628.6$ & 1.81 & 1.74 & 1.36 & 53.7 & $1,574.8$ \\
\hline 2025 & 16.88 & 939.8 & $1,744.3$ & 1.86 & 1.81 & 1.4 & 57.5 & $1,686.8$ \\
\hline 2030 & $17.0^{\prime} 7$ & 972.9 & $1,846.0$ & 1.9 & 1.86 & 1.44 & 60.9 & $1,785.0$ \\
\hline
\end{tabular}

Sector - 2. Fast-Growing Manufacturing

$\begin{array}{llrrllllr}1990 & 15.01 & 430.1 & 385.7 & 0.9 & 0 & 0.63 & 0 & 385.7 \\ 1995 & 15 & 546.3 & 487.2 & 0.89 & 0.89 & 0.69 & 0 & 487.2 \\ 2000 & 14.98 & 666.0 & 580.9 & 0.87 & 0.9 & 0.63 & 0 & 580.9 \\ 2005 & 15.6 & 805.3 & 686.2 & 0.85 & 0.88 & 0.62 & 0 & 686.2 \\ 2010 & 16.2 & 934.8 & 786.4 & 0.84 & 0.85 & 0.58 & 0 & 786.4 \\ 2015 & 16.45 & 1,079.2 & 895.8 & 0.83 & 0.84 & 0.57 & 0 & 895.8 \\ 2020 & 16.69 & 1,235.7 & 1,019.4 & 0.82 & 0.83 & 0.56 & 0 & 1,019.4 \\ 2025 & 16.88 & 1,380.0 & 1,131.4 & 0.82 & 0.83 & 0.56 & 0 & 1,131.4 \\ 2030 & 17.07 & 1,530.7 & 1,256.3 & 0.82 & 0.82 & 0.55 & 0 & 1,256.3\end{array}$

Sector - 3. Pulp and Paper

$\begin{array}{lllllllll}1990 & 15.01 & 28.14 & 316.7 & 11.26 & 0 & 9.57 & 139.3 & 177.3 \\ 1995 & 15 & 30.92 & 359.0 & 11.61 & 11.16 & 10.36 & 157.9 & 201.0 \\ 2000 & 14.98 & 34.21 & 410.9 & 12.01 & 11.73 & 10.52 & 180.8 & 230.1 \\ 2005 & 15.6 & 36.51 & 452.0 & 12.34 & 12.1 & 10.87 & 198.8 & 253.1 \\ 2010 & 16.2 & 39.51 & 499.3 & 12.64 & 12.39 & 11.06 & 219.7 & 279.6 \\ 2015 & 16.45 & 41.35 & 532.1 & 12.87 & 12.68 & 11.28 & 234.1 & 298.0 \\ 2020 & 16.69 & 42.92 & 560.6 & 13.06 & 12.9 & 11.5 & 246.6 & 313.9 \\ 2025 & 16.88 & 44.52 & 588.7 & 13.23 & 13.09 & 11.64 & 259.0 & 329.7 \\ 2030 & 17.07 & 45.85 & 614.0 & 13.39 & 13.25 & 11.77 & 270.1 & 343.8\end{array}$

Sector - 4. Inorganics

$\begin{array}{lllllllll}1990 & 15.01 & 19.02 & 202.5 & 10.65 & 0 & 9.05 & 29.7 & 172.7 \\ 1995 & 15 & 19.41 & 221.6 & 11.42 & 10.53 & 10.16 & 32.5 & 189.0 \\ 2000 & 14.98 & 19.94 & 244.6 & 12.27 & 11.57 & 10.75 & 35.9 & 208.6 \\ 2005 & 15.6 & 20.01 & 261.0 & 13.04 & 12.39 & 11.49 & 38.3 & \mathbf{2 2 2 . 6} \\ 2010 & 16.2 & 20.24 & 278.3 & 13.75 & 13.1 & 12.06 & 40.9 & 237.4 \\ 2015 & 16.45 & 20.16 & 289.5 & 14.36 & 13.8 & 12.65 & 42.5 & 246.9 \\ 2020 & 16.69 & 19.91 & 296.5 & 14.9 & 14.4 & 13.22 & 43.5 & 252.9 \\ 2025 & 16.88 & 20.14 & 308.2 & 15.31 & 14.96 & 13.66 & 45.3 & 262.9 \\ 2030 & 17.07 & 20.23 & 315.8 & 15.61 & 15.33 & 14 & 46.4 & 269.3\end{array}$


TABLE 5.2 (Cont.)

\begin{tabular}{|c|c|c|c|c|c|c|c|c|}
\hline Year & $\mathrm{Pe}$ & $\mathbf{Q}$ & $\mathrm{Ee}$ & EIe & PEIe & IEIe & SGUE & PURCHE \\
\hline \multicolumn{9}{|c|}{ Sector - 5. Organics } \\
\hline 1990 & 15.01 & 48.98 & 237.2 & 4.84 & 0 & 4.12 & 70.2 & 167 \\
\hline 1995 & 15 & 52.52 & 272.9 & 5.2 & 4.8 & 4.62 & 80.7 & 192.1 \\
\hline 2000 & 14.98 & 56.7 & 314.6 & 5.55 & 5.24 & 4.87 & 93.1 & 221.5 \\
\hline 2005 & 15.6 & 59.22 & 347.5 & 5.87 & 5.59 & 5.2 & 102.8 & 244.6 \\
\hline 2010 & 16.2 & 62.32 & 384.1 & 6.16 & 5.89 & 5.44 & 113.7 & 270.4 \\
\hline 2015 & 16.45 & 65.23 & 418.5 & 6.42 & 6.18 & 5.69 & 123.8 & 294.6 \\
\hline 2020 & 16.69 & 67.71 & 449.1 & 6.63 & 6.43 & 5.93 & 132.9 & 316.1 \\
\hline 2025 & 16.88 & 70.22 & 477.1 & 6.8 & 6.65 & 6.12 & 141.2 & 335.9 \\
\hline 2030 & 17.07 & 72.33 & 499.7 & 6.91 & 6.8 & 6.25 & 147.9 & 351.8 \\
\hline \multicolumn{9}{|c|}{ Sector - 6. Petroleum Refining } \\
\hline 1990 & 15.01 & 27.21 & 154.8 & 5.69 & 0 & 4.84 & 34.5 & 120.3 \\
\hline 1995 & 15 & 27.09 & 162 & 5.98 & 5.52 & 5.43 & 36.1 & 125.8 \\
\hline 2000 & 14.98 & 27.14 & 178.2 & 6.57 & 6.19 & 5.74 & 39.7 & 128.5 \\
\hline 2005 & 15.6 & 26.97 & 191.1 & 7.08 & 6.73 & 6.14 & 42.6 & 148.4 \\
\hline 2010 & 16.2 & 27.01 & 203.1 & 7.52 & 7.16 & 6.44 & 45.2 & 157.8 \\
\hline 2015 & 16.45 & 26.23 & 207.1 & 7.9 & 7.59 & 6.76 & 46.1 & 160.9 \\
\hline 2020 & 16.69 & 25.27 & 207.6 & 8.22 & 7.95 & 7.06 & 46.3 & 161.3 \\
\hline 2025 & 16.88 & 24.3 & 205.9 & 8.47 & 8.27 & 7.3 & 45.9 & 160.0 \\
\hline 2030 & 17.07 & 23.22 & 201.0 & 8.66 & 8.5 & 7.48 & 44.8 & 156.2 \\
\hline \multicolumn{9}{|c|}{ Sector - 7. Glass } \\
\hline 1990 & 15.01 & 10.08 & 37.4 & 3.72 & 0 & 3.34 & 0.5 & 36.8 \\
\hline 1995 & 15 & 10.03 & 39.9 & 3.98 & 3.68 & 3.75 & 0.6 & 39.3 \\
\hline 2000 & 14.98 & 10.05 & 43.1 & 4.3 & 4.03 & 3.96 & 0.6 & 42.5 \\
\hline 2005 & 15.6 & 9.99 & 45.7 & 4.58 & 4.33 & 4.24 & 0.6 & 45.0 \\
\hline 2010 & 16.2 & 10 & 48.3 & 4.84 & 4.6 & 4.45 & 0.7 & 47.6 \\
\hline 2015 & 16.45 & 9.96 & 50.3 & 5.05 & 4.85 & 4.66 & 0.7 & 49.5 \\
\hline 2020 & 16.69 & 9.84 & 51.6 & 5.24 & 5.07 & 4.87 & 0.7 & 50.8 \\
\hline 2025 & 16.88 & 9.95 & 53.6 & 5.39 & 5.26 & 5.03 & 0.8 & 52.8 \\
\hline 2030 & 17.07 & 10 & 54.9 & 5.49 & 5.4 & 5.15 & 0.8 & 54.1 \\
\hline \multicolumn{9}{|c|}{ Sector - 8. Cement } \\
\hline 1990 & 15.01 & 2.2 & 32.5 & 14.82 & 0 & 11.86 & 0.4 & 32.0 \\
\hline 1905 & 15 & 2.22 & 35.2 & 15.9 & 14.6 & 13.31 & 0.5 & 34.7 \\
\hline 2000 & 14.98 & 2.26 & 38.7 & 17.15 & 16.18 & 14.21 & 0.5 & 38.1 \\
\hline 2005 & 15.6 & 2.24 & 40.9 & 18.27 & 17.37 & 15.27 & 0.6 & 40.3 \\
\hline 2010 & 16.2 & 2.25 & 43.3 & 19.31 & 18.38 & 16.13 & 0.6 & 42.7 \\
\hline 2015 & 16.45 & 2.24 & 45.1 & 20.2 & 19.4 & 16.99 & 0.6 & 44.5 \\
\hline 2020 & 16.69 & 2.21 & 46.3 & 20.99 & 20.28 & 17.8 & 0.7 & 45.6 \\
\hline 2025 & 16.88 & 2.23 & 48.2 & 21.61 & 21.06 & 18.44 & 0.7 & 47.5 \\
\hline 2030 & 17.07 & 2.24 & 49.5 & 22.07 & 21.65 & 18.94 & 0.7 & 48.7 \\
\hline
\end{tabular}


TABLE 5.2 (Cont.)

\begin{tabular}{|c|c|c|c|c|c|c|c|c|}
\hline Year & $\mathrm{Pe}$ & $\mathbf{Q}$ & $\mathrm{Ee}$ & EIe & PEIe & IEIe & SGUE & PURCHE \\
\hline \multicolumn{9}{|c|}{ Sector - 9. Stone and Clay } \\
\hline 1990 & 15.01 & 21.86 & 47.3 & 2.16 & 0 & 1.73 & 0.7 & 46.6 \\
\hline 1995 & 15 & 22.31 & 51.2 & 2.3 & 2.14 & 1.91 & 0.7 & 50 \\
\hline 2000 & 14.98 & 22.92 & 55.9 & 2.44 & 2.33 & 2.02 & 0.8 & 55 \\
\hline 2005 & 15.6 & 23.35 & 59.9 & 2.57 & 2.47 & 2.14 & 0.9 & 59 \\
\hline 2010 & 16.2 & 23.98 & 64.3 & 2.68 & 2.58 & 2.24 & 0.9 & 63 \\
\hline 2015 & 16.45 & 24.12 & 67.1 & 2.78 & 2.69 & 2.34 & 1.0 & 66 \\
\hline 2020 & 16.69 & 24.06 & 69.1 & 2.87 & 2.79 & 2.43 & 1.0 & 68 \\
\hline 2025 & 16.88 & 24.33 & 71.6 & 2.94 & 2.88 & 2.5 & 1.0 & 70 \\
\hline 2030 & 17.07 & 24.45 & 73.2 & 2.99 & 2.95 & 2.56 & 1.1 & \\
\hline
\end{tabular}

Sector - 10. Iron and Steel

$\begin{array}{lllllllll}1990 & 15.01 & 32.61 & 241.8 & 7.42 & 0 & 6.67 & 24.9 & 216.9 \\ 1995 & 15 & 32.79 & 265.5 & 8.1 & 7.31 & 7.6 & 27.3 & 238.1 \\ 2000 & 14.98 & 33.18 & 296.7 & 8.94 & 8.22 & 8.17 & 30.5 & 266.1 \\ 2005 & 15.6 & 32.98 & 321.2 & 9.74 & 9.04 & 8.9 & 33.0 & 288.1 \\ 2010 & 16.2 & 33.02 & 346.0 & 10.48 & 9.79 & 9.49 & 35.6 & 310.4 \\ 2015 & 16.45 & 32.88 & 362.5 & 11.03 & 10.52 & 10.12 & 37.3 & 325.2 \\ 2020 & 16.69 & 32.48 & 373.2 & 11.49 & 11.06 & 10.62 & 38.4 & 334.8 \\ 2025 & 16.88 & 32.85 & 389.6 & 11.86 & 11.52 & 11.02 & 40.4 & 349.5 \\ 2030 & 17.07 & 33 & 400.0 & 12.12 & 11.88 & 11.32 & 41.2 & 358.8\end{array}$

Sector - 11. Primary Aluminum

$\begin{array}{lllllllll}1990 & 15.01 & 2.2 & 219.6 & 99.63 & 0 & 94.64 & 2.4 & 217.2 \\ 1995 & 15 & 2.79 & 216.7 & 98.75 & 99.2 & 95.12 & 2.3 & 214.3 \\ 2000 & 14.98 & 2.2 & 216.3 & 98.39 & 99.27 & 93.76 & 2.3 & 214 \\ 2005 & 15.6 & 2.13 & 208.8 & 97.99 & 98.8 & 93.21 & 2.3 & 206.5 \\ 2010 & 16.2 & 2.08 & 203.2 & 97.66 & 98.2 & 92.34 & 2.2 & 201.0 \\ 2015 & 16.45 & 1.97 & 191.9 & 97.35 & 97.84 & 91.83 & 2.1 & 189.8 \\ 2020 & 16.69 & 1.85 & 179.9 & 97.17 & 97.49 & 91.56 & 1.9 & 177.9 \\ 2025 & 16.88 & 1.78 & 172.8 & 97.03 & 97.3 & 91.26 & 1.9 & 170.9 \\ 2030 & 17.07 & 1.7 & 165.0 & 97.01 & 97.11 & 91.04 & 1.8 & 163.2\end{array}$

Sector - 12. Nonferrous

$\begin{array}{lllllllll}1990 & 15.01 & 18.55 & 74.3 & 4.01 & 0 & 3.41 & 0.8 & 73.5 \\ 1995 & 15 & 18.46 & 78.9 & 4.27 & 3.98 & 3.82 & 0.8 & 78.0 \\ 2000 & 14.98 & 18.5 & 83.9 & 4.54 & 4.31 & 4.01 & 0.9 & 82.9 \\ 2005 & 15.6 & 17.93 & 85.4 & 4.77 & 4.57 & 4.25 & 0.9 & 84.5 \\ 2010 & 16.2 & 17.51 & 87.0 & 4.97 & 4.78 & 4.42 & 0.9 & 86.1 \\ 2015 & 16.45 & 16.58 & 85.2 & 5.14 & 4.99 & 4.6 & 0.9 & 84.3 \\ 2020 & 16.69 & 15.57 & 83.0 & 5.33 & 5.15 & 4.76 & 0.9 & 82.1 \\ 2025 & 16.88 & 14.98 & 82.0 & 5.47 & 5.34 & 4.92 & 0.9 & 81.1 \\ 2030 & 17.07 & 14.31 & 79.8 & 5.58 & 5.48 & 5.04 & 0.8 & 79\end{array}$


TABLE 5.2 (Cont.)

\begin{tabular}{|c|c|c|c|c|c|c|c|c|}
\hline Year & $\mathrm{Pe}$ & $\mathbf{Q}$ & $\mathrm{Ee}$ & EIe & PEIe & IEIe & SGUE & PURCHE \\
\hline \multicolumn{9}{|c|}{ Sector - 13. Agriculture } \\
\hline 1990 & 15.01 & 113.5 & 100.8 & 0.89 & 0 & 0.71 & 0 & 100.8 \\
\hline 1995 & 15 & 118.7 & 107.6 & 0.9 & 0.88 & 0.78 & 0 & 107.3 \\
\hline 2000 & 14.98 & 125.0 & 115.9 & 0.93 & 0.92 & 0.76 & 0 & 115.9 \\
\hline 2005 & 15.6 & 130.6 & 123.3 & 0.94 & 0.94 & 0.77 & 0 & 123.3 \\
\hline 2010 & 16.2 & 137.4 & 132 & 0.96 & 0.95 & 0.76 & 0 & 132 \\
\hline 2015 & 16.45 & 140.3 & 136.4 & 0.97 & 0.96 & 0.77 & 0 & 136.4 \\
\hline 2020 & 16.69 & 142.1 & 139.9 & 0.98 & 0.98 & 0.78 & 0 & 139.9 \\
\hline 2025 & 16.88 & 147.3 & 146.4 & 0.99 & 0.99 & 0.79 & 0 & 146.4 \\
\hline 2030 & 17.07 & 151.7 & 152.2 & 1 & 1 & 0.79 & 0 & 152.2 \\
\hline \multicolumn{9}{|c|}{ Sector - 14. Mining } \\
\hline 1990 & 15.01 & 24.6 & 152.9 & 6.22 & 0 & 4.97 & 7.6 & 145.2 \\
\hline 1995 & 15 & 24.49 & 157.9 & 6.45 & 6.16 & 5.55 & 7.9 & 150.0 \\
\hline 2000 & 14.98 & 24.54 & 163.2 & 6.65 & 6.51 & 5.47 & 8.1 & 155.0 \\
\hline 2005 & 15.6 & 24.38 & 166.2 & 6.82 & 6.7 & 5.63 & 8.3 & 157.9 \\
\hline 2010 & 16.2 & 24.41 & 170.5 & 6.99 & 6.84 & 5.63 & 8.5 & 162.0 \\
\hline 2015 & 16.45 & 23.71 & 168.7 & 7.12 & 7.01 & 5.71 & 8.4 & 160.3 \\
\hline 2020 & 16.69 & 22.84 & 165.4 & 7.25 & 7.13 & 5.84 & 8.2 & 157.2 \\
\hline 2025 & 16.88 & 21.97 & 161.1 & 7.34 & 7.26 & 5.92 & 8.0 & 153.1 \\
\hline 2030 & 17.07 & 20.99 & 155.7 & 7.42 & 7.35 & 5.97 & 7.7 & 147.9 \\
\hline \multicolumn{9}{|c|}{ Sector - 15. Oil and Natural Gas } \\
\hline 1990 & 15.01 & 55.7 & 96.8 & 1.74 & 0 & 1.39 & 4.8 & 91.9 \\
\hline 1995 & 15 & 55.44 & 98.7 & 1.78 & 1.7 & 1.55 & 4.9 & 93.7 \\
\hline 2000 & 14.98 & 55.55 & 103.5 & 1.86 & 1.82 & 1.53 & 5.1 & 98.3 \\
\hline 2005 & 15.6 & 53.84 & 103.9 & 1.93 & 1.9 & 1.57 & 5.2 & 98.7 \\
\hline 2010 & 16.2 & 52.58 & 104.4 & 1.99 & 1.95 & 1.57 & 5.2 & 99.2 \\
\hline 2015 & 16.45 & 51.06 & 103.7 & 2.03 & 2 & 1.6 & 5.1 & 98.5 \\
\hline 2020 & 16.69 & 49.18 & 102 & 2.07 & 2.04 & 1.63 & 5.1 & 96.9 \\
\hline 2025 & 16.88 & 47.31 & 99.6 & 2.11 & 2.08 & 1.65 & 4.9 & 94.6 \\
\hline 2030 & 17.07 & 45.2 & 96.4 & 2.13 & 2.11 & 1.67 & 4.8 & 91.5 \\
\hline \multicolumn{9}{|c|}{ Sector -16 . Construction } \\
\hline 1990 & 15.01 & 247.7 & 45.4 & 0.18 & 0 & 0.15 & 0 & 45.4 \\
\hline 1995 & 15 & 252.7 & 47.7 & 0.19 & 0.18 & 0.16 & 0 & 47.7 \\
\hline 2000 & 14.98 & 259.6 & 51.0 & 0.2 & 0.19 & 0.16 & 0 & 51.0 \\
\hline 2005 & 15.6 & 264.5 & 53.6 & 0.2 & 0.2 & 0.17 & 0 & 53.6 \\
\hline 2010 & 16.2 & 271.6 & 56.5 & 0.21 & 0.2 & 0.17 & 0 & 56.5 \\
\hline 2015 & 16.45 & 277.3 & 59 & 0.21 & 0.21 & 0.17 & 0 & 59 \\
\hline 2020 & 16.69 & 280.8 & 60.9 & 0.22 & 0.21 & 0.17 & 0 & 60.9 \\
\hline 2025 & 16.88 & 284.0 & 62.4 & 0.22 & 0.22 & 0.17 & 0 & 62.4 \\
\hline 2030 & 17.07 & 285.3 & 63.5 & 0.22 & 0.22 & 0.18 & 0 & 63.5 \\
\hline
\end{tabular}


TABLE 5.2 (Cont.)

\begin{tabular}{|c|c|c|c|c|c|c|c|c|}
\hline Year & $\mathrm{Pe}$ & $\mathbf{Q}$ & $\mathrm{Ee}$ & EIe & PEIe & IEIe & SGUE & PURCHE \\
\hline \multicolumn{9}{|c|}{ Sector - 17. Feedstocks } \\
\hline $\begin{array}{l}1990 \\
1995 \\
2000 \\
2005 \\
2010 \\
2015 \\
2020 \\
2025 \\
2030\end{array}$ & $\begin{array}{l}15.01 \\
15 \\
14.98 \\
15.6 \\
16.2 \\
16.45 \\
16.69 \\
16.88 \\
17.07\end{array}$ & $\begin{array}{l}10 \\
10.77 \\
11.61 \\
12.2 \\
12.82 \\
13.47 \\
14.16 \\
14.52 \\
14.88\end{array}$ & $\begin{array}{l}0 \\
0 \\
0 \\
0 \\
0 \\
0 \\
0 \\
0 \\
0\end{array}$ & $\begin{array}{l}0 \\
0 \\
0 \\
0 \\
0 \\
0 \\
0 \\
0 \\
0\end{array}$ & $\begin{array}{l}0 \\
0 \\
0 \\
0 \\
0 \\
0 \\
0 \\
0 \\
0\end{array}$ & $\begin{array}{l}0 \\
0 \\
0 \\
0 \\
0 \\
0 \\
0 \\
0 \\
0\end{array}$ & $\begin{array}{l}0 \\
0 \\
0 \\
0 \\
0 \\
0 \\
0 \\
0 \\
0\end{array}$ & $\begin{array}{l}0 \\
0 \\
0 \\
0 \\
0 \\
0 \\
0 \\
0 \\
0\end{array}$ \\
\hline \multicolumn{9}{|c|}{ Sector - 18. Uranium } \\
\hline $\begin{array}{l}1990 \\
1995 \\
2000 \\
2005 \\
2010 \\
2015 \\
2020 \\
2025 \\
2030\end{array}$ & $\begin{array}{l}15.01 \\
15 \\
14.98 \\
15.6 \\
16.2 \\
16.45 \\
16.69 \\
16.88 \\
17.07\end{array}$ & $\begin{array}{l}10 \\
10 \\
10 \\
10 \\
10 \\
10 \\
10 \\
10 \\
10\end{array}$ & $\begin{array}{l}92 \\
92 \\
92 \\
92 \\
92 \\
92 \\
92 \\
92 \\
92\end{array}$ & $\begin{array}{l}9.2 \\
9.2 \\
9.2 \\
9.2 \\
9.2 \\
9.2 \\
9.2 \\
9.2 \\
9.2\end{array}$ & $\begin{array}{l}0 \\
9.2 \\
9.2 \\
9.2 \\
9.2 \\
9.2 \\
9.2 \\
9.2 \\
9.2\end{array}$ & $\begin{array}{l}9.2 \\
9.2 \\
9.2 \\
9.2 \\
9.2 \\
9.2 \\
9.2 \\
9.2 \\
9.2 \\
\end{array}$ & $\begin{array}{l}0 \\
0 \\
0 \\
0 \\
0 \\
0 \\
0 \\
0 \\
0\end{array}$ & $\begin{array}{l}92 \\
92 \\
92 \\
92 \\
92 \\
92 \\
92 \\
92 \\
92 \\
\end{array}$ \\
\hline
\end{tabular}

a $Q=$ production. Census value added in billion $1990 \$$. Growth rates are based on real gross output.

$\mathrm{E}=$ energy consumption. Purchased electricity in $10^{12} \mathrm{Btu}(3,412 \mathrm{Btu} / \mathrm{kWh})$.

$\mathrm{EI}=$ energy intensities, $\mathbf{E} / \mathbf{Q}$.

IEI = ideal (or cost-effective) energy intensity; an internal modeling characteristic.

$P=$ energy prices in $1990 \$ / 10^{6}$ Btu.

$\mathrm{S}=$ fuel share.

SGUE = self-generated electricity used on-site.

PURCHE = purchased electricity.

PEI and SEI = internal modeling characteristics. 


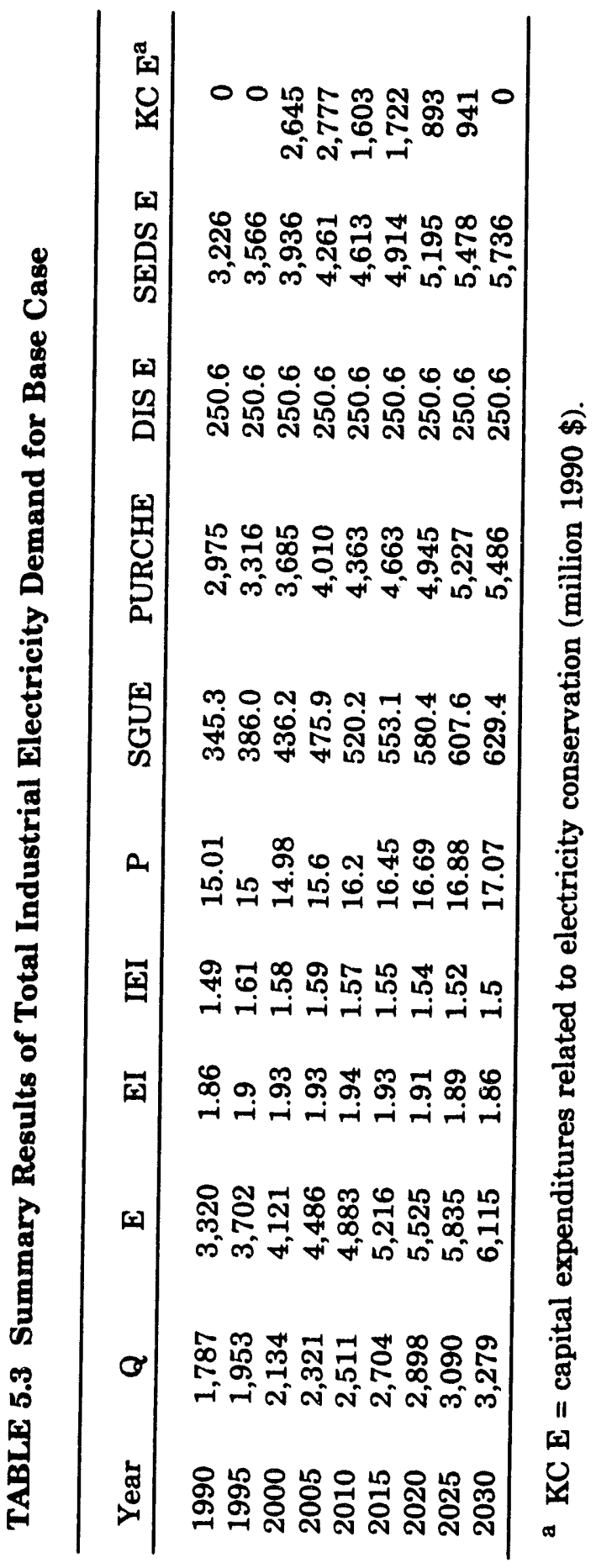




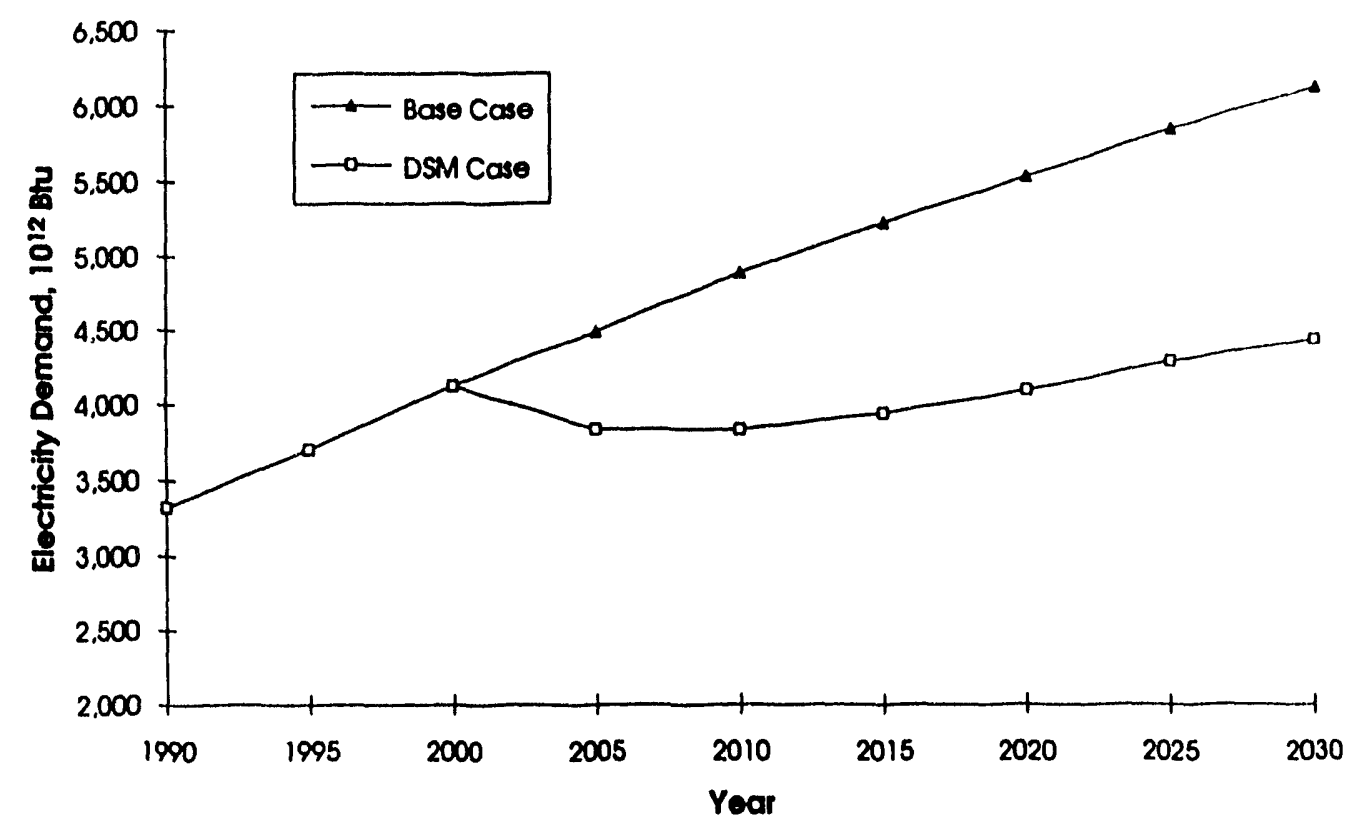

FIGURE 5.1 Comparison of Base-Case and DSM-Case Electricity

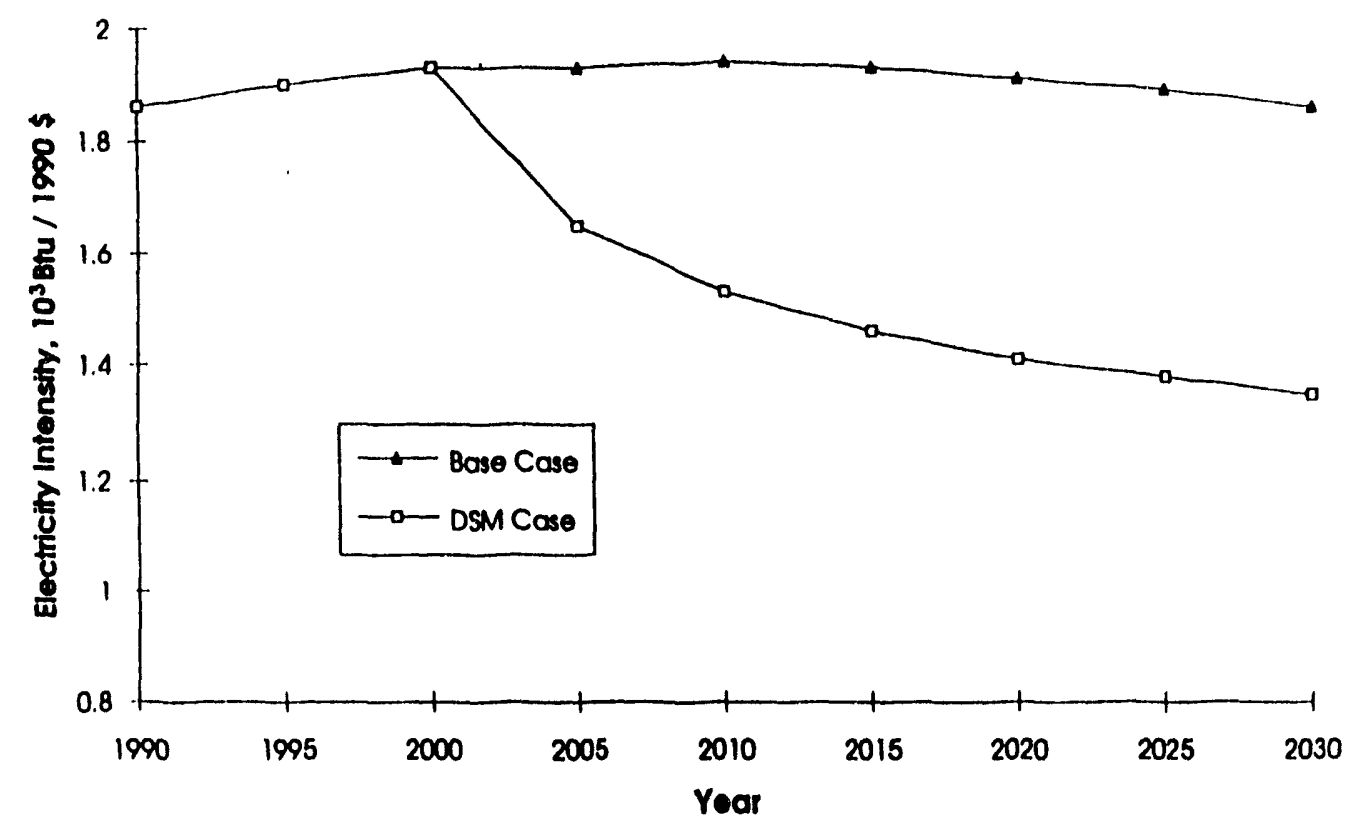

FIGURE 5.2 Comparison of Base-Case and DSM-Case Electricity Intensities 
TABLE 5.4 Divisia Decomposition of Electricity for Base Case (all industry)

\begin{tabular}{llllll}
\hline Year & \multicolumn{1}{c}{$\mathrm{I}_{\mathrm{E}}$} & \multicolumn{1}{c}{$\mathrm{I}_{\mathrm{Q}}$} & \multicolumn{1}{c}{$\mathrm{I}_{\mathrm{S}}$} & \multicolumn{1}{c}{$\mathrm{I}_{\mathrm{I}}$} & $\mathrm{I}_{\mathrm{Q}} \times \mathrm{l}_{\mathrm{S}} \times \mathrm{I}_{\mathrm{I}}$ \\
\hline 1990 & 1 & 1 & 1 & 1 & 1 \\
1995 & 1.114 & 1.092 & 0.970 & 1.051 & 1.114 \\
2000 & 1.241 & 1.194 & 0.944 & 1.099 & 1.239 \\
2005 & 1.351 & 1.298 & 0.910 & 1.140 & 1.348 \\
2010 & 1.470 & 1.404 & 0.884 & 1.180 & 1.467 \\
2015 & 1.570 & 1.512 & 0.854 & 1.211 & 1.567 \\
2020 & 1.663 & 1.621 & 0.825 & 1.240 & 1.660 \\
2025 & 1.757 & 1.728 & 0.803 & 1.261 & 1.752 \\
2030 & 1.841 & 1.834 & 0.782 & 1.280 & 1.836 \\
\hline
\end{tabular}

in intensity associated with the shift in composition of production, represented by $\mathrm{I}_{\mathrm{S}}$, almost exactly offsets the rise in the real electricity intensity (the appropriately weighted intensity of the separate sectors), represented by $I_{1}$.

Electricity consumption is forecast to grow at the same rate as aggregate industrial production, even though autonomous electrification continues strongly in most sectors and for most of the forecast period.

Investment in energy conservation projects is forecast to be $\$ 2.6$ billion in the second half of the 1990s (in $1990 \$$ ) (Table 5.3). The rate of investment is strongly dependent on the forecast penetration rates (Table 5.1e), which we have chosen here to relate to the price forecast (especially the fuel price rise in the forecast).

\subsection{DEMAND-SIDE MANAGEMENT SCENARIO}

The input variables for the DSM scenario are also found in Table 5.1. Only two parameter series are altered from the base case, pen $(t)$ and $\operatorname{CRF}(t)$. The penetration series for the base case and DSM case are derived from the historical behavior (Section 4) and the authors' judgment. In fact, there is little data and analysis on industrial DSM programs upon which to base the penetration rates, which are critical to the DSM forecast. (See the discussion in Ross and Hwang [1992], especially Section 8, which pertains to the challenges facing successful DSM programs, and Section 5, which details the basis for the 5\% per year penetration rate assumed here.) The $\mathrm{CRF}(\mathrm{t})$ series assumed here is more straightforward, since it is based on incentives to electricity customers that amount to $50 \%$ of the installed cost of qualifying energy conservation projects (Ross and Hwang 1992).

The results for the DSM scenario are presented in Table 5.4 and are summarized in Table 5.5 and in Figures 5.1 and 5.2 The growth rates for electricity consumption (total industry) are $0.7 \%$ per year for $1900-2010,0.7 \%$ per year for $2010-2030$, and $0.7 \%$ per year 
TABLE 5.5 DSM-Case Forecast for Electricity Demand ${ }^{\text {a }}$

\begin{tabular}{|c|c|c|c|c|c|c|c|c|}
\hline Year & $\mathrm{Pe}$ & $\mathbf{Q}$ & Ee & EIe & PEIe & IEIe & SGUE & PURCHE \\
\hline \multicolumn{9}{|c|}{ Sector - 1. General Manufacturing } \\
\hline 1990 & 15.01 & 685.4 & 882.4 & 1.29 & 0 & 0.9 & 29.1 & 853.3 \\
\hline 1995 & 15 & 717.0 & $1,007.9$ & 1.41 & 1.28 & 1.06 & 33.2 & 974.7 \\
\hline 2000 & 14.98 & 755.1 & $1,131.7$ & 1.5 & 1.42 & 1.1 & 37.3 & $1,094.3$ \\
\hline 2005 & 15.6 & 788.7 & $1,014.3$ & 1.29 & 1.51 & 0.8 & 33.4 & 980.8 \\
\hline 2010 & 16.2 & 830.0 & $1,003.9$ & 1.21 & 1.29 & 0.83 & 33.1 & 970.8 \\
\hline 2015 & 16.45 & 868.7 & $1,045.9$ & 1.2 & 1.21 & 0.87 & 34.5 & $1,011.4$ \\
\hline 2020 & 16.69 & 901.7 & $1,105.4$ & 1.23 & 1.21 & 0.91 & 36.4 & $1,068.9$ \\
\hline 2025 & 16.88 & 939.8 & $1,176.7$ & 1.25 & 1.23 & 0.94 & 38.8 & $1,137.9$ \\
\hline 2030 & 17.07 & 972.9 & $1,231.2$ & 1.27 & 1.25 & 0.97 & 40.6 & $1,190.5$ \\
\hline
\end{tabular}

Sector - 2. Fast-Growing Manufacturing

$\begin{array}{lllllllll}1990 & 15.01 & 430.1 & 385.7 & 0.9 & 0 & 0.63 & 0 & 385.7 \\ 1995 & 15 & 546.3 & 487.2 & 0.89 & 0.89 & 0.69 & 0 & 487.2 \\ 2000 & 14.98 & 666.0 & 580.9 & 0.87 & 0.9 & 0.63 & 0 & 580.9 \\ 2005 & 15.6 & 805.3 & 522.4 & 0.65 & 0.88 & 0.32 & 0 & 522.4 \\ 2010 & 16.2 & 934.8 & 508.9 & 0.54 & 0.65 & 0.3 & 0 & 508.9 \\ 2015 & 16.45 & 1,079.2 & 539.0 & 0.5 & 0.55 & 0.29 & 0 & 539.0 \\ 2020 & 16.69 & 1,235.7 & 593.8 & 0.48 & 0.5 & 0.29 & 0 & 593.8 \\ 2025 & 16.88 & 1,380.0 & 651.4 & 0.47 & 0.48 & 0.29 & 0 & 651.4 \\ 2030 & 17.07 & 1,530.7 & 709.5 & 0.46 & 0.47 & 0.28 & 0 & 709.5\end{array}$

Sector - 3. Pulp and Paper

\begin{tabular}{llllllrll}
1990 & 15.01 & 28.14 & 316.7 & 11.26 & \multicolumn{1}{c}{0} & 9.57 & 139.3 & 177.3 \\
1995 & 15 & 30.92 & 359.0 & 11.61 & 11.16 & 10.36 & 157.9 & 201.0 \\
2000 & 14.98 & 34.21 & 410.9 & 12.01 & 11.73 & 10.52 & 180.8 & 230.1 \\
2005 & 15.6 & 36.63 & 408.6 & 11.16 & 12.1 & 9.21 & 179.8 & 228.8 \\
2010 & 16.2 & 39.51 & 429.3 & 10.87 & 11.2 & 9.37 & 188.9 & 240.4 \\
2015 & 16.45 & 41.35 & 448.9 & 10.86 & 10.9 & 9.56 & 197.5 & 251.3 \\
2020 & 16.69 & 42.92 & 469.3 & 10.93 & 10.88 & 9.75 & 206.5 & 262.8 \\
2025 & 16.88 & 44.52 & 491.8 & 11.05 & 10.96 & 9.87 & 216.4 & 275.4 \\
2030 & 17.07 & 45.85 & 510.6 & 11.14 & 11.06 & 9.97 & 224.6 & 285.9
\end{tabular}

Sector - 4. Inorganics

$\begin{array}{llllllrll}1990 & 15.01 & 19.02 & 202.5 & 10.65 & 0 & 9.05 & 29.7 & 172.7 \\ 1995 & 15 & 19.41 & 221.6 & 11.42 & 10.53 & 10.16 & 32.5 & 189.0 \\ 2000 & 14.98 & 19.94 & 244.6 & 12.27 & 11.57 & 10.75 & 35.9 & 208.6 \\ 2005 & 15.6 & 20.01 & 236.6 & 11.82 & 12.39 & 9.74 & 34.7 & 201.8 \\ 2010 & 16.2 & 20.24 & 240.4 & 11.88 & 11.88 & 10.22 & 35.3 & 205.0 \\ 2015 & 16.45 & 20.16 & 245.6 & 12.19 & 11.92 & 10.72 & 36.1 & 209.5 \\ 2020 & 16.69 & 19.91 & 249.8 & 12.55 & 12.22 & 11.2 & 36.7 & 213.0 \\ 2025 & 16.88 & 20.14 & 259.1 & 12.87 & 12.58 & 11.57 & 38.1 & 221.0 \\ 2030 & 17.07 & 20.23 & 264.5 & 13.08 & 12.89 & 11.86 & 38.8 & 225.6\end{array}$


TABIE 5.5 (Cont)

\begin{tabular}{|c|c|c|c|c|c|c|c|c|}
\hline Year & $\mathrm{Pe}$ & $\mathbf{Q}$ & $\mathbf{E e}$ & EIe & PEIe & IEIe & SGUE & PURCHE \\
\hline \multicolumn{9}{|c|}{ Sector - 5. Organics } \\
\hline 1990 & 15.01 & 48.98 & 237.2 & 4.84 & 0 & 4.12 & 70.2 & 167 \\
\hline 1995 & 15 & 52.52 & 272.9 & 5.2 & 4.8 & 4.62 & 80.7 & 192.1 \\
\hline 2000 & 14.98 & 56.7 & 314.6 & 5.55 & 5.24 & 4.87 & 93.1 & 221.5 \\
\hline 2005 & 15.6 & 59.22 & 315.0 & 5.32 & 5.59 & 4.4 & 93.2 & 221.7 \\
\hline 2010 & 16.2 & 62.32 & 331.8 & 5.32 & 5.34 & 4.61 & 98.2 & 233.6 \\
\hline 2015 & 16.45 & 65.23 & 355.1 & 5.44 & 5.34 & 4.82 & 105.1 & 250 \\
\hline 2020 & 16.69 & 67.71 & 378.3 & 5.59 & 5.46 & 5.03 & 112 & 266.3 \\
\hline 2025 & 16.88 & 70.22 & 401.2 & 5.71 & 5.6 & 5.18 & 118.7 & 282.4 \\
\hline 2030 & 17.07 & 72.33 & 418.7 & 5.79 & 5.72 & 5.3 & 123.9 & 294.7 \\
\hline \multicolumn{9}{|c|}{ Sector - 6. Petroleum Refining } \\
\hline 1990 & 15.01 & 27.21 & 154.8 & 5.69 & 0 & 4.84 & 34.5 & 120.3 \\
\hline 1995 & 15 & 27.09 & 162 & 5.98 & 5.52 & 5.43 & 36.1 & 125.8 \\
\hline 2000 & 14.98 & 27.14 & 178.2 & 6.57 & 6.19 & 5.74 & 39.7 & 138.5 \\
\hline 2005 & 15.6 & 26.97 & 173.2 & 6.42 & 6.73 & 5.2 & 38.6 & 134.5 \\
\hline 2010 & 16.2 & 27.01 & 175.4 & 6.49 & 6.49 & 5.46 & 39.1 & 136.2 \\
\hline 2015 & 16.45 & 26.23 & 175.6 & 6.7 & 6.55 & 5.73 & 39.1 & 136.4 \\
\hline 2020 & 16.69 & 25.27 & 174.8 & 6.92 & 6.74 & 5.98 & 38.9 & 135.8 \\
\hline 2025 & 16.88 & 24.3 & 173.0 & 7.12 & 6.96 & 6.18 & 38.5 & 134.4 \\
\hline 2030 & 17.07 & 23.22 & 168.2 & 7.25 & 7.14 & 6.34 & 37.5 & 130.7 \\
\hline \multicolumn{9}{|c|}{ Sector - 7. Glass } \\
\hline 1990 & 15.01 & 10.08 & 37.4 & 3.72 & 0 & 3.34 & 0.56 & 36.8 \\
\hline 1995 & 15 & 10.03 & 39.9 & 3.98 & 3.68 & 3.75 & 0.6 & 39.3 \\
\hline 2000 & 14.98 & 10.05 & 43.1 & 4.3 & 4.03 & 3.96 & 0.65 & 42.5 \\
\hline 2005 & 15.6 & 9.99 & 42.0 & 4.21 & 4.33 & 3.59 & 0.63 & 41.3 \\
\hline 2010 & 16.2 & 10 & 42.6 & 4.26 & 4.22 & 3.77 & 0.64 & 42.0 \\
\hline 2015 & 16.45 & 9.96 & 43.6 & 4.39 & 4.28 & 3.95 & 0.66 & 43.0 \\
\hline 2020 & 16.69 & 9.84 & 44.5 & 4.52 & 4.4 & 4.12 & 0.67 & 43.8 \\
\hline 2025 & 16.88 & 9.95 & 46.1 & 4.64 & 4.53 & 4.26 & 0.69 & 45.4 \\
\hline 2030 & 17.07 & 10 & 47.1 & 4.72 & 4.64 & 4.36 & 0.71 & 46.4 \\
\hline \multicolumn{9}{|c|}{ Sector - 8. Cement } \\
\hline 1990 & 15.01 & 2.2 & 32.5 & 14.82 & 0 & 11.86 & 0.49 & 32.0 \\
\hline 1905 & 15 & 2.22 & 35.2 & 15.9 & 14.6 & 13.31 & 0.53 & 34.7 \\
\hline 2000 & 14.98 & 2.26 & 38.7 & 17.15 & 16.18 & 14.21 & 0.58 & 38.1 \\
\hline 2005 & 15.6 & 2.24 & 37.0 & 16.52 & 17.37 & 13.37 & 0.56 & 36.4 \\
\hline 2010 & 16.2 & 2.25 & 37.3 & 16.62 & 16.61 & 14.13 & 0.56 & 36.7 \\
\hline 2015 & 16.45 & 2.24 & 38.2 & 17.1 & 16.7 & 14.88 & 0.57 & 37.6 \\
\hline 2020 & 16.69 & 2.21 & 38.9 & 17.65 & 17.16 & 15.59 & 0.58 & 38.4 \\
\hline 2025 & 16.88 & 2.23 & 40.5 & 18.14 & 17.71 & 16.15 & 0.61 & 39.9 \\
\hline 2030 & 17.07 & 2.24 & 41.4 & 18.46 & 18.18 & 16.59 & 0.62 & 40.8 \\
\hline
\end{tabular}


TABLE 5.5 (Cont.)

\begin{tabular}{|c|c|c|c|c|c|c|c|c|}
\hline Year & $\mathrm{Pe}$ & $\mathbf{Q}$ & Ee & EIe & PEIe & IEIe & SGUE & PURCHE \\
\hline \multicolumn{9}{|c|}{ Sector - 9. Stone and Clay } \\
\hline 1990 & 15.01 & 21.86 & 47.3 & 2.16 & 0 & 1.73 & 0.71 & 46.6 \\
\hline 1995 & 15 & $2 z .31$ & 51.2 & 2.3 & 2.14 & 1.91 & 0.77 & 50 \\
\hline 2000 & 14.98 & 22.92 & 55.9 & 2.44 & 2.33 & 2.02 & 0.84 & 55 \\
\hline 2005 & 15.6 & 23.35 & 54.1 & 2.32 & 2.47 & 1.88 & 0.8 & 53 \\
\hline 2010 & 16.2 & 23.98 & 55.2 & 2.31 & 2.33 & 1.96 & 0.83 & 54 \\
\hline 2015 & 16.45 & 24.12 & 56.7 & 2.35 & 2.32 & 2.05 & 0.85 & 55 \\
\hline 2020 & 16.69 & 24.06 & 57.9 & 2.41 & 2.36 & 2.13 & 0.87 & 57 \\
\hline 2025 & 16.88 & 24.33 & 59.9 & 2.46 & 2.42 & 2.19 & 0.9 & 59 \\
\hline 2030 & 17.07 & 24.45 & 61.0 & 2.5 & 2.47 & 2.24 & 0.92 & \\
\hline
\end{tabular}

Sector - 10. Iron and Steel

$\begin{array}{lllllllll}1990 & 15.01 & 32.61 & 241.8 & 7.42 & 0 & 6.67 & 24.9 & 216.9 \\ 1995 & 15 & 32.79 & 265.5 & 8.1 & 7.31 & 7.6 & 27.3 & 238.1 \\ 2000 & 14.98 & 33.18 & 2967 & 8.94 & 8.22 & 8.17 & 30.5 & 266.1 \\ 2 \text { D0. } & 15.6 & 32.98 & 291.9 & 8.85 & 9.04 & 7.3 & 30.0 & 261.8 \\ 2010 & 16.2 & 33.02 & 299.9 & 9.08 & 8.9 & 7.78 & 30.8 & 269.0 \\ 2015 & 16.45 & 32.88 & 308.4 & 9.38 & 9.12 & 8.29 & 31.7 & 276.7 \\ 2020 & 16.69 & 32.48 & 315.2 & 3.71 & 9.41 & 8.71 & 32.4 & 282.8 \\ 2025 & 16.88 & 32.85 & 328.2 & 9.99 & 9.73 & 9.03 & 33.8 & 294.4 \\ 2030 & 17.07 & 33 & 335.9 & 10.18 & 10.01 & 9.28 & 34.6 & 301.3\end{array}$

Sector - 11. Primary Aluminun:

$\begin{array}{lllllllll}1990 & 15.01 & 2.2 & 219.6 & 99.63 & 0 & 94.64 & 2.42 & 217.2 \\ 1995 & 15 & 2.79 & 216.7 & 98.75 & 99.2 & 95.12 & 2.38 & 214.3 \\ 2000 & 14.98 & 2.2 & 216.3 & 98.39 & 99.27 & 93.76 & 2.38 & 214 \\ 2005 & 15.6 & 2.13 & 200.4 & 94.04 & 98.8 & 87.23 & \mathbf{2} .2 & 198.2 \\ 2010 & 16.2 & 2.08 & 191.1 & 91.84 & 94.23 & 86.41 & 2.1 & 189.0 \\ 2015 & 16.45 & 1.97 & 179.0 & 90.84 & 92.01 & 85.93 & 1.97 & 177.1 \\ 2020 & 16.69 & 1.85 & 167.3 & 90.38 & 90.97 & 85.68 & 1.84 & 165.4 \\ 2025 & 16.88 & 1.78 & 160.5 & 90.16 & 90.49 & 85.41 & 1.77 & 158.8 \\ 2030 & 17.07 & 1.7 & 153.0 & 89.96 & 96.24 & 85.19 & 1.68 & 151.3\end{array}$

Sector - 12. Nonferrous

$\begin{array}{lllllllll}1990 & 15.01 & 18.55 & 74.3 & 4.01 & 0 & 3.41 & 0.82 & 73.5 \\ 1995 & 15 & 18.46 & 78.9 & 4.27 & 3.98 & 3.82 & 0.87 & 78.0 \\ 2000 & 14.98 & 18.5 & 83.9 & 4.54 & 4.31 & 4.01 & 0.92 & 82.9 \\ 2005 & 15.6 & 17.93 & 77.4 & 4.32 & 4.57 & 3.6 & 0.85 & 76.5 \\ 2010 & 16.2 & 17.51 & 75.2 & 4.3 & 4.33 & 3.74 & 0.83 & 74.3 \\ 2015 & 16.45 & 16.58 & 72.3 & 4.36 & 4.31 & 3.89 & 0.8 & 71.5 \\ 2020 & 16.69 & 15.57 & 69.9 & 4.49 & 4.37 & 4.03 & 0.77 & 69.1 \\ 2025 & 16.88 & 1.98 & 68.9 & 4.6 & 4.5 & 4.17 & 0.76 & 68.2\end{array}$


TABLE 5.5 (Cont.)

\begin{tabular}{rrrrrrrrr}
\hline Year & Pe & Q & Ee & Ele & PEIe & IEIe & SGUE & PURCHE \\
\hline 2030 & 17.07 & 14.31 & 66.93 & 4.68 & 4.61 & 4.27 & 0.74 & 66.19 \\
\multicolumn{2}{l}{ Sector } & 13. Agriculture & & & & & & \\
1990 & 15.01 & 113.5 & 100.8 & 0.89 & 0 & 0.71 & 0 & 100.8 \\
1995 & 15 & 118.7 & 107.6 & 0.9 & 0.88 & 0.78 & 0 & 107.3 \\
2000 & 14.98 & 125.0 & 115.9 & 0.93 & 0.92 & 0.76 & 0 & 115.9 \\
2005 & 15.6 & 130.6 & 102.2 & 0.78 & 0.94 & 0.52 & 0 & 102.2 \\
2010 & 16.2 & 137.4 & 98.7 & 0.72 & 0.79 & 0.51 & 0 & 98.7 \\
2015 & 16.45 & 140.3 & 97.7 & 0.7 & 0.72 & 0.52 & 0 & 97.7 \\
2020 & 16.69 & 142.1 & 98.4 & 0.69 & 0.7 & 0.52 & 0 & 98.4 \\
2025 & 16.88 & 147.3 & 102.2 & 0.69 & 0.69 & 0.53 & 0 & 102.2 \\
2030 & 17.07 & 151.7 & 105.1 & 0.69 & 0.7 & 0.53 & 0 & 105.1
\end{tabular}

Sector - 14. Mining

$\begin{array}{lllllllll}1990 & 15.01 & 24.6 & 152.9 & 6.22 & 0 & 4.97 & 7.65 & 145.2 \\ 1995 & 15 & 24.49 & 157.9 & 6.45 & 6.16 & \mathbf{5 . 5 5} & \mathbf{7 . 9} & \mathbf{1 5 0 . 0} \\ 2000 & 14.98 & 24.54 & 163.2 & 6.65 & \mathbf{6 . 5 1} & \mathbf{5 . 4 7} & \mathbf{8 . 1 6} & \mathbf{1 5 5 . 0} \\ 2005 & 15.6 & 24.38 & 138.0 & \mathbf{5 . 6 6} & 6.7 & 3.78 & 6.9 & 131.1 \\ 2010 & 16.2 & 24.41 & 127.8 & \mathbf{5 . 2 4} & \mathbf{5 . 6 8} & 3.78 & 6.39 & \mathbf{1 2 1 . 4} \\ 2015 & 16.45 & 23.71 & 121.2 & \mathbf{5 . 1 1} & \mathbf{5 . 2 5} & \mathbf{3 . 8 4} & \mathbf{6 . 0 6} & \mathbf{1 1 5 . 1} \\ 2020 & 16.69 & 22.84 & 116.6 & \mathbf{5 . 1 1} & \mathbf{5 . 1 2} & 3.92 & \mathbf{5 . 8 3} & \mathbf{1 1 0 . 8} \\ 2025 & 16.88 & 21.97 & 112.9 & \mathbf{5 . 1 4} & \mathbf{5 . 1 2} & 3.97 & \mathbf{5 . 6 5} & 107.2 \\ 2030 & 17.07 & 20.99 & 107.9 & \mathbf{5 . 1 4} & \mathbf{5 . 1 5} & 4.01 & \mathbf{5 . 4} & \mathbf{1 0 2 . 5}\end{array}$

Sector - 15. Oil and Natural Gas

\begin{tabular}{|c|c|c|c|c|c|c|c|c|}
\hline 1990 & 15.01 & 55.7 & 96.8 & 1.74 & 0 & 1.39 & 4.84 & 91.9 \\
\hline 1995 & 15 & 55.44 & 98.7 & 1.78 & 1.7 & 1.55 & 4.94 & 93.7 \\
\hline 2000 & 14.98 & 55.55 & 103.5 & 1.86 & 1.82 & 1.53 & 5.18 & 98.3 \\
\hline 2005 & 15.6 & 53.84 & 86.2 & 1.6 & 1.9 & 1.06 & 4.31 & 81.9 \\
\hline 2010 & 16.2 & 52.58 & 78.2 & 1.49 & 1.62 & 1.06 & 3.91 & 74.3 \\
\hline 2015 & 16.45 & 51.06 & 74.4 & 1.46 & 1.5 & 1.07 & 3.72 & 70.7 \\
\hline 2020 & 16.69 & 49.18 & 71.8 & 1.46 & 1.47 & 1.1 & 3.59 & 68.2 \\
\hline 2025 & 16.88 & 47.31 & 69.7 & 1.47 & 1.47 & 1.11 & 3.49 & 66.2 \\
\hline 2030 & 17.07 & 45.2 & 66.7 & 1.48 & 1.48 & 1.12 & 3.34 & 63.4 \\
\hline
\end{tabular}

Sector - 16. Construction

$\begin{array}{lllllllll}1990 & 15.01 & 247.7 & 45.4 & 0.18 & 0 & 0.15 & 0 & 45.4 \\ 1995 & 15 & 252.7 & 47.7 & 0.19 & 0.18 & 0.16 & 0 & 47.7 \\ 2000 & 14.98 & 259.6 & 51.0 & 0.2 & 0.19 & 0.16 & 0 & 51.0 \\ 2005 & 15.6 & 264.5 & 44.5 & 0.17 & 0.2 & 0.11 & 0 & 44.5 \\ 2010 & 16.2 & 271.6 & 42.4 & 0.16 & 0.17 & 0.11 & 0 & 42.4 \\ 2015 & 16.45 & 277.3 & 42.3 & 0.15 & 0.16 & 0.11 & 0 & 42.3 \\ 2020 & 16.69 & 280.8 & 42.9 & 0.15 & 0.15 & 0.12 & 0 & 42.9\end{array}$


TABLE 5.5 (Cont.)

\begin{tabular}{|c|c|c|c|c|c|c|c|c|}
\hline Year & $\mathrm{Pe}$ & $\mathbf{Q}$ & $\mathrm{Ee}$ & EIe & PEIe & IEIe & SGUE & PURCHE \\
\hline $\begin{array}{l}2025 \\
2030\end{array}$ & $\begin{array}{l}16.88 \\
17.07\end{array}$ & $\begin{array}{l}284.0 \\
285.3\end{array}$ & $\begin{array}{l}43.7 \\
44.0\end{array}$ & $\begin{array}{l}0.15 \\
0.15\end{array}$ & $\begin{array}{l}0.15 \\
0.15\end{array}$ & $\begin{array}{l}0.12 \\
0.12\end{array}$ & $\begin{array}{l}0 \\
0\end{array}$ & $\begin{array}{l}43.7 \\
44.0\end{array}$ \\
\hline \multicolumn{9}{|c|}{ Sector - 17. Feedstocks } \\
\hline $\begin{array}{l}1990 \\
1995 \\
2000 \\
2005 \\
2010 \\
2015 \\
2020 \\
2025 \\
2030\end{array}$ & $\begin{array}{l}15.01 \\
15 \\
14.98 \\
15.6 \\
16.2 \\
16.45 \\
16.69 \\
16.88 \\
17.07\end{array}$ & $\begin{array}{l}10 \\
10.77 \\
11.61 \\
12.2 \\
12.82 \\
13.47 \\
14.16 \\
14.52 \\
14.88\end{array}$ & $\begin{array}{l}0 \\
0 \\
0 \\
0 \\
0 \\
0 \\
0 \\
0 \\
0\end{array}$ & $\begin{array}{l}0 \\
0 \\
0 \\
0 \\
0 \\
0 \\
0 \\
0 \\
0\end{array}$ & $\begin{array}{l}0 \\
0 \\
0 \\
0 \\
0 \\
0 \\
0 \\
0 \\
0\end{array}$ & $\begin{array}{l}0 \\
0 \\
0 \\
0 \\
0 \\
0 \\
0 \\
0 \\
0\end{array}$ & $\begin{array}{l}0 \\
0 \\
0 \\
0 \\
0 \\
0 \\
0 \\
0 \\
0\end{array}$ & $\begin{array}{l}0 \\
0 \\
0 \\
0 \\
0 \\
0 \\
0 \\
0 \\
0\end{array}$ \\
\hline \multicolumn{9}{|c|}{ Sector - 18. Uranium } \\
\hline $\begin{array}{l}1990 \\
1995 \\
2000 \\
2005 \\
2010 \\
2015 \\
2020 \\
2025 \\
2030 \\
\end{array}$ & $\begin{array}{l}15.01 \\
15 \\
14.98 \\
15.6 \\
16.2 \\
16.45 \\
16.69 \\
16.88 \\
17.07 \\
\end{array}$ & $\begin{array}{l}10 \\
10 \\
10 \\
10 \\
10 \\
10 \\
10 \\
10 \\
10 \\
\end{array}$ & $\begin{array}{l}92 \\
92 \\
92 \\
92 \\
92 \\
92 \\
92 \\
92 \\
92 \\
\end{array}$ & $\begin{array}{l}9.2 \\
9.2 \\
9.2 \\
9.2 \\
9.2 \\
9.2 \\
9.2 \\
9.2 \\
9.2 \\
\end{array}$ & $\begin{array}{l}0 \\
9.2 \\
9.2 \\
9.2 \\
9.2 \\
9.2 \\
9.2 \\
9.2 \\
9.2 \\
\end{array}$ & $\begin{array}{l}9.2 \\
9.2 \\
9.2 \\
9.2 \\
9.2 \\
9.2 \\
9.2 \\
9.2 \\
9.2 \\
\end{array}$ & $\begin{array}{l}0 \\
0 \\
0 \\
0 \\
0 \\
0 \\
0 \\
0 \\
0 \\
\end{array}$ & $\begin{array}{l}92 \\
92 \\
92 \\
92 \\
92 \\
92 \\
92 \\
92 \\
92 \\
\end{array}$ \\
\hline
\end{tabular}

a See Table 5.2 for definitions of quantities.

for 1990-2030. The total electricity consumption in 2030 is 4.4 quads, ${ }^{*}$ while for the base case it is 6.1 quads. This difference equals a savings of 1.7 quad/yr in 2030, which corresponds to $57 \mathrm{GW}$ of average electricity consumption. (Industrial electricity consumption in 1990 was 2.98 quads, which corresponds to $100 \mathrm{GW}$ of average electricity consumption.) Secondary impacts of these electricity savings on industrial growth and electricity prices have not been taken into consideration.

The Divisia analysis shows that the overall effect of the DSM program is to reduce the index of real electricity intensity from its base-case value of $I_{I}=1.28$ to $I_{I}=0.95$, a $26 \%$ reduction, by 2030 . These savings are beyond the conservation induced in the base case in association with the $80 \%$ increase in fuel prices from 1990 to 2030 (Table 5.1). (Electricity prices are essentially unchanged over the period.) We consider this forecast to represent a highly successful DSM program - one that has overcome many challenges.

* 1 Quad $=10^{15}$ Btu. 
The conservation investment in the DSM scenario is roughly 10 times greater than in the base case (Table 5.6), with the peak value of $\$ 25$ billion in the period from 2000 to 2005. The total investment of $\$ 55$ billion above the amount spent in the base case is far less than the avoided investment of (very roughly) $\$ 300$ billion in new power facilities. However, the conservation investment as calculated does not include replacement of the conservation equipment or the cost of such equipment in new facilities that would replace retired production facilities in the same sector. Thus, the conservation investment shown in Table 5.6 may underestimate the total cumulative investment by a factor of two, or perhaps three, by 2030 . Table 5.7 breaks down electricity intensity into the Divisia decomposition index. 


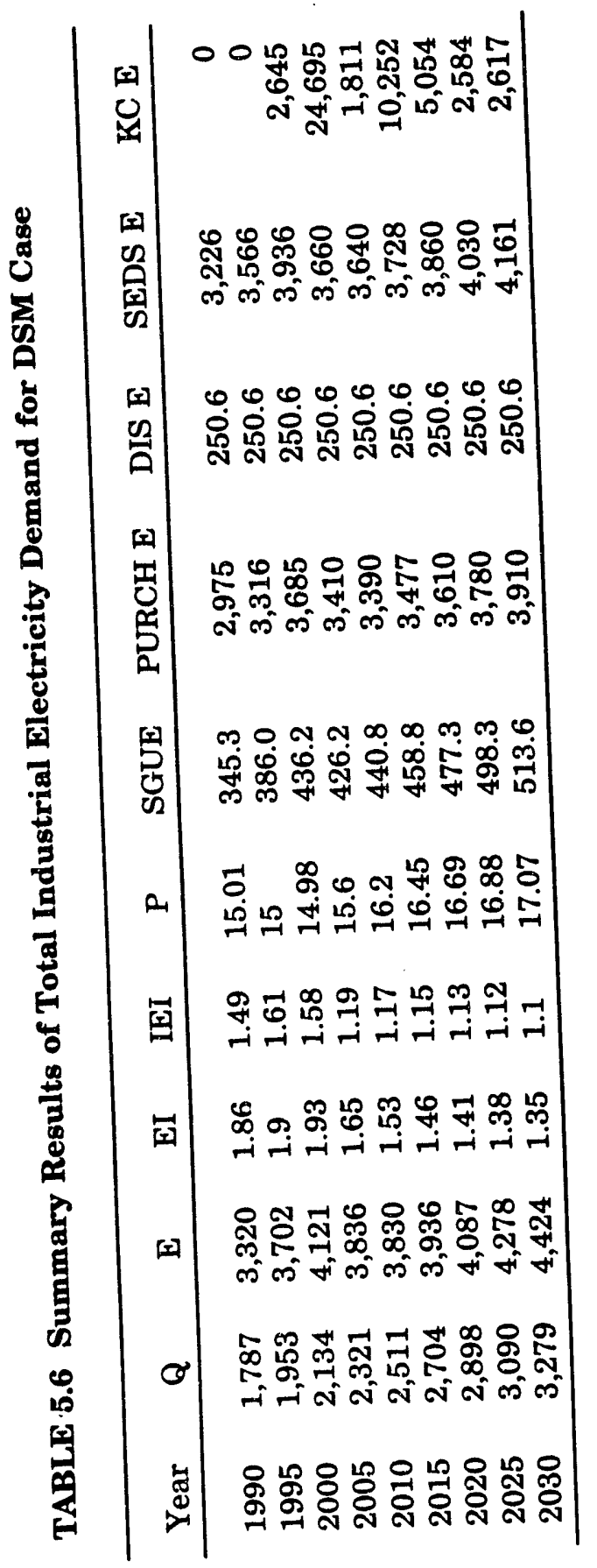


TABLE 5.7 Divisia Decomposition of Electricity for DSM Case (all industry)

\begin{tabular}{llllll}
\hline Year & \multicolumn{1}{c}{$\mathrm{I}_{\mathrm{E}}$} & \multicolumn{1}{c}{$\mathrm{I}_{\mathrm{Q}}$} & \multicolumn{1}{c}{$\mathrm{I}_{\mathrm{S}}$} & \multicolumn{1}{c}{$\mathrm{I}_{\mathrm{I}}$} & $\mathrm{I}_{\mathrm{Q}}{ }^{*} \mathrm{I}_{\mathrm{S}}{ }^{*} \mathrm{I}_{\mathrm{I}}$ \\
\hline 1990 & 1 & 1 & 1 & 1 & 1 \\
1995 & 1.114 & 1.092 & 0.970 & 1.051 & 1.114 \\
2000 & 1.241 & 1.194 & 0.944 & 1.099 & 1.239 \\
2005 & 1.155 & 1.298 & 0.909 & 0.975 & 1.152 \\
2010 & 1.536 & 1.404 & 0.880 & 0.929 & 1.149 \\
2015 & 1.185 & 1.512 & 0.846 & 0.923 & 1.181 \\
2020 & 1.230 & 1.621 & 0.811 & 0.932 & 1.226 \\
2025 & 1.288 & 1.728 & 0.786 & 0.944 & 1.283 \\
2030 & 1.332 & 1.834 & 0.761 & 0.949 & 1.327 \\
\hline
\end{tabular}




\section{ISSUES IN INDUSTRIAL MODELING WITH LIEF}

\subsection{SECTOR DISAGGREGATION DATA}

Forecasts of industrial electricity consumption vary strongly with the disaggregation of fabrication and assembly manufacturing, as discussed in Section 2.1. Separating the fastgrowing industries (a certain set of essentially three-digit sectors) can lead to a forecast that is very different from conventional forecasting based on two-digit SICs. In particular, if the LIEF user adopts the scenario that electricity intensity will not rise autonomously in sector 2 , the long-term forecast for electricity will be much lower than with a conventional forecast.

The historical forecasts described in Section 4 represent an experienced modeling effort. Two major problems that confront the novice are that the data (NES energy series and BLS output series) have flaws and the energy intensities are strongly capacity-utilization dependent. The result of the latter dependence is opposite from what is expected: recessions induce energy intensities to rise. Since the two most serious recessions were associated with energy price rises, a problem is apparent. With the LIEF historical forecasts, two steps are taken to ease these difficulties: alternative data series are freely adopted, and five-year running average energy intensities are fit. Only for these reasons do satisfactory parameters arise from the fits.

The historical analysis nevertheless has the disconcerting quality that, for all the individual-industry sectors (as opposed to aggregate sectors, such as sectors 1 and 2), physical output data and ASM total-electricity data, rather than the general BLS output and NEA purchased electricity series, are substantially different and often strongly preferred (Table 4.1). Therefore, problems exist with the general data series, as discussed in Section 3.2. Thisse problems tend to be hidden when industries are aggregated.

Similar difficulties will probably beset historical analysis of the chemical industry sectors (not yet done as of this report) and any further disaggregation of other energyintensive industries beyond the 18 sectors. The implications for forecasting are also disturbing. An important issue is determining the measure of output that should be used to convert the forecast energy intensities into energy consumption.

\subsection{ECONOMETRIC VS. ENGINEERING ANALYSIS}

Three important issues are (1) different categorizations of production technology, (2) econometric vs. engineering relationships, and (3) modeling of vintage effects.

\subsubsection{Categories of Technical Change}

Critically important to modeling is the decision to adopt new or modified production technology. The nature and locus of the decision are strongly affected by a project's characteristics, especially its size and its role in terms of business (Ross 1987). Large 
projects are the responsibility of top management, while smaller projects are primarily the responsibility of plant managers (at most large corporations). The evaluation of smaller costcutting projects is quite different from that of larger projects that are strategic in a business sense, which involve new products, markedly improved product quality, new geographical markets, and new relationships between inputs and outputs.

In LIEF, only the most basic categorization of technologies is made. This categorization of technologies is the same as that made, in effect, in the simplest econometric models: fundamental developments in production technology (which depend on production experience and are insensitive to price variations) and technical change in response to price changes. Even though this concept is very simple, it needs to be examined. The essential fact is that most of the fundamental production-process decisions are not price sensitive. The key elements of the steel mill, paper mill, or petroleum refinery of the future will depend on market advantages such as quality, variety of products, and overall efficiency. Narrowly specified cost advantages, like those related to energy, only affect details of the decision (e.g., plant location and detailed specifications). LIEF, or any other energy model, cannot describe the basic decision to adopt or not to adopt strategic technologies.

On the other hand, with only two categories of technology in LIEF, it turns out that the price-sensitive category is not confined to projects, such as insulation and heat recovery, where the sole purpose is energy conservation. Many multipurpose projects include energy cost analysis as an important part of the decision, in part because energy use can be reliably analyzed. Since the early 1970 s, it has become clear that projects like automatic process controls, which may improve product throughput, reliability of production, and product quality, as well as save energy, are often more important from an energy perspective than those where energy savings are the sole purpose. Multipurpose projects where energy benefits are important to the decision are part of the conservation supply curve represented in LIEF.

\subsubsection{Econometric vs. Engineering Relationships}

Econometric models are often designed so that, in statistical analysis of historical data, the results have clear statistical interpretation. In the simplest models, the relations are statistically convenient and the parameters are relatively few: own-price and cross-price elasticities for energy forms and a time (or cumulative production) trend. The form of the relationships does not simulate actual decision making. Nevertheless, in this approach parameters are determined from actual historical behavior.

An advantage of the "bottom-up" engineering approach is that it simulates some aspects of investment decision making in detail, and thus contains several policy-related handles. However, a credible engineering model for any industrial sector would have many sector-specific technologies and would be laborious to construct and maintain. Even with a large modeling budget, credibility would be severely in question. With this kind of modeling, the tendency has been to exaggerate the energy-cost-savings opportunity represented by a few 
favorable technologies, while leaving out most of the significant technologies. A conservation supply curve (Figure 2.2) is not really meaningful if it is constructed in this way.

LIEF is a hybrid model that attempts to capture some essential qualities of the engineering approach by adopting the CSC form but parameterizing it very simply, leaving out explicit reference to technologies. Many policy handles are retained. LIEF also attempts to capture an advantage of econometric models - historical determination of parameters. As modeled in this report, too many parameters exist to determine them all within narrow bounds from the kind of aggregate historical analysis done here. We are optimistic that by adopting reasonable relations among some of the parameters and, perhaps, through use of historical data at the plant level (Bock et al. 1992), it will be possible to determine the parameters accurately from historical data.

\subsubsection{Vintage of Production Facilities}

LIEF, as developed so far, does not differentiate explicitly between the energy intensity of production in new and old facilities. This simplification is important. Some econometric models explicitly account for vintage and for the greater difficulty of retrofitting an existing facility in response to an energy price increase, rather than incorporating changes in a new facility (Peck et al. 1988). Such models tend to involve sweeping assumptions or to include more parameters than are appropriate for aggregate analysis.

Bottom-up engineering models can, in principle, explicitly account for the different opportunities and costs involved in responding to an energy price increase in an old facility and responding to the same price increase in a new facility.

In a future revision, LIEF should address the vintage issue in industries where good vintage information can be obtained (Bock et al. 1992). The hopes are that, with judicious modeling, some of the present parameters will represent vintage effects that are directly interpretable and that new parameters will be determined with new information about vintage distributions and capital turnover practices.

\subsection{OTHER POTENTIAL MODIFICATIONS OF LIEF}

\subsubsection{Expanding the Detail Represented}

Forecasters and analysts need projections of energy use by fuel type and region, as well as associated emissions, for many purposes. Fuel allocation can be relatively soundly related to fuel price forecasts on the basis of economic or engineering approaches and need not be discussed further.

The potential for useful regional forecasting is substantially less than for national forecasting. Base-year data at the 18-sector level of disaggregation in LIEF are not complete and would require further development for a regional disaggregation of interest for 
environmental analysis. Forecasts of regional industrial activity in terms of the 18 LIEF sectors are also much less reliable than at the national level. This issue is not unique to LIEF. For many models, regionalization is achieved simply but crudely. Some models, however, incorporate base-year data with real geographic detail. Either approach could be followed in regionalization of LIEF.

Environmental coefficients by industrial subsector involve both fuel combustion and process-specific emissions that are not due to fuel combustion as such. Both vary with sector. In this situation a model can offer, even with rough estimates of the coefficients, a consistent picture - a forecast that will vary in a consistent manner with assumed patterns of future energy prices and regional industrial development. It would be better still if base-year regional energy and emissions data were reasonably accurate.

\subsubsection{Modifying Relationships in LIEF}

Within the structure of the current version of LIEF, particular relationships should be varied in order to improve model justification or to explore model sensitivity. We discuss three such relationships. The first is that for expected price (used in Equation B.12). Initially, the price trend used was:

$$
E P(t)=2 P(t-T) \cdot P(t-2 T) .
$$

Here $\operatorname{EP}(t)$ is the expected price in the period $t-T$ to $t$, and $T$ is the time interval of five years used in LIEF (Ross and Hwang 1992). Better historical results in periods of rapid price change, especially the price drop in the early 1980s, are obtained with Equation B.11:

$$
E P(t)=0.5 P(t)+P(t-T) \cdot 0.5 P(t-2 T),
$$

where the future price is partially anticipated. This issue merits further exploration.

The autonomous time trend, $\exp [-\mathrm{B}(\mathrm{t}) \times \mathrm{T}]$, during each time interval might be better expressed as a function of experience (e.g., by using cumulative production as the variable) rather than time. Cumulative production is the variable used in experience or learning curve analyses, and it is sensitive, as would seem desirable, to rapid growth.

The penetration rate, now estimated off-line, could be determined as a function, for example, of relative price change (Figure 4.4). The advantage is to eliminate adjustable parameters. The disadvantage is that some important energy-related motivation is not immediately price driven. An example is the natural gas shortages in the early 1970 s.

\subsubsection{Modeling Technologies Explicitly}

A major goal of industrial energy modeling is to assist U.S. Department of Energy research and development program managers in forecasting the potential benefits of a new technology. In its present form, LIEF generates energy forecasts for a group of disaggregated 
sectors, which is useful for this purpose. However, LIEF does not provide product/processspecific information about the applicability of a technology, nor does it model the decision to adopt a specific technology. As suggested in Section 6.2.1, at least two categories of technology should be considered. As just discussed (Section 6.2.1), energy models should not be used to analyze the decision to adopt a technology that is strategic in a business sense, although the model could keep accounts of the engineering potential. Decisions on energyprice-sensitive technology, on the other hand, can be modeled. While LIEF is not a model that incorporates technology details, it could be modified to accommodate any individual energy technology as an aspect of its parameterized CSC. The formalism for this is not included in the present version. 


\section{REFERENCES}

ACEEE (1990a). The Achievable Conservation Potential in New York State from Utility Demand-Side Management Programs. Prepared by American Council for an Energy Efficient Economy, principal investigators S. Nadel and H. Tress, Washington D.C., NYSERDA Report 90-18, Nov.

ACEEE (1990b). Lessons Learned: A Review of Utility Experience with Conservation and Load Management Programs for Commercial and Industrial Customers. Prepared by American Council for an Energy Efficient Economy, principal investigator S. Nadel, Washington D.C., NYSERDA Report 90-8, April.

ASM (1990 and earlier years). Annual Survey of Manufactures, Fuel and Electric Energy Cost. U.S. Bureau of the Census, Washington D.C.

Berg, C.A. (1978). "Process Innovation and Changes in Industrial Energy Use," Science 199: 608-614.

Berry, L. (1990). The Market Penetration of Energy-Efficiency Programs. Oak Ridge National Laboratory, ORNL/CON-299, April.

Berry, L. (1991). "The Administrative Costs of Energy Conservation Programs," Energy Systems and Policy, 15:1-21.

BLS (1989). Productivity Measures for Selected Industrial and Government Sectors, Bull. 2322. Office of Productivity and Technology, Bureau of Labor Statistics, Department of Labor, Washington D.C.

Bock, M.J., G.A. Boyd, S.H. Karlson, M.J. Niefer, and M.H. Ross (1992). Vintage-Level and Plant-Level Industrial Energy and Environmental Performance. A report to the U.S. Department of Energy, prepared by Argonne National Laboratory, Argonne, Ill.

Boyd, G., and S. Karlson (1993). "Impact of Energy Prices on Technology Choice in the U.S. Steel Industry," Energy Journal, 14(2).

Boyd, G., D. Hanson, and T. Sterner (1988). "Decomposition of Changes in Energy Intensity: A Comparison of the Divisia Index and Other Methods," Energy Economics, 10:309-312.

Boyd, G., E. Kokkelenberg, and M. Ross (1991). Sectoral Electricity and Fossil Fuel Demand in U.S. Manufacturing: Development of the Regional Activity and Energy Demand (INRAD) Model. Argonne National Laboratory, Argonne, Ill., ANL/EAIS/TM-35.

Boyd, G., J.F. McDonald, M. Ross, and D.A. Hanson (1987). "Separating the Changing Composition of U.S. Manufacturing Production from Energy Efficiency Improvements: A Divisia Index Approach," Energy Journal, 8:77-97. 
Boyd, G.A., S.H. Karlson, M.J. Niefer, and M.H. Ross (1992). "Potential for Steel Industry Energy Intensity Improvements: Electricity Use in Minimills," forthcoming in Contemporary Policy Issues.

Doblin, C.P. (1988). "Declining Energy Intensity in the U.S. Manufacturing Sector," The Energy Journal, 9(2):109-135.

DOC (1990a). Census of Manufactures. U.S. Department of Commerce, Bureau of the Census, Washington, D.C.

DOC (1990b). Census of Construction-Industry Series. U.S. Department of Commerce, Bureau of the Census, Washington, D.C.

DOC (1990c). Census of Mineral Industries. U.S. Department of Commerce, Bureau of the Census, Washington, D.C.

DOC (1990d). Census of Agriculture. U.S. Department of Commerce, Bureau of the Census, Washington, D.C.

DOC (1990e). Business Statistics. U.S. Department of Commerce, Washington, D.C.

DOE (1991). Limiting Net Greenhouse Gas Emissions in the United States: Volume I - Energy Technologies, Volume II - Energy Responses. U.S. Department of Energy. Eds. R. Bradley, E. Watts, and E. Williams, DOE/PE-0101.

DOE (1991/1992a). National Energy Strategy, First Edition. U.S. Department of Energy.

DOE (1991/1992b). Technical Annex 2. Integrated Analysis Supporting the National Energy Strategy: Methodology, Assumptions and Results. U.S. Department of Energy, DOE/S-0086P.

Edison Electric Institute (1988). Demand-Side Management: Volume 5 - Industrial Markets and Programs. Report to Electric Power Research Institute, EPRI-EA/EM-3597.

EGUMS (1989). EGUMS: Electric and Gas Utility Modeling System, Technical Documentation. Report by R. Ciliano, C. Lang, and F. Stern, RCG/Hagler, Bailly, Inc., Boulder, Co., to U.S. Environmental Protection Agency.

EIA (1990). Energy Consumption and Conservation Potential: Supporting Analysis for the National Energy Strategy. Energy Information Administration, U.S. Department of Energy, SR/NES/90-02.

Faruqui, A. (1987). "Utility Planning and Industrial Structural Change," The Changing Structure of American Industry and Energy Use Patterns. Eds. A. Faruqui and J. Broehl, Palo Alto, Calif., Battelle Press, Sept. 
Faruqui, A., and E. Haites (1991). "Impact of Efficient Electricity Use and DSM Programs on United States Electricity Demand and the Environment," Demand-Side Management and the Global Environment, April 22-23, Arlington, Va. Prepared by Synergic Resources Corporation, Bala Cynwyd, Penn.

Gellings, C., and T. Yau (1991). Demand-Side Management and Global Warming. Electric Power Research Institute, April 22.

Herman, R., S.A. Ardekani, and J.H. Ausubel (1989). "Dematerialization," Technology and Environment. Ed. J.H. Ausubel, Washington D.C., National Academy Press, 50-69.

Hirst, E. (1991). Possible Effects of Electricity Utility DSM Programs, 1990 to 2010. Oak Ridge National Laboratory, ORNL/CON-312.

Howarth, R. (1991). "Energy Use in U.S. Manufacturing: The Impacts of the Energy Shocks on Sectoral Output, Industry Structure, and Energy Intensity," The Journal of Energy and Development, 14 (2):175-191.

Huntington, H., and J. Myers (1987). "Sectoral Shift and Industrial Energy Demand: What Have We Learned?" The Changing Structure of American Industry and Energy Use Patterns. Eds. A. Faruqui and J. Broehl, Palo Alto, Calif., Battelle Press, 353-388.

Hwang, R., and M. Ross (1992). "Reducing Energy Demand and Carbon Emissions from U.S. Manufacturing, an Application of LIEF." Lawrence Berkeley Laboratory (draft).

ISTUM (1982). ISTUM-2 Industrial Sector Technology Use Model (Vols. 1-8). Energy and Environmental Analysis, Inc., Arlington, Va.

Kahane, A., and R. Squitieri (1987). "Electricity Use in Manufacturing," Annual Review of Energy, 12:233-51.

Karlson, S.H. (1990). "The Impact of Energy Prices on Technology Choice in the United States Steel Industry." Working Paper, Department of Economics, Northern Illinois University, DeKalb, Ill.

Krause, F., and J. Eto (1988). Least-Cost Utility Planning Handbook for Public Utility Commissioners, Volume 2 - The Demand Side: Conceptual and Methodological Issues. Prepared for the National Association of Regulatory Utility Commissioners by Lawrence Berkeley Laboratory, Dec.

Larsen, W. (1990). Energy Conservation in Petroleum Refining. Ph.D. dissertation, Physics Department, University of Michigan.

Marlay, R.C. (1984). "Trends in Industrial Use of Energy," Science, 226:1277-1283. 
Marlay, R.C. (1987). "Industrial Electricity Consumption and Changing Economic Conditions," The Changing Structure of American Industry and Energy Use Patterns. Eds. A. Faruqui and J. Broehl, Palo Alto, Calif., Battelle Press, 77-111.

Meier. A., J. Wright, and A.H. Rosenfeld (1983). Supplying Energy through Greater Efficiency. Berkeley and Los Angeles, University of California Press.

NEA (1988). National Energy Accounts 1958-1985. Jack Faucett Associates, prepared for the U.S. Department of Commerce, Washington D.C.

NRC (1991). Policy Implications of Greenhouse Warming. Report of the Mitigation Panel. National Research Council, Washington D.C., National Academy Press.

OTA (1991). Changing by Degrees: Steps to Reduce Greenhouse Gases, Chapter 6 - The Manufacturing Sector. Office of Technology Assessment, U.S. Congress.

Peck, S., et al. (1988). "Industrial Energy Demand: A Simple Structural Approach," Resources and Energy, 10:1-23.

Ross, M. (1986). "Capital Budgeting Practices of Tweive Large Manufacturers," Financial Management, Winter:15-22.

Ross, M. (1987). "Industrial Energy Conservation and the Steel Industry of the United States," Energv, 12(10/11):1135-1152.

Ross, M. (1990). Conservation Supply Curves for Manufacturing. 25th Intersociety Energy Conversion Engineering Science Conference, American Institute of Chemical Engineers, New York, N.Y.

Ross, M. (1991). "The Potential for Reducing the Energy Intensity and Carbon Dioxide Emissions in U.S. Manufacturing," The Energy Sourceboor. A Guide to Technology, Resources, and Policy. Eds. R. Howes and A. Fainberg, New York, N.Y., American Institute of Physics.

Ross, M., and R. Fisher (1991). Will Energy Consumption Grow in the Long-Term? University of Michigan, Ann Arbor, Dec. 18 (draft).

Ross, M., and R. Hwang (1992). A Model for Long-term industrial Energy Forecasting. Lawrence Berkeley Laboratory, LBL-31861, Feb.

SCB (1991). Survey of Current Business. U.S. Department of Commerce, Washington, D.C., July.

Solow, R.M. (1957). "Technical Change and the Aggregate Reduction Function," The Review of Economics and Statistics, 39:312-320. 
Steinmeyer, D. (1990). "Learn From Energy Conservation," Hydrocarbon Processing, Aug., 57-59.

Williams, R.H., E.D. Larsen, and M.H. Ross (1987). "Materials, Affluence, and Industrial Energy Use," Annual Review of Energy, 12: 99-144. 


\section{APPENDIX A:}

\section{LIEF USER'S MANUAL}

\section{A.1 LIEF HARDWARE REQUIREMENTS}

The 18-sector Long-term Industrial Energy Forecasting (LIEF) model is a personal computer (PC)-based model programmed in $\mathrm{C}++$ language. The model comes compiled and runs under DOS or Microsoft Windows. LIEF requires $640 \mathrm{~K}$ of random access memory (RAM) and approximately $500 \mathrm{~K}$ of clisk space (either on a floppy disk or a hard drive). The disk space required depends on the number of scenarios being run. LIEF requires $250 \mathrm{~K}$ of disk space, and each scenario requires approximately $200 \mathrm{~K}$, if input and output files are saved. LIEF can run on IBM XT, $286,386,486$, or any PC clone machines.

The source code to LIEF can be obtained from Argonne National Laboratory (ANL) if you want to modify the program. One rationale for reprogramming LIEF in $\mathrm{C}++$ is to enable you to experiment with key relationships, such as expected price, autonomous time irend (or a trend based on cumulative output instead of time), conservative supply curve (CSC) shape, and expression of penetration in terms of price changes and other variables. Modifications should only be made once you have experience running the model.

\section{A.2 LIEF INSTALLATION}

If you intend to run LIEF on a floppy disk, no installation is required. You only need to make a backup disk of the LIEF model in case the original disk is corrupted in the future. To run the model from the floppy disk, insert the disk into the drive, go to that drive, and type LIEF 1 <enter>. For example, if the disk is in the b drive, type b: <enter>, and at the b prompt, type LIEF1 <enter>. If the error message "bad command or file name" appears on the screen, you selected the wrong drive.

For hard-drive installations, make a directory on your hard drive named LIEF or whatever directory you prefer (MD LIEF), go to the LIEF directory (cd ILIEF), and copy all the files from the floppy disk to the hard drive. For example, type copy a: ${ }^{*} . *$ if the disk is in the a drive; otherwise, substitute the correct drive name. Once the files have been copied, type LIEF1 while in your new subdirectory to start the model. To run LIEF under Microsoft Windows, while in Windows select file new, file item. For the description, type LIEF, select browse, and select the LIEF1.exe file in your new subdirectory to execute. Also, change your working directory to your new LIEF subdirectory. Once this step is complete, double click the LIEF icon, and LIEF will run properly. Refer to the Windows manual for additional help.

LIEF is not copy protected. You are welcome to make backup copies of the model as well as distribute the model to other users. If you have problems running the model, contact Prakash Thimmapuram or Ron Fisher at (708) 252-9291 or (708) 252-3508, respectively. ANL also operates a bulletin board (BBS) to provide technical assistance to 
LIEF. If your files become corrupt, contact Thimmapuram or Fisher to establish an account on the BBS. The BBS is a closed system, so you must contact ANL to establish an account before dialing the system. The telephone number for the BBS is (708) 252-3954. The BBS also has a mail option to communicate LIEF problems and updates.

\section{A.3 RUNNING LIEF}

Once LIEF has been started, either by typing LIEF1 in DOS or double clicking the LIEF icon in Windows, the screen displays the beginning menu (Figure A.1).

Typing A, B, C, D, E, or Q takes you to different menus. The first step, however, is to select a scenario (A). The model is not case sensitive, so you can type either a lowercase or uppercase letter A. Type A <enter> to show the scenario menu (Figure A.2).

In the scenario menu, you can either create a new scenario or load an existing scenario. ANL has established a 1990 baseline case and recommends that you use this scenario. To load the baseline case, select $L$ to load a scenario; type <enter>, and after the

\begin{tabular}{|ll|}
\hline MAIN MENU & \\
Scenario & - A \\
Economy & - B \\
Sector & - C \\
Calculate & - D \\
Results & - E \\
Exit Model & - Q \\
& \\
Enter Your Selection - \\
\hline
\end{tabular}

FIGURE A.1 Opening

Screen of LIEF

\begin{tabular}{|c|c|}
\hline \multicolumn{2}{|c|}{ MAIN MENU } \\
\hline Create & $-\mathrm{C}$ \\
\hline Load & $-\mathrm{L}$ \\
\hline Save & $-\mathbf{S}$ \\
\hline Save As & $-\mathbf{A}$ \\
\hline Description & $-D$ \\
\hline Main Menu & $-\mathbf{M}$ \\
\hline Enter You & \\
\hline
\end{tabular}

FIGURE A.2 Scenario

Menu of LIEF 
prompt "Enter file name," type base90.dat <enter>. The baseline numbers will flash across the screen very quickly. These numbers are being loaded into RAM, and you can examine the parameters in a different screen, if desired.

After the numbers have been loaded, LIEF displays "Scenario was loaded successfully" on the screen followed by the scenario menu. If the "Scenario was loaded successfully" message is not displayed, reload the scenario. If you are still unsuccessful, there must be an error with the scenario file. The scenario file is on the ANL BBS and can be downloaded if corrupt.

At this point, if the model loaded the scenario correctly, you can run the model. If the parameters and economic assumptions are acceptable, go to the main menu (M) and select the calculate option (D). After the run is completed, refer to Figure A.7 for examining results of the model run.

The create option is available if you want to customize the model to operate with different base-year data or a different number of sectors. Substantial effort went into calibrating the baseline data for the 18-sector model, and the custom option should not be used unless a reduced sector model run is desired. This option is useful if you want to run many scenarios for one or a few of the sectors. The model runs much faster when you run only a subset of the sectors. It is not advisable to change the baseline data because they have been calibrated with various census and other government data sources.

The other options in the scenario menu are straightforward. If you changed the scenario and want to save the changes, select the save option (S). The save as option allows you to create a new scenario while leaving the old scenario unchanged. The description option allows you to type a description name for the scenario, and the main menu option returns you to the main menu screen.

After loading a scenario, go to the economy menu. At the main menu, type B <enter>. The menu on the screen should be similar to the one shown in Figure A.3.

If display is selected, Figure A.4 is displayed. The T is the incremental time period; with $\mathrm{T}=5$, the model runs in five-year increments. The base year is the reference year for a model run, which is 1990 for the data supplied. The fuel switch variable tells the model whether to allow fuel substitution between fossil fuels and electricity. If the fuel switch parameter is set at 0 , no fuel switching is allowed. If fuel switching is desired, the parameter should be set at 0.02 in initial runs. This value was determined from historical analysis. The parameter's range is approximately 0 to 0.03 .

Variables that vary by time are the growth rate for gross output of industry (G.Rate), the price of electricity (Elec.P), and the price of fossil fuel (FuelP). G.Rate is the percent per year growth, and the fuel prices are given in dollars per million Btu, with electrical energy converted at $3,413 \mathrm{Btu} / \mathrm{kWh}$. The energy price series starts one period before the base year. The heat rate represents the average heat rate and is used to create primary energy numbers for use in the fuel switching modeling. 


\begin{tabular}{|ll|}
\hline ECONOMY MENU & \\
Display & $-\mathrm{D}$ \\
Change & $-\mathrm{C}$ \\
Main Menu & $-\mathrm{M}$ \\
& \\
Enter Your Selection - \\
\hline
\end{tabular}

\section{FIGURE A.3 Economy} Menu of LIEF

\begin{tabular}{|c|c|c|c|}
\hline \multicolumn{4}{|c|}{$\begin{array}{l}T=5 \\
\text { Base Year }=1990 \\
\text { Fuel Switch }=0.02 \\
\text { Heat Rate }=3.33\end{array}$} \\
\hline Year & G.Rate & Elec.P & FuelP \\
\hline 1985 & & 13.100 & 3.410 \\
\hline 1990 & 0.000 & 11.000 & 2.400 \\
\hline 1995 & 1.800 & 10.880 & 2.650 \\
\hline 2000 & 1.800 & 11.310 & 3.470 \\
\hline 2005 & 1.700 & 11.790 & 4.310 \\
\hline 2010 & 1.600 & 12.280 & 5.150 \\
\hline 2015 & 1.500 & 12.330 & 5.480 \\
\hline 2020 & 1.400 & 12.380 & 5.820 \\
\hline 2025 & 1.300 & 12.430 & 6.040 \\
\hline 2030 & 1.200 & 12.470 & 6.250 \\
\hline 2035 & 1.100 & 12.510 & 6.460 \\
\hline
\end{tabular}

FIGURE A.4 Economy Display Screen of LIEF

A note of caution is warranted with regard to beginning the time series for each time-dependent input variable. In the input data file, data fields for all these variables are shown starting in $t_{o}-T$. Howaver, only the two price series are used starting in $t_{0}-T$. The CRF and $R_{i}$ series are used starting with $t_{0}$, and the pen, $G$, and $g_{i}$ series are used starting in $t_{o}+T$. Thus, for example, the first two fields for $G$ appear in the data file but are not used; the third field is the value of $G$ for $t_{0}+T$.

Selecting the change option under the economy menu allows you to modify any of these parameters. LIEF goes through all the economic assumptions, starting with $\mathrm{T}$ and ending with FuelP in the last year. LIEF gives you the current value for the parameter. To modify the value for the parameter, type the new value and then <enter>. If the value is acceptable, press <enter> to go to the next parameter.

The next menu is the sector menu (Figure A.5). Type $\mathrm{C}<$ enter $>$ from the main menu to go to the sector menu. Selecting $D$ displays the default data, and selecting $C$ allows you 
to change the default data. If you select either the $\mathrm{C}$ or $\mathrm{D}$ option, the model asks for a sector number to display or change. This number must be an integer value between 1 and 18 .

If you select display, the parameters for the desired sector are shown. Figure A.6 is a sample screen from the default data for sector 1 . The following list gives a brief description of the parameters and acceptable ranges for these parameters. Variables ending in e apply to electricity; $f$ applies to fossil fuels. The default parameters used for all 18 sectors from the file base 90.data are found in Table 5.1.

- REI - Recycling energy intensity, REI. If REI is set to 0 , there is no recycling in the sector. Recycling only occurs in sectors $3,5,7,10$, and 12. The REI parameter is the ratio of the energy required to manufacture with recycled material compared to that with virgin material. If the REI value is less than one, the recycled materials use less energy than the virgin material. If the value is greater than one, more energy is required in the process with the recycled material than with the virgin material. At this time, the primary aluminum sector does not directly involve recycled material, so there is no explicit recycling. Instead, increased recycling would affect production growth rates for primary aluminum.

- Total energy used in the base year (in trillion Btu), E0. The derivation of $\mathrm{EO}$ is discussed in Appendix B.

- Difference in sectoral prices from average prices (i.e., P[sector] -P), DPO. This option is not used at this time.

- Slope of the conservation supply curve, A. This value has been roughly estimated from historical data and should not be changed in initial model runs. This parameter is the long run elasticity (taken with a positive sign), with values between about 0.1 and 1.0 .

- Autonomous time trend, B0. B0 is the most sensitive parameter. It measures the rate of decline (fraction per year) of the energy intensity. For fuel, the value should be positive. For electricity, the value should

\begin{tabular}{|ll|}
\hline SECTOR MENU & \\
& \\
Display & $-\mathrm{D}$ \\
Change & $-\mathrm{C}$ \\
Main Menu & $-\mathrm{M}$ \\
Enter Your Selection - & \\
\hline
\end{tabular}

FIGURE A.5 Sector Menu of LIEF 


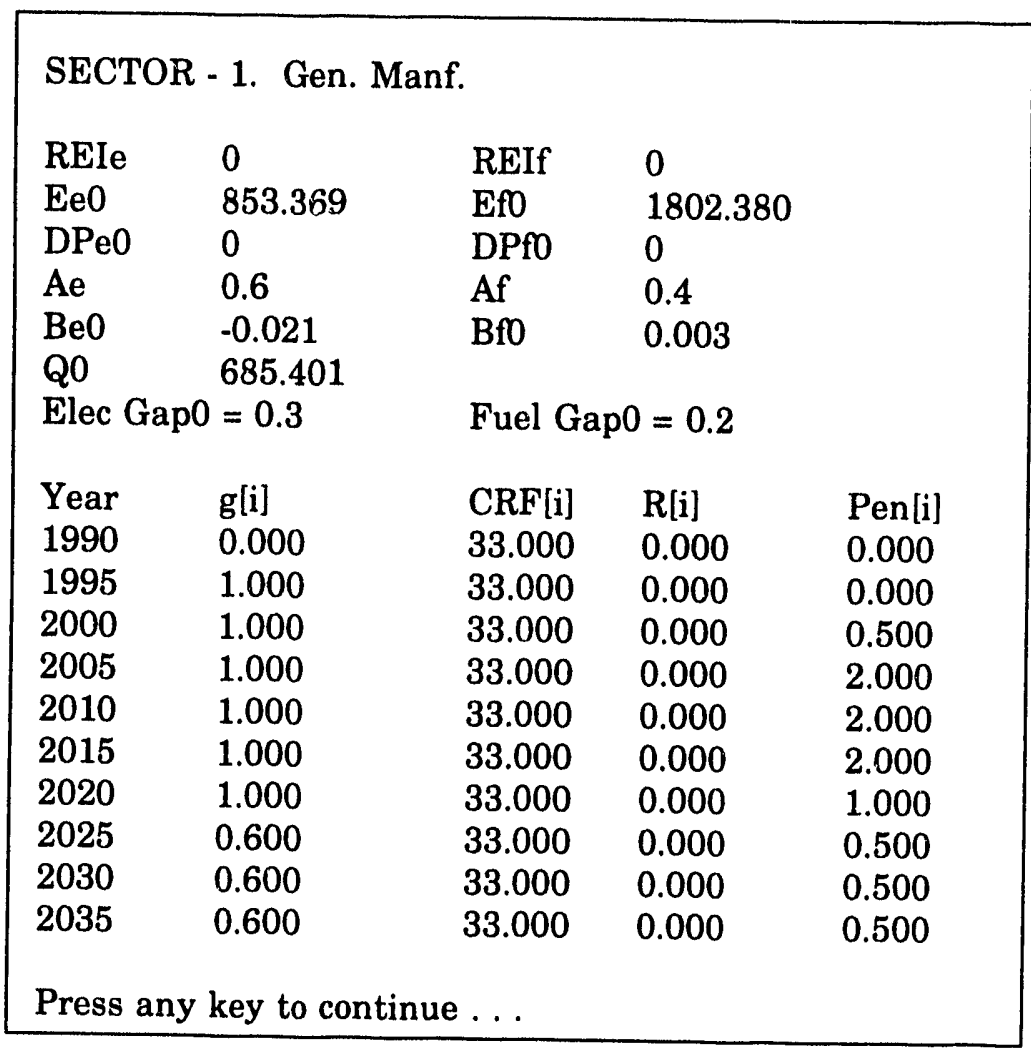

FIGURE A.6 Sector Menu Display Option of LIEF

typically be negative because of ongoing electrification. However, in sector 2 and in an electricity-intensive industry, like primary aluminum, it can be positive.

- Amount of production in base year (in billions of dollars), Q0. For the base year, this value has been computed on the basis of the census value-added or other value-added sources (Appendix B). Note, however, that growth rates are based on production, such as gross output, rather than on value added.

- Intensity gap, Gap0. The intensity gap is the base-year fraction by which the "ideal" intensity is less than the actual (e.g., if the Gap is 0.2, IEI is $0.8 \times \mathrm{EI})$. The values of Gap 0 have been estimated by using historical data and should not be changed in initial model runs. The parameter has values in the range from about 0.1 to 0.5 .

- Production growth rate of output from the sector in percent per year, $\mathrm{g}(\mathrm{t})$. The growth rate should be for physical production (e.g., tons) or for deflated shipments (gross output).

- Capital recovery factor, CRF (t). This factor is related to the implicit discount rate for conservation investments; $\left.C R F=d /\left[1-(1+d)^{-n}\right)\right]$, 
where $d$ is the discount rate and $n$ the project life, which is typically 10 years. All sectors start with $\mathrm{CRF}=33 \%$ per year in the base case. Reducing the CRF relative to its base-year value reduces the ideal energy intensity.

- Recycling ratio, $R(t)$. This ratio gives the amount of recycling that occurs in the sector: the percent of total material input that is recycled materials. Sectors 10 and 12 have the highest recycling ratios. These parameters can be modified to examine the effects of recycling.

- Percent toward which energy intensity moves to the ideal energy intensity per year, pen ( $t$ ). The higher the percentage, the less energy used. If no developments encourage investment decision makers to make energy conservation a high priority, pen $=0$. If price increases of other developments encourage a high priority, pen $>0$. At the height of the energy crisis, pen rose to $10-15 \%$ per year.

The change option allows you to modify any of the parameters shown in Figure A.6. You can specify which sector to modify, and if you press <enter>, no change is made to the parameter.

Once all parameters have been modified, you can run LIEF. Select calculate at the main menu to run the model. When the model is finished running, a message appears in the middle of the screen that states the model was solved. You can examine the results menu (Figure A.7) only after the model is run. On the basis of trial runs, these model runs (i.e., from starting the model, to loading a scenario, to actually running the model) take approximately 20 seconds on a 486 PC versus 1 minute 30 seconds on a 386 PC.

You can display results either by sector, by variable, or by summaries of all the sectors combined. Figure A.8 shows results by sector. Figure A.9 shows the variables that you can display, and Figure A.10 shows results provided by summary.

\begin{tabular}{|ll|}
\hline RESULTS MENU & \\
& \\
Display by Sector & $-\mathrm{S}$ \\
Display by Variable & $-\mathrm{V}$ \\
Display Summary & $-\mathrm{U}$ \\
Save to File & $-\mathrm{F}$ \\
Custom Report & $-\mathrm{R}$ \\
Change Format & $-\mathrm{C}$ \\
Main Menu & $-\mathrm{M}$ \\
& \\
Enter Your Selection - & \\
\hline
\end{tabular}

FIGURE A.7 Results Menu of LIEF 
Enter sector number - 1

Fossil Fuels

Sector - 1. General Manufacturing

Year Pf Q

1990

$\begin{array}{ll}\text { Pf } & \mathrm{Q} \\ 2.4 & 685.402\end{array}$

Ef

1995

2.65

719.684

2000

3.47

760.316

2005

4.31

797.142

2010

5.15

841.468

2015

5.48

883.192

2020

5.82

919.101

2025

6.04

958.06

2030

6.25

993.924

1802.38

1888.382

1961.403

1968.371

1986.723

1995.604

2029.434

2088.473

2141.658

2035

6.46

1023.911

2183.415

$\begin{array}{lllll}\text { EIf } & \text { PEIf } & \text { IEIf } & \text { SEf } & \text { Sf } \\ 2.63 & 0 & 2.104 & 1.000 & 0.388 \\ 2.624 & 2.654 & 2.243 & 1.009 & 0.367 \\ 2.58 & 2.624 & 1.851 & 1.009 & 0.346 \\ 2.469 & 2.58 & 1.627 & 1.009 & 0.327 \\ 2.361 & 2.469 & 1.502 & 1.009 & 0.311 \\ 2.26 & 2.361 & 1.43 & 1.009 & 0.298 \\ 2.208 & 2.26 & 1.415 & 1.009 & 0.287 \\ 2.18 & 2.208 & 1.383 & 1.009 & 0.28 \\ 2.155 & 2.18 & 1.366 & 1.009 & 0.275 \\ 2.132 & 2.155 & 1.347 & 1.009 & 0.272\end{array}$

Press any key to continue...

\section{Electricity}

Sector - 1. General Manufacturing

\begin{tabular}{|c|c|c|c|c|c|c|c|c|}
\hline Year & $\mathrm{Pe}$ & $\mathbf{Q}$ & $\mathrm{Ee}$ & EIe & PEIe & IEIe & See & $\mathrm{Se}$ \\
\hline 1990 & 11 & 685.402 & 853.369 & 1.245 & 0 & 0.872 & 1 & 0.612 \\
\hline 1995 & 10.88 & 719.684 & 979.177 & 1.361 & 1.238 & 0.969 & 0.994 & 0.633 \\
\hline 2000 & 11.31 & 760.316 & 1115.722 & 1.467 & 1.361 & 0.987 & 0.994 & 0.654 \\
\hline 2005 & 11.79 & 797.142 & 1215.831 & 1.525 & 1.467 & 1.022 & 0.994 & 0.673 \\
\hline 2010 & 12.28 & 841.468 & 1320.85 & 1.57 & 1.525 & 1.061 & 0.994 & 0.689 \\
\hline 2015 & 12.33 & 883.192 & 1413.786 & 1.601 & 1.57 & 1.103 & 0.994 & 0.702 \\
\hline 2020 & 12.38 & 919.101 & 1511.136 & 1.644 & 1.601 & 1.16 & 0.994 & 0.713 \\
\hline 2025 & 12.43 & 958.06 & 1613.525 & 1.684 & 1.644 & 1.194 & 0.994 & 0.72 \\
\hline 2030 & 12.47 & 993.924 & 1696.91 & 1.707 & 1.684 & 1.217 & 0.994 & 0.725 \\
\hline 2035 & 12.51 & 1023.911 & 1753.772 & 1.713 & 1.707 & 1.228 & 0.994 & 0.728 \\
\hline
\end{tabular}

FIGURE A.8 Results by Sector

The variables menu (Figure A.9) is useful for displaying ranges for a specific parameter over all 18 sectors. The summary menu (Figure A.10) is useful for showing aggregate numbers, but not specific sectors. Summary tables similar to those shown in Figure A.8 are provided for the following sectors: energy intensive manufacturing (3-12); total manufacturing (1-12); nonmanufacturing (13-16); and total industry (1-18), where sector 17 is use of fuels as materials (feedstocks), and sector 18 is uranium enrichment (normally included within the chemicals sector of manufacturing). At this time, the custom report option is not available.

To print a model run, select the save to file option $(F)$ in the results 'nenu. The model saves data under a filename. Once you exit the model, you can print the document by using the DOS print command. The syntax for this command is to type "print filename.ext" (the filename is the new name you have created, with its appropriate file extension). Both the executables and source code files are available in compressed form by using pkzip, which is also on the ANL BBS. 


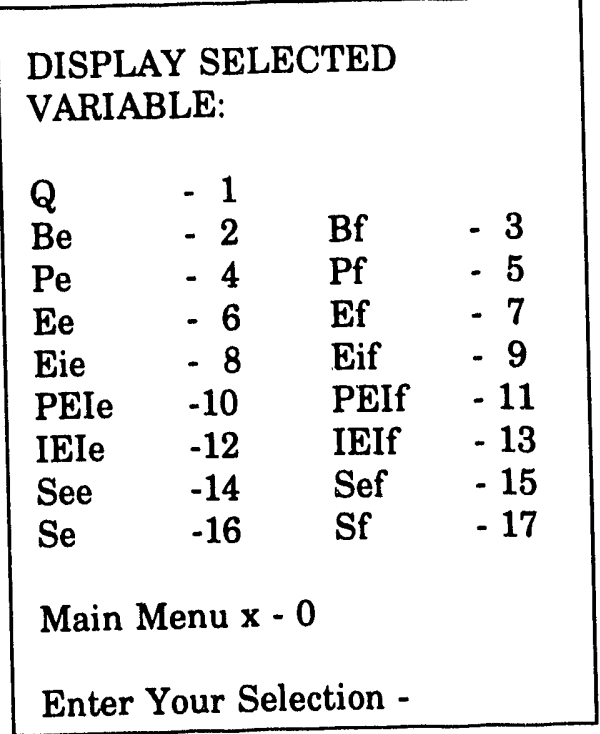

FIGURE A.9 Results by Variable Option

\begin{tabular}{|ll|}
\hline Summary for Electricity & -1 \\
Summary for Fossil Fuel & -2 \\
Energy Intensity for Electricity & -3 \\
Energy Intensity for Fossil Fuel & -4 \\
Production & -5 \\
Energy Use - Electricity & -6 \\
Energy Use - Fossil Fuel & -7 \\
Energy Price - Electricity & -8 \\
Energy Price - Fossil Fuel & -9 \\
Return to Main Menu & -0 \\
& \\
Enter Your Selection - & \\
\hline
\end{tabular}

FIGURE A.10 Results by Summary Option

\section{A.4 FUTURE UPDATES}

The original LIEF model consisted of four sectors. The present version of LIEF consists of 18 sectors. Future enhancements could include regionalizing LIEF to operate at 10 federal or 4 census regions, allocating fuel use among several categories, and providing forecasts of major emissions. Also, new baselines and scenarios will be made available as they are generated. Any updates made to LIEF will be maintained on the ANL BBS and will be made available for downloading upon request. 


\section{APPENDIX B:}

\section{MODEL DOCUMENTATION}

\section{B.1 SOURCES OF INPUTS: BASE-YEAR AND ACCOUNTING PARAMETERS}

The parameters used in the Long-term Industrial Energy Forecasting (LIEF) model can be grouped into the following categories: (1) base-year energy consumption and production; (2) accounting parameters that specify the pririod and scope of the forecast, that enable reporting of purchased and self-generated elect icity and of the State Energy Data System (SEDS) totals, and that give recycling characteristics (which, although some are baseyear and others are future values, can be considered part of an accounting procedure); and (3) forecasting parameters internal to the modeling analysis, conservative supply curve (CSC) parameters, energy prices, and production growth rates. The following sections briefly define the parameters in the first two groups and describe how the values shown in Section 5, Table 5.1, were selected.

\section{B.1.1 Base-Year Sectoral Electricity Demand}

The total electricity consumption in the base year (1990) for manufacturing (sectors 1-12) and nonmanufacturing (sectors 13-16) sectors is taken from different sources. For manufacturing sectors, the electricity consumption rates are from the Annual Survey of Manufactures, Fuel and Electric Energy Cost (ASM 1990). The ASM reports electricity consumption in millions of kilowatt-hours for the different standard industrial classifications (SIC) manufacturing sectors. These consumption values are aggregated (wherever necessary) according to the relationships between LIEF sectors and SIC sectors (Table B.1). The total electricity consumption is the sum of (1) purchased electricity and (2) self-generated electricity that is used on-site. Electricity consumption is converted to trillion Btu (1 kWh = 3,412 Btu).

Self-generated and used electricity (SGUE) are given for the base year and final year of forecasting; for the years in between, linear interpolation is used:

$$
S G U E_{i}(t)=S G U E_{i}\left(t_{o}\right)+\frac{t-t_{o}}{n T}\left[S G U E_{i}\left(t_{o}+n T\right)-S G U E_{i}\left(t_{o}\right)\right]
$$

where $\mathrm{SGUE}_{\mathrm{i}}\left(\mathrm{t}_{\mathrm{o}}\right)$ and $\mathrm{SGUE}_{\mathrm{i}}\left(\mathrm{t}_{\mathrm{o}}+\mathrm{nT}\right)$ represent the base-year and final-year SGUE. The user is required to input the final-year $S G U E_{i}$ forecast.

A different methodology has been adopted for nonmanufacturing sectors because there are no 1990 data. For agriculture (sector 13), electricity consumption for 1982 and 1987 has been estimated from expenditures on electricity and electricity prices. The expenditures 
TABLE B.1 Grouping of Manufacturing and Nonmanufacturing Sectors in the 18-Sector LIEF Model

SIC $\quad$ Industry

Sector 1: General Manufacturing

$20 \quad$ Food and Kindred Products

21 Tobacco Products

22 Textile Mill Products

23 Apparel and Other Finished Textile Products

24 Lumber and Wood Products (except furniture)

251 Household Furniture

265 Paperboard Containers and Boxes

267 Converted Paper and Paper Products

285 Paints, Varnishes, Lacquers, and Enamels

2861 Gum and Wood Chemicals

2879 Pesticides and Agriculture Chemicals

289 Miscellaneous Chemical Products

31 Leather and Leather Products

$34 \quad$ Fabricated Metal Products

$351 \quad$ Engines and Turbines

352

353

354

355

356

358

367

362

Farm and Garden Machinery and Equipment

Construction, and Mining Machinery and Equipment

Metal Working Machinery and Equipment

Special Industry Machinery

General Industrial Machinery and Equipment

Refrigeration and Service Industry Machinery

Electric Transmission and Distribution Equipment

Electrical Industrial Apparatus

Household Appliances

364

Electric Lighting Wiring Equipment

371

372

Motor Vehicles and Motor Vehicle Equipment

Aircraft and Parts

373

374

Ship and Boat Building and Repairing

Railroad Equipment

375

376

3792

3799

Motorcycles, Bicycles, and Parts

Guided Missiles and Space Vehicles and Parts

Travel Trailers and Camper

39

Transportation Equipment (not classified elsewhere)

Miscellaneous Manufacturing Industries

Sector 2: Fast-Growing Manufacturing

252

253

254

259

27

283

284

30
Office Furniture

Public Building and Related Furniture

Partitions, Shelving, Lockers, and Office Fixtures

Miscellaneous Firniture and Fixtures

Printing, Publishing, and Allied Industries

Drugs

Cosmetics, Toilet and Cleaning Products

Rubber and Miscellaneous Plastics Products 
TABLE B.1 (Cont.)

\begin{tabular}{ll}
\multicolumn{1}{c}{ SIC } & \multicolumn{1}{c}{ Industry } \\
\cline { 2 - 2 } Sector 2 (Cont.) \\
357 & Computer and Office Equipment \\
359 & $\quad$ Miscellaneous Industrial and Commercial Machinery \\
365 & $\quad$ Household Audio and Video Equipment \\
366 & Communications Equipment \\
367 & Electronic Components and Accessories \\
369 & Miscellaneous Electrical Machinery and Supplies \\
3795 & Tanks and Tank Components \\
38 & Measuring, Analyzing, and Controlling Instruments
\end{tabular}

Sector 3: Pulp and Paper Mills

$261 \quad$ Pulp Mills

262 Paper Mills

263 Paperboard Mills

Sector 4: Industrial Inorganic Chemicals

281 Industrial Inorganic Chemicals (excluding uranium enrichment)

2873 Nitrogenous Fertilizers

2874 Phosphatic Fertilizers

$2875 \quad$ Fertilizers, Mixing

Sector 5: Industrial Organic Chemicals

$282 \quad$ Plastics and Other Synthetic Materials

2865 Cyclic Organic Crudes, Dies and Pigments

$2869 \quad$ Industrial Organic Chemicals, n.e.c.

Sector 6: Petroleum Refining

29 Petroleum Refining and Related Industries

Sector 7: Glass and Glass Products

$321 \quad$ Flat Glass

322 Glass and Glassware, Pressed or Blown

323 Glass Products, Made of Purchased Products

Sector 8: Cement

324

Cement, Hydraulic

Sector 9: Stone and Clay Products

325

Structural Clay Products

$326 \quad$ Pottery and Related Products 
TABLE B.1 (Cont.)

\begin{tabular}{ll}
\hline SIC & Industry \\
\hline
\end{tabular}

Sector 9 ( Cont.)

$327 \quad$ Concrete, Gypsum, and Plaster Products

$328 \quad$ Cut and Stone Products

329 Abrasive, Asbestos, and Miscellaneous Products

Sector 10: Iron and Steel

331 Steel Works, Blast Furnaces, and Rolling Mills

$332 \quad$ Iron and Steel Foundries

$339 \quad$ Miscellaneous Primary Metal Products

Sector 11: Primary Aluminum

$3334 \quad$ Primary Production of Aluminum

Sector 12: Nonferrous Metals (excluding primary aluminum)

$3331 \quad$ Primary Smelting and Refining of Copper

3399 Primary Smelting and Refining of Other Metals

334 Secondary Smelting and Refining of Nonferrous Metals

335 Rolling, Drawing, and Extruding of Nonferrous Metals

$336 \quad$ Nonferrous Foundries

Sector 13: Agriculture

01 Agricultural Production, Crops

02 Agricultural Production, Livestock and Animal Feed

071 Soil Preparation Services

$072 \quad$ Crop Services

$075 \quad$ Animal Services (except veterinary)

076 Farm Labor and Machinery Services

$078 \quad$ Landscape and Horticultural Services

08 Forestry

$09 \quad$ Fishing, Hunting, and Trapping

Sector 14: Mining (excluding oil and gas)

101 Iron Ores

$102 \quad$ Copper Ores

103 Lead and Zinc Ores

104 Gold Silver Ores

106 Alloy Ores (except vanadium)

pt. 108 Metal Mining Services

109 Miscellaneous Metal Ores

122 Bituminous Coal and Lignite Mining

123 Anthracite Mining

pt. 124 Coal Mining Services 
TABLE B.1 (Cont.)

\begin{tabular}{ll}
\hline \multicolumn{1}{c}{ SIC } & \multicolumn{1}{c}{ Industry } \\
\hline Sector 14 & (Cont.) \\
141 & Dimension Stone \\
142 & Crushed and Broken Stone (including riprap) \\
144 & Sand and Gravel \\
145 & Clay, Ceramic, and Refractory Minerals \\
147 & Chemicals and Fertilizer Mineral Mining \\
pt. 148 & Nonmetallic Minerals Services (except fuels) \\
149 & Miscellaneous Nonmetallic Minerals (except fuels) \\
Sector 15: & Oil and Gas Extraction \\
131 & Crude Petroleum and Natural Gas \\
132 & Natural Gas Liquids \\
Sector 16: & Feedstocks \\
Sector 17: & Uranium Enrichment (part of 2819)
\end{tabular}

on electricity are reported the Census of Agriculture (DOC 1990a). The 1982 electricity price is from Statistical Abstracts of the United States (DOC 1992), while 1987 electricity prices are from the State Energy Price and Expenditure Report (EIA 1991a) (taken as that of commercial sector). The electricity intensities for these two years are calculated from the above estimated electricity consumption and gross farm product (GFP), as reported in Stasistical Abstracts of the United States (DOC 1992). These electricity intensities have been extrapolated to 1989 (the latest year for which the GFP is available). Electricity consumption is then obtained from the product of GFP and the extrapolated electricity intensity for 1989. A similar procedure has been adopted for mining (sector 14), oil and gas extraction (sector 15), and construction (sector 16). For these sectors, however, the expenditure on electricity is from the Census of Mineral Industries (DOC 1990b) (sectors 14 and 15) and Census of Construction-Industries Series (sector 16) (DOC 1990c). Also, the gross national product (GNP) by industry is used instead of the GFP. The 1989 GNP values are reported in Statistical Abstracts of the United States (DOC 1992) for the respective sectors.

There is no electricity consumption in feedstock (sector 17), and the consumption for uranium enrichment (sector 18) is only electricity (Ewing 1992). This electricity consumption has been subtracted from ASM data to obtain the electricity consumption for LIEF inorganics (sector 4). The base-year energy consumption for all the sectors is presented in Section 5, Table 5.1.

For sectors that do not consume electricity, a small value should be given instead of zero to avoid division by zero. 
The base-year electricity consumption of all the industries determined from bottomup analysis, as described above, may not agree with the total electricity consumption from SEDS. The differences among these totals are given as discrepancies for the base year and final year of forecasting; for tl_c years in between, linear interpolation is used:

$$
D I S C_{e}(t)=D I S C_{e}\left(t_{o}\right)+\frac{t-t_{o}}{n * T}\left[D I S C_{e}\left(t_{o}+n T\right)-D I S C_{e}\left(t_{o}\right)\right]
$$

where DISC $\mathrm{e}_{\mathrm{e}}\left(\mathrm{t}_{\mathrm{o}}\right)$ and DISC $_{\mathrm{e}}\left(\mathrm{t}_{\mathrm{o}}+\mathrm{nT}\right)$ are discrepancies in the base year and final year, $n$ is the number of periods, and $\mathrm{T}$ is the length of one period. The user is required to input the final year $\mathrm{DISC}_{\mathrm{e}}$ forecast.

\section{B.1.2 Base-Year Sectoral Fossil Fuel Demand}

The most recent fossil fuel consumption data available are for 1988 manufacturing and for 1987 nonmanufacturing. The 1990 base-year data set has been created by extrapolation. NEA accounting is used for manufacturing fuel consumption for heat and power, with the most recent data being from the Manufacturing Energy Consumption Survey - 1988 (EIA 1991b). A smooth extrapolation of the ratio of aggregate fossil fuel to purchased electricity is made to 1990 for two-digit SIC sectors; it is converted to absolute fuel consumption by using electricity consumption for 1990 from ASM. Where needed, the fuel use is shared out below the two-digit level by using the NEA 1985 shares.

For nonmanufacturing (sectors 13-16), fuel consumption includes energy used for heat and power, for off-road use in agriculture (sector 13), for construction (sector 16), and for energy produced and consumed within mining (sector 14) and oil and gas extraction (sector 15). For these sectors fosil fuel consumption data from the quintennial censuses (1982 and 1987) were used to construct fuel intensities (fuel use per dollar of value added). These intensities were extrapolated to 1989 , the most recent year with full economic data. (The details with citations are given in Section B.1.1.)

For ftedstock (sector 17), a different methodology has been employed. The Basic Petroleum Data Book (American Petroleum Institute 1992) provides the total U.S. demand for petroleum products; and the Manufacturing Energy Consumption Survey - 1988 (EIA 1991b) reports the natural gas consumption for nonfuel purposes. It is assumed that only $10 \%$ of the propane in BPDB is used as feedstock, and the rest is used as fuel (Hatch and Matar 1981). Also, the still gas component included in the miscellaneous products in the BPDB has been subtracted. The still gas consumption is from MECS 1988. The heating values to convert the physical quantities reported in BPDB to trillion Btu are taken from the Historical Monthly Energy Review 1973-1988 (EIA 1991c), Energy Information Administration. For uranium enrichment (sector 18), there is no fossil fuel consumption. The base-year fuel consumption rates are presented in Table 5.1. 
For sectors that do not consume fossil fuel, a small value should be given instead of zero to avoid division by zero.

The base-year fuel consumption for the entire industry determined from bottom-up analysis does not agree with the total fuel consumption from SEDS. The procedures for electricity are used for fuel, with $\operatorname{DISC}_{f}\left(t_{0}\right)$ and $\operatorname{DISC}_{f}\left(t_{0}+n_{i}^{m}\right.$; replacing the DISC, parameters.

\section{B.1.3 Base-Year Sectoral Production Rates}

The results generated in each sector are in effect independent of the base-year production. The energy forecasts relate to the base-year energy consumption and the energy intensities scale with base-year production. Interpretation of aggregate intensities depends, however, on the use of a consistent set of production rates by sector.

The base-year (1990) production rates for the manufacturing sectors are the value added by manufacture in billions of dollars, as reported in ASM (1990). For nonmanufacturing sectors, production rates are GNP, as reported in Statistical Abstracts of the United States (DOC 1992), except for agriculture, for which it is GFP. The latest year for which the GNiP or GFP reported is 1989 , and those values are used.

The production rates for feedstock (sector 17) and uranium enrichment (sector 18) are arbitrary. They are not included in calculations of future production rates for industry as a whole.

\section{B.1.4 Recycle Ratios}

The recycle ratio is the fraction of materials (e.g., fiber, inetals, glass, chemicals) recycled from sources outside the plant. Jome sectors listed in Table 5.1 include run-around or in-plant scrap. All sectors show considerable extrapolation and intexpolation between years. The various sources for the recycle ratios are as follows:

- Pulp and paper (sector 3): American Paper Institute (1970-1988). Statistics of Paper and Paperboard, New York, NY.

- Glass (sector 7): U.S. Department of Commerce (1990). Current Industrial Reports, Washington, D.C.; and U.S. Departinent of Commerce (1990). Census of Manufactures, Bureau of the Census, Washington, D.C.

- Iron and steel (sector 10): American Iron and Steel Institute (1970-1988). Annual Statistical Report. Washington, D.C. 
- Nonferrous (sector 12): U.S. Department of Commerce (1961-1988). Survey of Current Business. Bureau of Economic Analysis, Washington, D.C.

The relationship for external scrap in steel making is described in Ross and Liu (1991).

\section{B.1.5 Relative Recycle Intensities}

The relative recycle intensity is a measure of the energy intensity of manufacturing with recycled materials compared to that with virgin materials. The intensity is assumed fixed for the forecast and is based on historical values. The various sources for the recycle sectors are as follows:

- Pulp and paper: Elaahi, A., and H.E. Lowitt (1988). The U.S. Pulp and Paper Industry: An Energy Perspective," DOE/RL/018530-T57, prepared for the Office of Industrial Technology by Energetics Inc., Columbia, Md.

- Iron and steel: Ross, M. (1988). "Industrial Energy Conservation and the Steel Industry of the U.S.," Energy, 12:1135-1152.

- Nonferrous: Gaines, L. (1980). Energy and Materials Flows in the Copper Industry, ANL/CNSV-11, Argonne National Laboratory, Argonne, Ill.

- Organics: authors' judgment.

\section{B.2 SOURCES OF INPUTS: FORECASTING PARAMETERS}

The forecasting parameters are the primary focus for the user, once base-year and accounting parameters are set. The following sections briefly describe the choices made for the U.S. electricity forecasts, base-case and demand-side management (DSM) program, as shown in Table 5.1.

\section{B.2.1 Technical Change Parameters}

The technical change parameters are as follows: CSC slopes (A's), autonomous time trends (B's), and fractional differences between actual energy intensity and ideal energy intensity in the base year (Gap0). These parameters are at the heart of the LIEF model and were selected on the basis of historical analyses of key sectors and by authors' judgment. The details of historical analyses are given in Section 4. The value of B' is taken to be 50 years, roughly conforming to the value of 75 years adopted in the historical forecasts. 


\section{B.2.2 Prices of Electricity and Fossil Fuels}

The prices of electricity and fuel are from the EIA, PC-IM base case, which was run for NES on July 20, 1990. The prices are reported in 1990 dollars per million Btu.

\section{B.2.3 Penetration}

Penetration is the rate at which the energy intensity moves toward the ideal energy intensity per year. The penetrations were chosen on the basis of historical analyses and authors' judgment (Section 4).

\section{B.2.4 Capital Recovery Factor}

The value of $33 \%$ per year is taken for the base year (Ross and Hwang 1992). The model depends only on changes in the capital recovery factor (CRF). The forecast values are unchanged for the base case and are 17\% per year for the DSM case (Table 5.1). This latter value is based on economic analysis of DSM (Ross and Hwang 1992).

\section{B.2.5 Production Growth Rates}

The production growth rates for the sectors are based on the extension of historical trends and authors' judgment. The user would typically have a production forecast that would need to be adapted for use in LIEF. First, the forecast should be adapted so that growth rates agree with real gross output in the historical period. Second, historical trends could be used to achieve the necessary aggregations and disaggregations of the 18 sectors, while preserving the production forecast growth rates.

The overall industrial growth rate would often be specified for the user. In the case shown here (Table 5.1), the aggregate industrial growth rate is $0.8 \%$ per year slower than the GNP growth rate used in exercises for the NES, as discussed in Section 5.1. The sectoral growth rates are adjusted by adding a sector independant correction so that the correct overall growth rate is realized.

\section{B.2.6 Fuel Switching Parameters and Heat Rates}

The fuel switching parameter is chosen to agree with that from the historical forecasts, $C=0.02$. Heat rate is used in calculating fuel switching facturs $S_{i j}$. If the baseyear and final-year heat rates are given as inputs, the heat rates for years in between are calculated by using linear interpolation:

$$
\operatorname{Hrate}(t)=\operatorname{Hrate}\left(t_{o}\right)=\frac{t-t_{o}}{n t}\left[\operatorname{Hrate}\left(t_{o}+n T\right)-\operatorname{Hrate}\left(t_{o}\right)\right],
$$


where Hrate $\left(t_{o}\right)$ and Hrate $\left(t_{o}+n T\right)$ represent the base-year and final-year heat rates, respectively.

\section{B.3 MODEL EQUATIONS}

Ross and Hwang (1992) have discussed the model in detail. In particular, the documentation in the annex to their report is very detailed; the equations are included here. The model was developed at Lawrence Berkeley Laboratory (LBL) for four sectors in a spreadsheet. The present LIEF model has been extended to 18 sectors. The LIEF model was designed to be a flexible, easy-to-use, powerful model. It can be used in either the interactive mode or the batch mode. The batch mode supports integration of the model into a larger system, if needed. The interactive mode allows the user to modify scenario inputs, solve, and immediately look at the results without leaving the model.

The LIEF model's implementation design uses an object-oriented methodology. It groups data and functions that manipulate the data into objects. This approach makes the model flexible, easy to program, and easy to maintain.

The mathematical relationships given in the LBL report have been modified in a few specific areas. The following sections briefly give the expressions used in the model.

\section{B.3.1 Production}

Production for the first 16 sectors is given by

$$
Q_{i}(t)=K * \exp \left\{T * \ln \left[1+g_{i}(t)\right]\right\} * Q_{i}(t-T)
$$

where

$$
K=\frac{\left[\Sigma_{i} Q_{i}(t-T)\right] * \exp \{T * \ln [1+G(t)]\}}{\Sigma_{i}\left[Q_{i}(t-T)\right] * \exp \left\{T * \ln \left[1+g_{i}(t)\right]\right\}}
$$

Here, the values of $g_{i}$ are relative growth rates for the 16 sectors. They are all adjusted by the factor $\mathrm{K}$ to achieve the overall growth rate $\mathrm{G}(\mathrm{t})$. Sectors 17 and 18 are not adjusted in obtaining the overall growth rate (i.e., $\mathrm{K}$ does not appear in Equation B.4 for those two sectors). 


\section{B.3.2 Autonomous Technical Change*}

The rate of autonomous technical change that declines to zero in Bpr periods is given by

$$
B_{i j}(t)=B_{i j}\left(t_{0}\right) *\left[1-\frac{\left(t-t_{0}\right)}{(T * B p r)}\right]
$$

\section{B.3.3 Electricity Fuel Share ${ }^{\dagger}$}

by

The energy intensity used in a previous period, adjusted for fuel switching, is given

$$
P E I_{i j}(t)=E I_{i j}(t-T) *\left[1+\Delta S_{i j}(t)\right]
$$

where

$$
\Delta S_{i j}=\left[\frac{C}{S_{i j}(t-T)}\right] * \ln \left[\frac{p_{i j}^{\prime}(t-T) / p_{i j}(t-T)}{p_{i j}^{\prime}(t-2 T) / p_{i j}(t-2 T)}\right] .
$$

The prime denotes the energy form other than $j$. Here,

$$
S_{i, e}(t)=\frac{\operatorname{Hrate}_{i, e} E_{i, e}(t)}{\operatorname{Hrate} * E_{i, e}(T)+E_{i, f}(T)}
$$

and

$$
S_{i, f}(t)=1-S_{i, e}(t)
$$

where subscripts $e$ and $f$ are for electricity and fossil fuel respectively.

* In the following sections, the subscript $\mathrm{i}$ denotes sector and $\mathrm{j}$ denotes energy form, either electricity or fossil fuel.

$\dagger$ The LIEF model is continuing to evolve. As of this writing (April 1993), this section is being modified. For up-to-date information, consult one of the authors or the bulletin board (Section A.2). 


\section{B.3.4 Expected Prices of Energy}

The expression for the expected prices for electricity and fossil fuel have been modified from the LBL report as follows:

$$
E P_{i j}(t)=0.5 * P e_{i j}(t)+P e_{i j}(t-T)-0.5 * P e_{i j}(t-2 T)
$$

\section{B.3.5 Ideal Energy Intensity}

The ideal energy intensity is a function of expected prices, the behavioral CRF, the $\mathrm{CSC}$, and the autonomous technical change and is given by the expression

$$
I E I_{i j}(t)=I E I_{i j}\left(t_{0}\right) *\left[\frac{E P_{i j}(t) / C R F(t-T)}{p_{i j}\left(t_{0}\right) / C R F\left(t_{0}\right)}\right]^{A_{i j}} * \exp \left[-\sum_{n=0}^{N} B_{i j}\left(t_{o}+n T\right) * T\right]
$$

where $\left.N=\left[\left(t-t_{0}\right) / T\right)\right]-1$ is the number of periods less one. In the above equation, a mistake in the LBL report has been corrected. The base-year ideal energy intensity $I E I_{i j}\left(t_{0}\right)$ is given by

$$
I E I_{i j}\left(t_{0}\right)=\left(1-G a p_{i j}\right) * E I_{i j}\left(t_{0}\right)
$$

\section{B.3.6 Cumulative Fuel Switching Factor}

The cumulative fuel switching factor $\mathrm{SE}_{\mathrm{ij}}$ is given by

$$
S E_{i j}(t)=\frac{P E I_{i j}(t)}{E I_{i j}(t-T)} * S E_{i j}(t-T) \text { for } t>t_{0} ; S E_{i j}\left(t_{0}\right)=1
$$

\section{B.3.7 Energy Intensity}

The energy intensity steps through the time periods and is given by

$$
E I_{i j}(t)=P E I_{i j}(t) * \exp \left[-B_{i j}(t) * T\right] *[1-P E N(t)]+P E N(t) * I E I_{i j}(t) * S E_{i j}(t)
$$

where

$$
\operatorname{PEN}(T)=1-\exp \{T * \ln [1-\operatorname{PENYR}(T)]\}
$$


and

if $I E I(t)>\operatorname{PEI}(t)$ then $\operatorname{PEN}(t)=0$.

Equation B.17 is another modification to the LBL version of the LIEF model.

\section{B.3.8 Capital Expenditure on Energy Conservation}

The LIEF model calculates the capital expenditure $\left(\mathrm{KC}_{\mathrm{j}}\right)$ on energy conservation associated with the conservation supply curves. The CSC has the form given in Equation A.8 of Ross and Hwang (1992):

$$
\Delta K=[(1-G a p 0) /(1-s)]^{1 / A}\left(p_{0} / C R F_{0}\right) E_{0} \Delta s
$$

where $s=S / E_{0}$ and $S$ is the annual energy savings. Based on this, we use the following equations to represent the relationship between the capital expenditure and other parameters:

$$
\begin{aligned}
K C_{i j}(t) & =\left[\frac{1-G a p 0_{i j}}{-1-x(t)}\right]^{1 / A_{i j}} *\left(\frac{p_{0}}{C R F_{0}}\right) * Q_{i j}(t) * P E N(t) \\
& *\left\{P E I_{i j}(t) \exp \left[-B_{i j}(t-T) T\right]-I E I_{i j}(t) * S E_{i j}(t)\right\},
\end{aligned}
$$

where

$$
1-x(t)=\frac{E I_{i j}(t-T)}{E I_{i j}\left(t_{0}\right)} \exp \left[\sum_{n=0}^{N-1} B_{i j}\left(t_{0}+n T\right) * T\right] .
$$

The $\mathrm{KC}_{\mathrm{ij}}$ calculated above are summed over all sectors to give the capital expenditure for all industry and for each energy in each time period. Because energy prices are quoted in $\$ /$ million Btu and energy consumption is in trillion Btu, the units for $\mathrm{KC}$ are million $\$$ (expenditures during the period $\mathrm{t}-\mathrm{T}$ to $\mathrm{t}$ ).

\section{B.3.9 Divisia Analysis}

The Divisia analysis gives indices of aggregate production $\left(\mathrm{I}_{\mathrm{Q}}\right)$, shifting sectoral composition of production $\left(I_{S}\right)$, and the real intensity change $\left(I_{I}\right)$ that make up the index of total energy consumption $\left(\mathrm{I}_{\mathrm{E}}\right)$. The following expressions are used for each energy form $\mathrm{j}$ : 


$$
\begin{aligned}
& I_{Q}(t)=I_{Q}(t-T) \frac{\sum_{i} Q_{i}(t)}{\sum_{i} Q_{i}(t-T)} \text { and } I_{Q}\left(t_{0}\right)=1, \\
& I_{S j}(t)=\frac{I_{S j}(t-T) \exp \left\{T * \ln \left[1+\left\langle G(Q, t)>_{j}\right]\right\}\right.}{I_{Q}(t) / I_{Q}(t-T)} \text { and } I_{S j}\left(t_{0}\right)=1, \\
& I_{I j}(t)=I_{I j}(t-T) \exp \left\{T * \ln \left[1+\left\langle G\left(E I_{j}, t\right)\right]>\right\} \text { and } I_{I J}\left(t_{0}\right)=1,\right.
\end{aligned}
$$

and

$$
I_{E j}(t)=\frac{\sum_{i} E_{i j}(t)}{\sum_{i j} E_{i j}\left(t_{0}\right)},
$$

where

$$
\begin{aligned}
& <G(Q, t)>_{j}=\sum_{i} W_{i j}(t) * G\left(Q_{i}, t\right), \\
& G\left(Q_{i}, t\right)=\frac{1}{T} \ln \left(\frac{Q_{i}(t)}{Q_{i}(t-T)}\right), \\
& W_{i j}(t)=\frac{1}{2}\left[\frac{E_{i j}(t)}{\sum_{i} E_{i j}(t)}+\frac{E_{i j}(t-T)}{\sum_{i} E_{i j}(t-T)}\right], \\
& \left\langle G\left(E I_{j}, t\right)>=\sum_{i} W_{i j}(t) * G\left(E I_{i j}, t\right),\right.
\end{aligned}
$$

and

$$
G\left(E I_{i j}, t\right)=\frac{1}{T} \ln \left(\frac{E I_{i j}(t)}{E I_{i j}(t-T)}\right)
$$




\section{B.4 APPENDIX B REFERENCES}

ASM (1990). Annual Sur:sey of Manufactures, Fuel and Electric Energy Cost. U.S. Bureau of the Census, Washington D.C.

American Petroleum Insticute (1992). The Basic Petroleum Data Book, Vol. XII, No. 1, Jan. DOC (1990a). Census of Agriculture. U.S. Department of Commerce, Bureau of the Census, Washington, D.C.

DOC (1990b). Census of Mineral Industries. U.S. Department of Commerce, Bureau of the Census, Washington. D.C.

DOC (1990c). Census of Construction-Industry Series. U.S. Department of Commerce, Bureau of the Census, Washington, D.C.

DOC (1992). Statistical Abstracts of the United States. U.S. Department of Commerce, Bureau of the Census, Washington, D.C.

EIA (1991a). State Energy Price and Expenditure Report. U.S. Department of Energy, Washington, D.C.

EIA (1991b). Manufacturing Energy Consumption Survey - 1988. U.S. Department of Energy, Washington, D.C.

EIA (1991c). Historical Monthly Energy Review - 1973-1988. U.S. Department of Energy, Washington, D.C.

Ewing, L., 1992, personal communication. U.S. Department of Energy, Washington, D.C.

Hatch, L.F., and S. Matar (1981). From Hydrocarbons to Petrochemicals, Gulf Publishing Company, Houston, Texas.

NEA (1988). National Energy Accounts. Jack Faucett Associates, prepared for the U.S. Department of Commerce, Washington, D.C.

Ross, M., and F. Liu (1991). "The Energy Efficiency of the Steel Industry of China," Energy, 16:833-848.

Ross, M., and R. Hwang (1992). A Model for Long-term Industrial Energy Forecasting. LBL-31861, Lawrence Berkeley Laboratory, Livermore, Calif. 

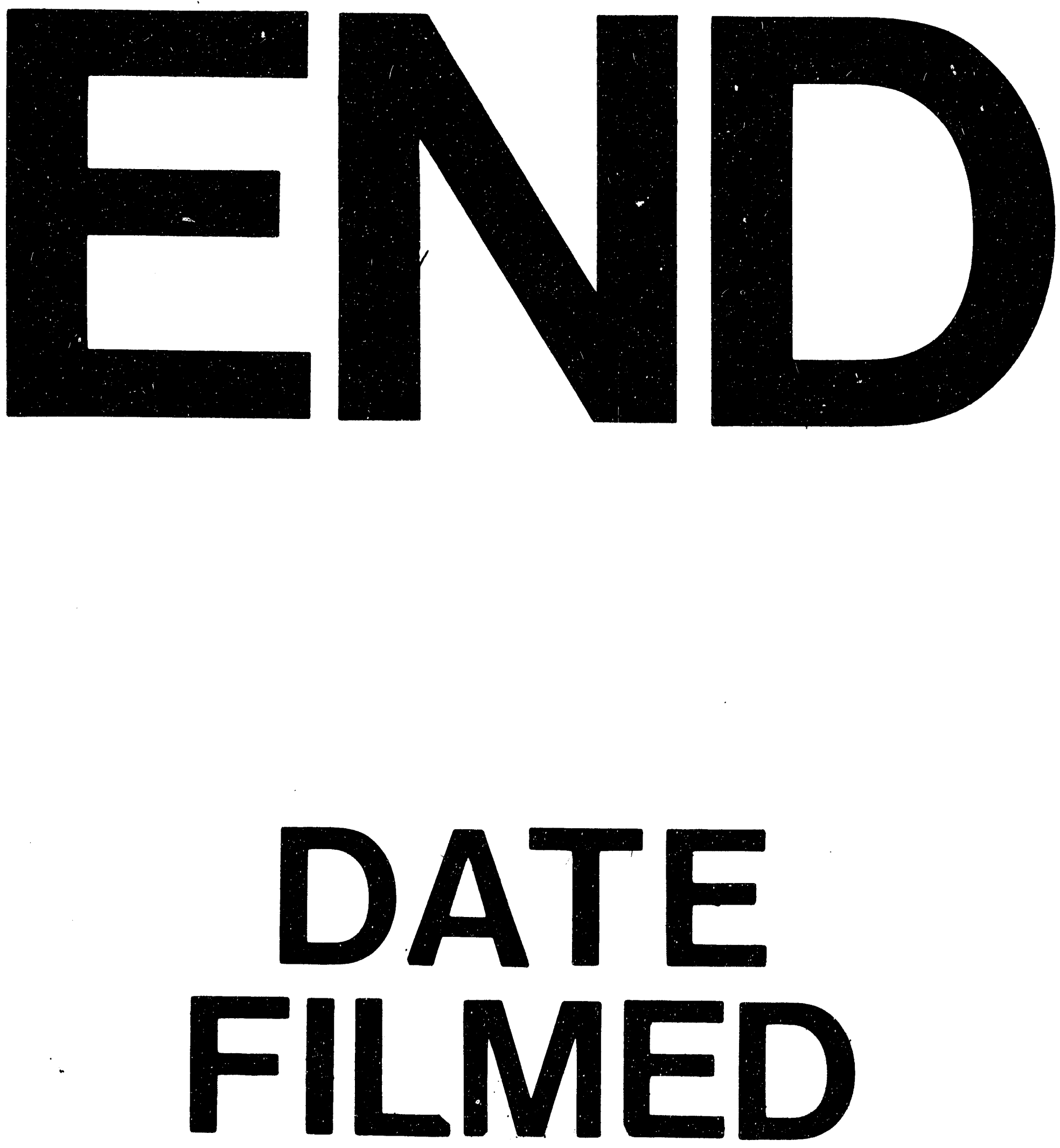

1

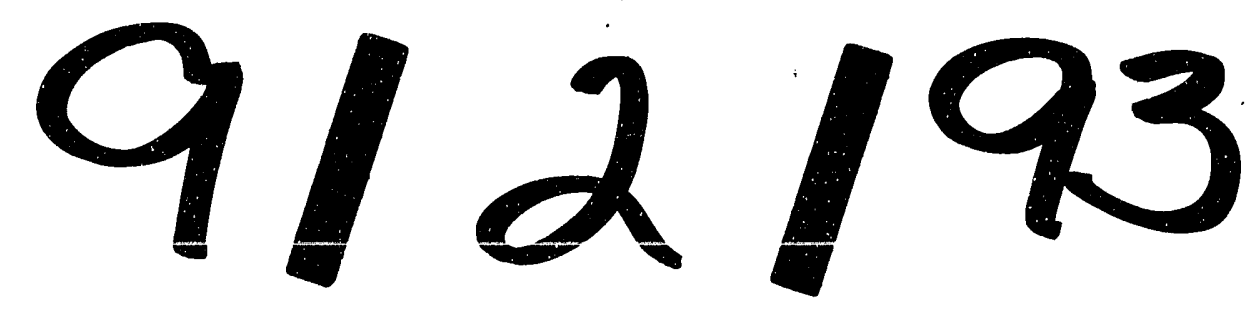




\section{-}

